Portland State University

PDXScholar

Spring 5-22-2017

\title{
Influence of Mixing and Buoyancy on Competition Between Cyanobacteria Species in Upper Klamath Lake
}

Roberta Joann Brunkalla

Portland State University

Follow this and additional works at: https://pdxscholar.library.pdx.edu/open_access_etds

Part of the Water Resource Management Commons

Let us know how access to this document benefits you.

\section{Recommended Citation}

Brunkalla, Roberta Joann, "Influence of Mixing and Buoyancy on Competition Between Cyanobacteria Species in Upper Klamath Lake" (2017). Dissertations and Theses. Paper 3998.

https://doi.org/10.15760/etd.5882

This Thesis is brought to you for free and open access. It has been accepted for inclusion in Dissertations and Theses by an authorized administrator of PDXScholar. Please contact us if we can make this document more accessible: pdxscholar@pdx.edu. 
Influence of Mixing and Buoyancy on Competition Between Cyanobacteria Species in Upper Klamath Lake

by

Roberta Joann Brunkalla

A thesis submitted in partial fulfillment of the requirements for the degree of

\author{
Master of Science \\ in \\ Environmental Science and Management
}

Thesis Committee:

John Rueter, Chair

Yangdong Pan

Angela Strecker

Portland State University

2017 
(C) 2017 Roberta Joann Brunkalla 


\begin{abstract}
Cyanobacterial blooms in lakes impact human health, the economy, and ecosystem health. It is predicted that climate change will promote and increase the frequency and intensity of cyanobacterial blooms due to unique physiological adaptions that allow cyanobacteria to exploit warm stable water bodies. Key cyanobacteria physiological adaptions include nitrogen fixation, buoyancy regulation and higher optimum growth temperatures. The largest uncertainty of predicting the effect of climate change is in understanding how the interactions among species will change. Adding to the ambiguity, cyanobacteria physiological adaptions can vary based on lakespecific ecotypes and can have different sensitivities to temperature. It is critical to understand how cyanobacterial physiological adaptions impact species interactions in order to improve and devise adaptable, short-term management methods for bloom control. This study investigated how weather patterns and algal buoyancy regulation influence the competition and accumulation of two bloom-forming buoyant cyanobacteria species (Aphanizomenon flos-aquae (APFA) and toxin-forming Microcystis aeruginosa (MSAE)) in Upper Klamath Lake (UKL), Oregon. The focus was confirming the buoyancy rate of the APFA in Upper Klamath Lake and exploring whether short-term weather conditions could lead to dangerous accumulations of APFA or MSAE. A sensitivity analysis was conducted on the model's buoyancy terms and growth curves to see if the outcome of competition was influenced by these parameters.
\end{abstract}


UKL specific buoyancy rates were measured on APFA from samples taken directly from the lake in the summer of 2015. Tracking software was used to measure APFA movement through water, and individual colony movement was averaged to obtain a single buoyancy rate. There was a high degree of agreement between the calculated APFA buoyancy rate in UKL $\left(0.89+/-0.34 \mathrm{~m} \mathrm{hr}^{-1}\right)$ with the rate published by Walsby (1995; $\left.0.9+/-0.5 \mathrm{~m} \mathrm{hr}^{-1}\right)$.

This study investigated how weather patterns and buoyancy regulation influenced the outcome of competition between APFA and MSAE. Weather and water column temperature data were collected from UKL in the summer of 2016. A onedimensional hydrodynamic model was used to calculate the lake's thermal and turbulence structure on days with contrasting weather patterns (hot/cool and windy/calm). A competition model was used to calculate the accumulation of APFA and MSAE cells in regular intervals through the water column under the various weather scenarios. MSAE accumulation was significantly influenced by the thermal and turbulence regimes, but APFA maintained high accumulations under every regime and was the better competitor under every thermal and turbulence regime. MSAE was more negatively impacted by high turbulence than low temperatures.

APFA's optimum temperature growth curve was found to be important in determining the outcome of competition between APFA and MSAE. Surprisingly, competition was not sensitive to changes in buoyancy rates. Buoyancy was not found to be a function of algal accumulation under any thermal and turbulence regime. 
The impacts of climate change and human-induced enrichment has the potential to change existing patterns of species interactions in lentic systems. Restoration and management efforts should consider the significance of cascading ecological responses to climate change. Understanding how key physiological adaptions operate is the first step to assessing the scope of this impact. While buoyancy might not play a large role in competition in UKL, it might be possible to use mixing to suppress MSAE because it is negatively impacted by high turbulence. If MSAE hot spots become a reoccurring problem in UKL, lakes managers might be able to use localized mixing to suppress MSAE blooms in these problem areas. 


\section{Acknowledgements}

There a lot of people who helped make this work possible. I'd like to first thank my husband, Phil, for keeping my back free and supporting me through the years as I slowly pieced this together. This would not have been possible without the countless lab meetings and support from the Rueter lab. Thank you Dr. Rueter for your guidance and insights into modeling. Thanks to Kit Rouhe for helping me devise a sampling plan for measuring the buoyancy of Aphanizomenon flos-aquae. The feedback of Dr. Pan and Dr. Strecker was essential in developing my hypotheses and statistical analyses. Lastly, thanks go to Heather Hendrixson at The Nature Conservancy for allowing entry to their property and coordinating access. Collecting data from Upper Klamath Lake would have been difficult without access to TNC's property. 


\section{Table of Contents}

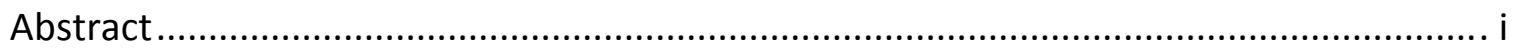

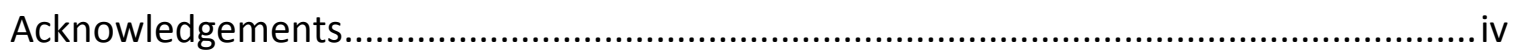

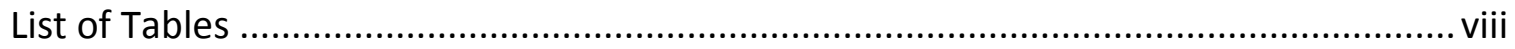

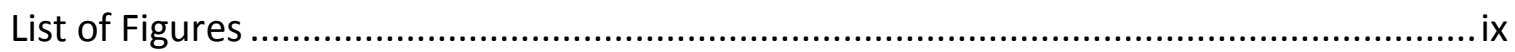

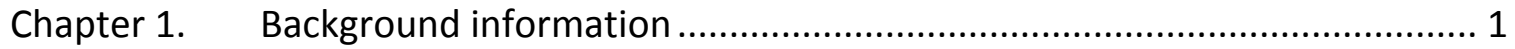

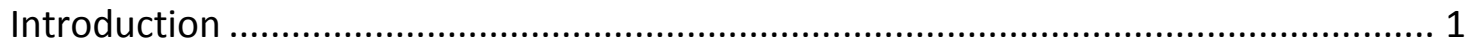

Impact of lake morphology and watershed geology on cyanobacteria physiology ... 2

Impact of climate on cyanobacteria physiology ..................................................... 3

Impact of climate change on lake hydrodynamics and chemical properties ............. 4

Key cyanobacteria physiological adaptions ..................................................... 5

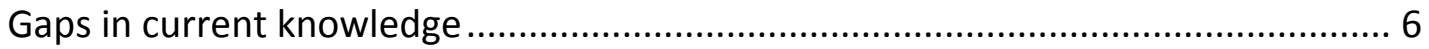

Cyanobacteria ecotype and physiology in the system of study ............................. 8

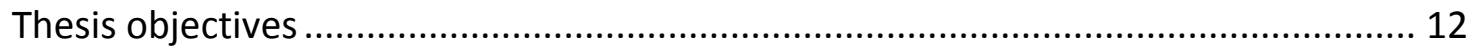

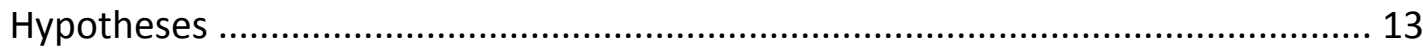

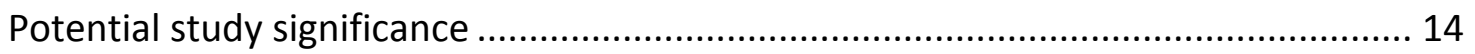

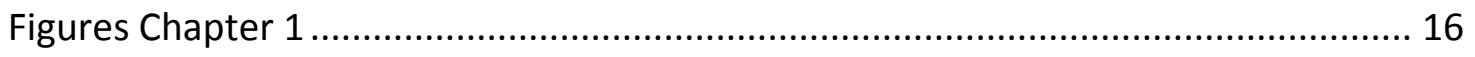

Chapter 2. Modeling water column mixing in Upper Klamath Lake .......................... 18

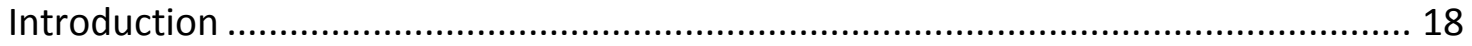

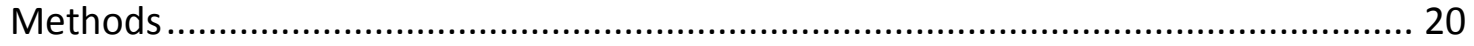

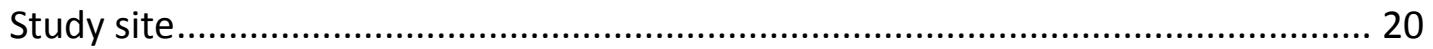

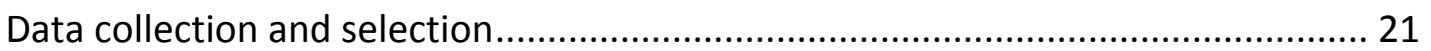

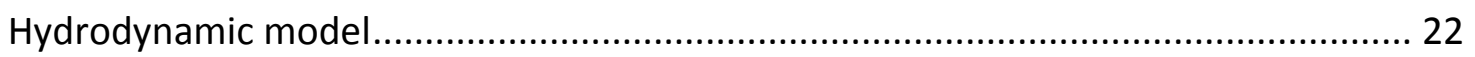

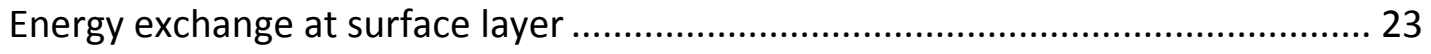

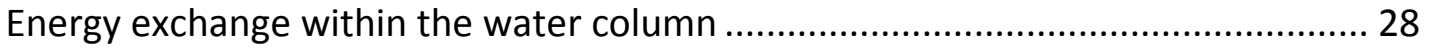

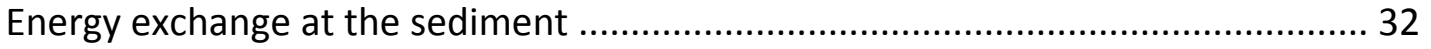

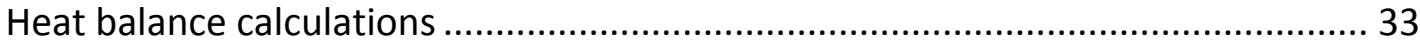

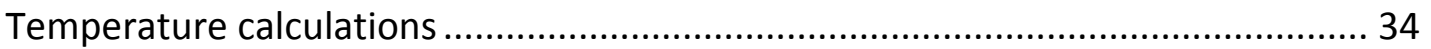

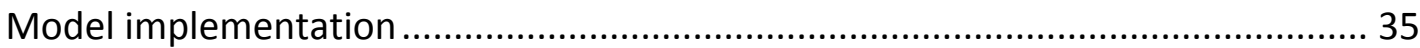

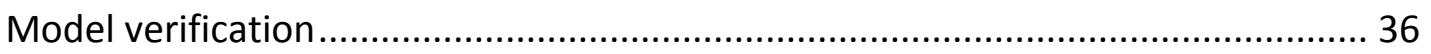

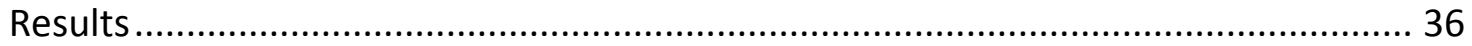




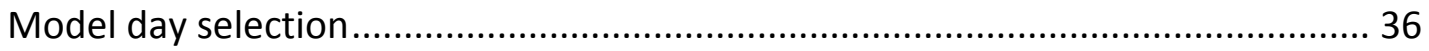

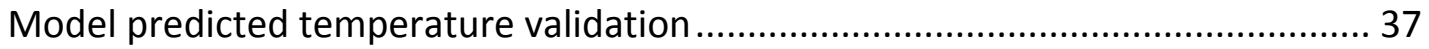

Model effective diffusion rates........................................................................... 38

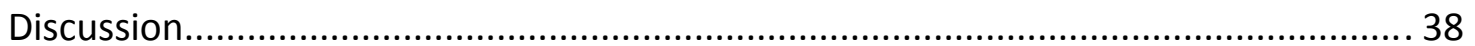

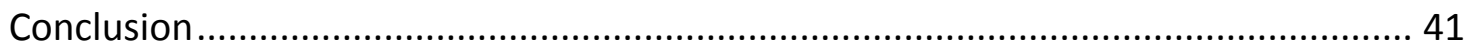

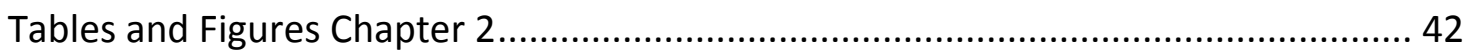

Chapter 3. Modeling the competition of cyanobacteria and the sensitivity of competition to buoyancy........................................................................................... 51

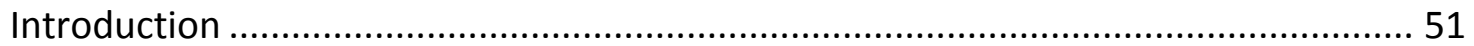

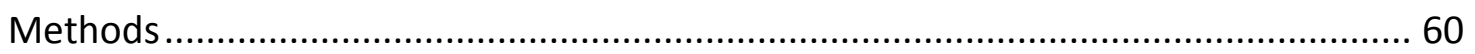

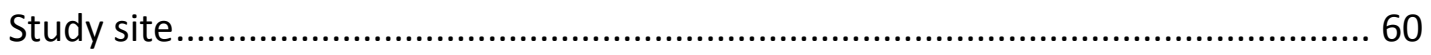

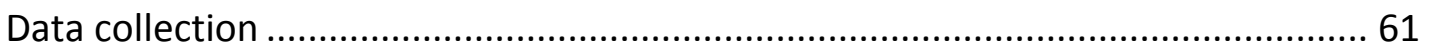

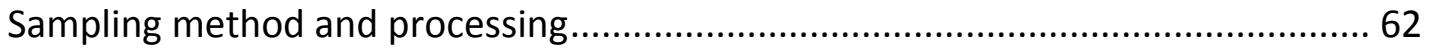

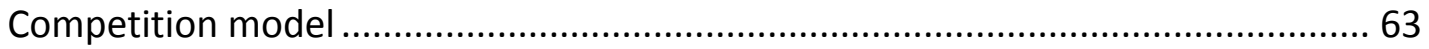

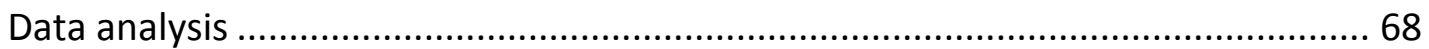

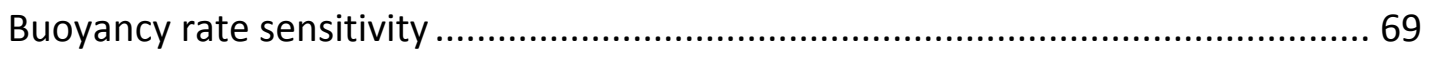

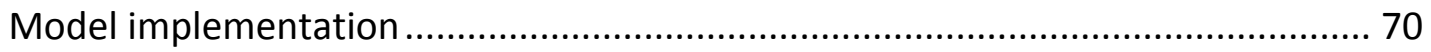

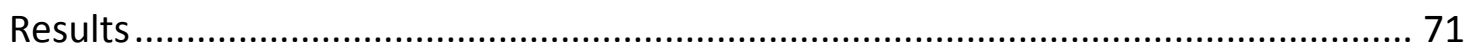

APFA buoyancy rates in UKL closely matched literature .......................................... 71

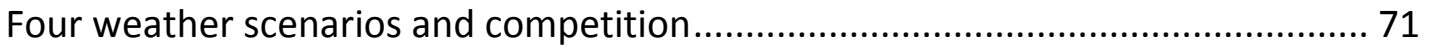

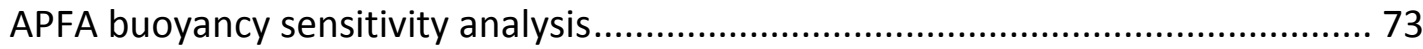

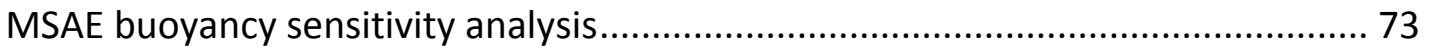

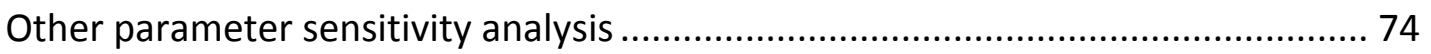

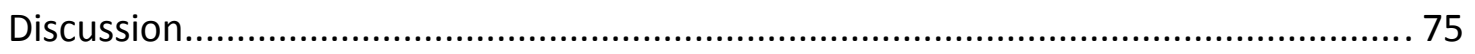

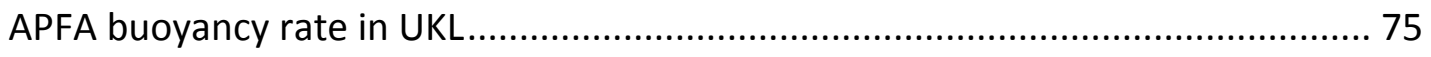

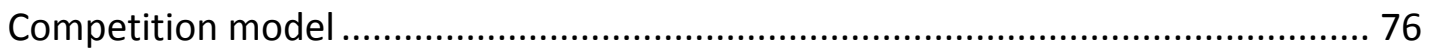

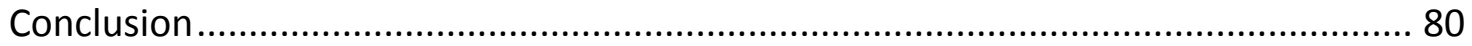

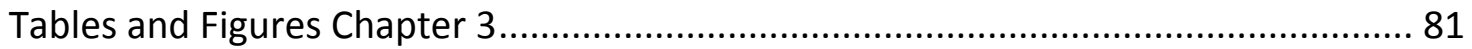

Chapter 4. Conclusions and potential future work ............................................... 92

Aphanizomenon flos-aquae buoyancy in Upper Klamath Lake................................... 92

Modeling cyanobacteria competition under different mixing regimes ....................... 93 


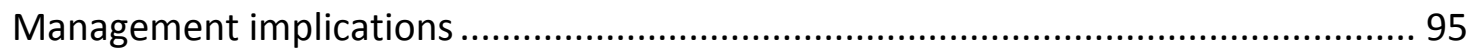

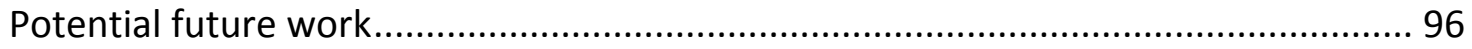

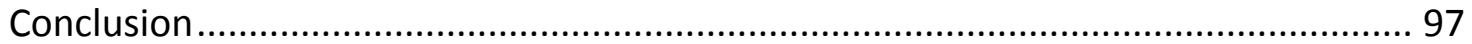

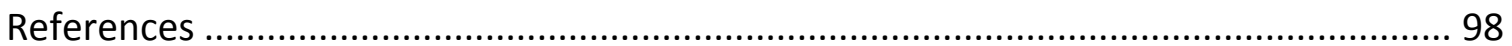

Appendix A. Hydrodynamic model ........................................................... 107

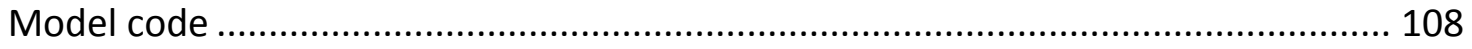

Appendix B. Competition model.............................................................. 116

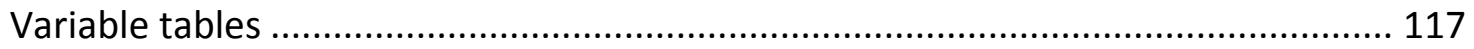

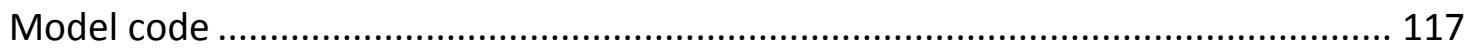




\section{List of Tables}

Table 2-1 Daily average and max air temperatures and wind speed at UKL. Asterisked dates represent days selected for modeling.

Table 2-2 The average measured temperature with depth for the four modeled days. . 44

Table 2-3 Model root mean square deviations (RMSD) by depth and modeled day...... 48

Table 2-4 Coefficient of variation (CV\%) by depth and modeled day.

Table 2-5 The absolute difference between the model predicted temperature and observed temperature was averaged at each depth for each modeled day. 48

Table 2-6 The daily average effective diffusion coefficient for each modeled day with depth.

Table 3-1 Repeated measures ANOVA table comparing the concentration of APFA and MSAE cells between different weather scenarios.

Table 3-2 Total cell accumulations for each species at the end of the 5-day simulations.

Totals assume a $1 \mathrm{~m}^{3}$ volume water column. 86

Table 3-3 Comparison of total APFA cells with depth in every weather scenario with decreasing APFA buoyancy rates (BR in $\mathrm{m} \mathrm{h}^{-1}$ ). Original APFA buoyancy rate is $0.89 \mathrm{~m} \mathrm{~h}^{-1}$. Green background indicates the highest concentration of cells within a scenario, and red indicates the smallest concentration of cells.

Table 3-4 Comparison of total MSAE cells with depth in every weather scenario with decreasing APFA buoyancy rates (BR in $\mathrm{m} \mathrm{h}^{-1}$ ). Original APFA buoyancy rate is $0.89 \mathrm{~m} \mathrm{~h}^{-1}$. Green background indicates the highest concentration of cells within a scenario, and red indicates the smallest concentration of cells. 88

Table 3-5 Comparison of total MSAE cells with depth in every weather scenario with increasing MSAE buoyancy rates (BR in $\mathrm{m} \mathrm{h}^{-1}$ ). Original MSAE buoyancy rate is $0.5 \mathrm{~m} \mathrm{~h}^{-1}$. Green background indicates the highest concentration of cells within a scenario, and red indicates the smallest concentration of cells. 89

Table 3-6 Comparison of total APFA cells with depth in every weather scenario with increasing MSAE buoyancy rates (BR in $\mathrm{m} \mathrm{h}^{-1}$ ). Original MSAE buoyancy rate is $0.5 \mathrm{~m} \mathrm{~h}^{-1}$. Green background indicates the highest concentration of cells within a scenario, and red indicates the smallest concentration of cells. 90

Table 3-7 Comparison of algal cell counts among different weather scenarios when MSAE parameters were changed to equal APFA's parameter, and the competition model was ran for a 5-day simulation.

Table 3-8 Repeated measures ANOVA table comparing the concentration of APFA and MSAE cells between different weather scenarios when the optimum temperature growth curve for APFA was used for both species. 


\section{List of Figures}

Figure 1-1 Conceptual diagram of the factors that impact cyanobacteria physiology and species interactions (temp = temperature, $\mathrm{DO}=$ dissolved oxygen).

Figure 1-2 Summary of effects of summer heatwaves on phytoplankton biomass (reprinted from Joehnk et al. 2008). Three meteorological variables (air temperature, cloudiness, and wind speed) affect water temperature and turbulent diffusion in the water column. The numbers inside the boxes represent the relative (left) and absolute (right) differences between the summer heatwave of 2003 in Lake Nieuwe Meer and an average summer. The phytoplankton functional groups are represented in the circles and show the relative increase or decrease in biovolume due to changes in water temperature and diffusivity

Figure 2-1 Map of the location of the meteorological station and temperature loggers in Upper Klamath Lake. 42

Figure 2-2 A schematic diagram showing how the water column was divided into volume elements for modeling. Depth ( $\mathrm{z}$ ) is shown at the boundaries and in the center of each volume element.

Figure 2-3 The selected modeled days are plotted against daily average wind speed ( $\mathrm{m} \mathrm{s}$ $\left.{ }^{1}\right)$ and daily average air temperature $\left({ }^{\circ} \mathrm{C}\right)$. The average temperature and average wind speed for the entire data set are plotted as vertical and horizontal lines, respectively. Categories are: $\mathrm{CW}=$ cool windy, $\mathrm{HW}=$ hot windy, $\mathrm{CC}=$ cool calm, $\mathrm{HC}=$ hot calm....... 43 Figure 2-4 Temperature and wind speed data for Upper Klamath Lake. Days highlighted in yellow were selected for modeling the water column's turbulence structure............ 44 Figure 2-5 1:1 line graphs of observed temperatures versus model predicted temperatures at all depths for the modeled cool calm day.

Figure 2-6 1:1 line graphs of observed temperatures versus model predicted temperatures at all depths for the modeled cool windy day.

Figure 2-7 1:1 line graphs of observed temperatures versus model predicted temperatures at all depths for the modeled hot calm day.

Figure 2-8 1:1 line graphs of observed temperatures versus model predicted temperatures at all depths for the modeled hot windy day.

Figure 2-9 Temperature with depth profile for all modeled days. The plotted values include modeled and interpolated temperatures at $12 \mathrm{pm}$ on each modeled day.

Figure 2-10 The average effective diffusion coefficient with depth for all modeled days.

Figure 3-1 Map of Upper Klamath Lake APFA collection sites.

Figure 3-2 This is the Logger Pro ${ }^{\circledR}$ tracking software interface. An APFA raft video has been loaded into the software. The subdivisions used in raft selection are marked (1-10).

Figure 3-3 schematic diagram of the competition model. 82 
Figure 3-4 Boxplot of buoyancy rates by location ( $\mathrm{hb}=$ Howard Bay, le = Lake Ewuana, and $\mathrm{mp}=$ Moore Park). A single outlier buoyancy rate can be seen in the 'le' location boxplot.

Figure 3-5 A 90\% confidence level graph for concentrations of MSAE under various weather scenarios ( $\mathrm{CC}=\mathrm{cool}$ calm, $\mathrm{CW}=\mathrm{cool}$ windy, $\mathrm{HC}=$ hot calm, and $\mathrm{HW}=$ hot windy). Confidence intervals were constructed using TukeyHSD test. Two confidence intervals were significant (HC-CC, $p=0.07$; HW-CC, $p=0.08$ )

Figure 3-6 Concentration of APFA cells with depth for each weather scenario at the end of simulation ( $\mathrm{CC}=\mathrm{cool}$ calm, $\mathrm{CW}=\mathrm{cool}$ windy, $\mathrm{HC}=$ hot calm, and $\mathrm{HW}=$ hot windy)........ 84 Figure 3-7 Concentration of MSAE cells with depth for each weather scenario at the end of simulation $(\mathrm{CC}=\mathrm{cool}$ calm, $\mathrm{CW}=\mathrm{cool}$ windy, $\mathrm{HC}=$ hot calm, and $\mathrm{HW}=$ hot windy)......... 85 


\section{Chapter 1. Background information}

\section{Introduction}

Cyanobacterial blooms in lakes are a major cause for concern due to impacts on human health, the economy, and the ecological health of water bodies. Cyanobacterial blooms can produce cyanotoxins that are harmful to fish, birds, livestock, and humans (Carmichael et al. 1985). The presence of cyanotoxins negatively impacts the health of waters used for recreational and drinking purposes, rendering them unusable while the bloom persists (Fogg 1969; Codd 1995; Paerl et al. 2001). The decomposition of blooms requires oxygen, which causes anoxia and increased mortality rates of local fish, shellfish and invertebrates (Codd 1995; Paerl and Huisman 2009). Cyanobacterial blooms are most often managed by limiting nitrogen and/or phosphorous nutrient inputs (Paerl et al. 2001; Paerl and Otten 2013). Some managers have reported success in managing blooms through hydrologic manipulations (McDonald and Lehman 2013) and mechanical mixing of the water column (Joehnk et al. 2008) when nutrient management is not possible. It is generally believed that climate change will promote and increase the frequency and intensity of cyanobacterial blooms due to their unique physiological adaptions (Paerl and Huisman 2008; Adrian et al. 2009; Paerl and Huisman 2009; Paerl et al. 2011; Carey et al. 2012; O’Neil et al. 2012), which will add more challenges to preventing and controlling blooms. To improve and devise new management methods for bloom control, it is critical to understand how cyanobacterial 
physiological adaptions interact with and are impacted by lake morphology, geology, climate, and a lake's physical and chemical properties (Figure 1-1).

Impact of lake morphology and watershed geology on cyanobacteria physiology

Many key physical and chemical characteristics of a lake are influenced by a lake's morphology and surrounding geology. The turbulence of a large shallow lake is more strongly influenced by wind waves than for deep lakes (Cardoso and Marques 2009), in part because it takes less energy to completely mix a shallow water column than a deeper water column. Unlike deep dimictic lakes, shallow polymictic lakes can occasionally stratify during warm days, but will normally not develop strong summertime thermal stratification due to the water column becoming completely mixed with very little wind.

The success of phytoplankton species is strongly influenced by the thermal stratification's impact on vertical mixing because this determines the physical location of a phytoplankton relative to nutrients and light (Winder and Hunter 2008). Many genera of cyanobacteria can exploit stratified conditions through the formation of gas vesicles and ballast, which allows them to control their position in the euphotic zone (Kromkamp and Walsby 1990; Ibelings et al. 1991; Paerl and Huisman 2008), but they lose this competitive advantage if they are entrained under turbulent conditions.

There is a wide range in naturally occurring nutrient concentrations, with some lakes having little phosphorous and others situated on apatite bedrocks, which can be 
high in phosphorous. Cultural eutrophication from human-induced environmental changes can over-enrich lakes (particularly with nitrogen and phosphorous; Paerl and Huisman 2009). Cyanobacteria have physiological adaptions that allow them to exploit both high and low nutrient scenarios. Cyanobacteria with heterocysts have the ability to fix atmospheric nitrogen and have a high affinity for, and ability to store, phosphorous (Carey et al. 2012).

The morphology and watershed geology of a lake affects the annual mixing patterns, light environment, and naturally occurring nutrient concentrations, which will influence the phytoplankton community composition within a lake. While lake morphology and geology creates the baseline physical and chemical conditions, climate exerts additional influence on a lake's physical and chemical properties, and thus community composition.

Impact of climate on cyanobacteria physiology

Climate strongly influences the physical, chemical and biological properties of lakes. Meteorological variables largely determine the physical forcing in a lake, and its tendencies to stratify or mix via heat exchange and wind action (Winder and Hunter 2008). High summer-time temperatures and lack of precipitation can cause strong stratification and increased evaporative losses of water, which can increase total nitrogen and ion solutes in a lake (Schindler 1990). Precipitation, and the resulting runoff, delivers nutrients into lakes. Increases or decreases in precipitation impact the 
salinity and volume of lakes (Pham et al. 2008). Wind patterns impact lake turbulence and stratification (Cardoso and Marques 2009). Climate regulates lake temperature and density gradients, nutrient concentration, and mixing rates, which selects for phytoplankton with certain physiological traits that can exploit these conditions.

Cyanobacteria physiological traits, such as phosphorous storage, nitrogen fixation, and buoyancy regulation, have evolved to exploit nutrient rich and stagnate conditions (Paerl and Huisman 2008; Carey et al. 2012). Climate change threatens to alter existing precipitation, temperature, and wind patterns, in ways which would promote more frequent and intense cyanobacteria blooms.

Impact of climate change on lake hydrodynamics and chemical properties

General climate change scenarios for temperate areas predict: increase air temperatures (particularly minimum nighttime temperature), altered wind patterns, and change in both the timing and volume of run-off into water bodies (Livingstone 2003; Moore et al. 2008; Joehnk et al. 2008; Paerl and Huisman 2008; Carey et al. 2012). Alteration of meteorological and hydrological variables has the potential to modify the existing thermal stability of a lake by decreasing convective cooling, and reducing turbulent eddy diffusivity (Livingstone, 2003; Joehnk et al. 2008), as well as increasing total nutrient loading and residence time by altering patterns of precipitation and drought (Paerl and Huisman 2008; Carey et al. 2012). This has the potential to increase water column stability, causing more intense and longer periods of lake stratification 
(Livingstone 2003; Carey et al. 2012), resulting in intensified stratification, which could amplify harmful cyanobacteria species due to several physiological traits, including: optimal growth rates at higher temperatures (Moore et al. 2008; Paerl and Huisman $2008 \& 2009$ ), and buoyancy regulation via creation of gas vesicles and ballast (Reynolds et al. 1987; Walsby 1994; Joehnk et al. 2008; Winder and Hunter 2008; Carey et al. 2012).

Key cyanobacteria physiological adaptions

Cyanobacteria are well positioned to exploit the physical and chemical changes in lakes due to climate change because of their unique physiological adaptions ( $\mathrm{O}^{\prime}$ Neil et al. 2012; Paerl and Otten 2013). Many species of cyanobacteria have an optimal growth rate at water temperatures greater than $25^{\circ} \mathrm{C}$ (Paerl and Huisman 2009), while diatoms and greens generally have optimal growth rates between $17-20^{\circ} \mathrm{C}$ (Joehnk et al. 2008). During blooms, cyanobacteria may further increase water temperatures through increased absorption of light, creating a positive feedback loop where surface blooms increase water temperature, further promoting blooms (Paerl and Huisman 2008).

Under conditions of decreased turbulent mixing (and stratification), cyanobacteria have another competitive advantage by formation of gas vesicles (Joehnk et al. 2008; Paerl and Huisman 2008). Gas vesicles are hollow ridged internal structures that are impermeable to water and are filled with air (Walsby 1994). Cell buoyancy is impacted by carbohydrate accumulation and the ability of the gas vesicle to withstand 
pressure, which varies among cyanobacteria species (Walsby 1994). Gas vesicles allow for buoyancy regulation across steep density gradients (Reynolds and Walsby 1975; Joehnk et al. 2008). In addition, as water temperature increases the viscosity of water decreases, resulting in faster flotation velocities for buoyant cyanobacteria and faster sinking velocities for non-buoyant species. Thus, cyanobacteria are better able to shade out competitors during blooms because of their superior position in the water column (Joehnk et al. 2008).

Because of these physiological traits, cyanobacteria species are expected to outcompete other phytoplankton species under enhanced stratification and nutrient enrichment, with the outcome of increased frequency and duration of harmful algal bloom events (Joehnk et al. 2008; Paerl and Huisman 2009; Carey et al. 2012; O'Neil et al. 2012). However, the underlying mechanisms that give one buoyant cyanobacteria species a competitive edge over another buoyant species are poorly understood.

\section{Gaps in current knowledge}

The competition and succession between different cyanobacteria genera is understudied and poorly understood (Wu et al. 2015), however some mechanisms have been proposed. All phytoplankton are impacted by the availability of light, but buoyant species can regulate their position in the water column, and thus influence the light environment of the water column via shading (Huisman et al. 2004). It has been shown that a buoyant light-limited phytoplankton that can control its position in the upper 
layer during stratification in a shallow turbid lake will have a significantly greater potential for growth than neutrally buoyant phytoplankton with similar specific growth rates (Sherman and Webster 1994). From this, it follows that buoyancy regulation has been suggested as a competition mechanism between buoyant cyanobacteria and neutrally buoyant phytoplankton (Bonnet and Poulin 2002).

Researchers have uncovered varying mechanisms for succession between Aphanizomenon flos-aquae (APFA) and Microcystis aeruginosa (MSAE). Wu et al. (2015) suggested temperature was the most important factor governing succession between APFA and MSAE in Dianchi Lake, while total nitrogen (TN) and/or total nitrogen: total phosphorous (TN:TP) ratio might influence population dynamics. Lehman et al (2009) found the dynamics of APFA and MSAE succession was driven by $\mathrm{NO}_{3}^{-}$concentrations in Lake Ford. An obvious mechanism to explain competition between cyanobacteria is the ability in some species to fix atmospheric nitrogen. The assumed dynamic is that nitrogen-fixing species (e.g. APFA dominate when nitrogen is limiting and non- $\mathrm{N}_{2}$ fixing species (e.g. MSAE) dominate when there is excess nitrogen, however this is often not observed in temperate lakes since MSAE often dominates in late summer when nitrogen concentrations are at their lowest (Paerl and Otten 2016). Yamamoto (2009) said nutrient concentrations and $\mathrm{pH}$ had no clear impact on APFA concentration, but the presence of MSAE and the progress of lake eutrophication are likely factors in determining the growth of APFA. Paerl and Otten (2016) noted a lack of detectable increase in nitrogen before, during and after APFA blooms. They suggest the 
competitive dominance of MSAE in late summer is due to superior nutrient uptake and/or higher growth rates at warmer temperatures rather than the concentration of TN. However, the sensitivity of cyanobacteria to temperature probably varies with regional ecotypes (Paerl and Otten 2016) and competitive advantage is only exploited at the upper and lower end of a cyanobacteria's tolerance. Thus, the underlying mechanisms of competition between buoyant cyanobacteria are dependent on what species are present, the cyanobacteria ecotype and on lake trophic state.

The interaction between climate warming and eutrophication is expected to promote cyanobacteria, however this proliferation is dependent on lake trophic state, cyanobacteria taxa, and the cyanobacteria's ecotype (i.e. sub-populations). The pattern of primary productivity in hypereutrophic lakes can change with changes in nutrients or higher temperatures because some taxa such as MSAE are more sensitive to temperature and others, such as APFA, are more sensitive to changes in nutrients (Rigosi et al. 2014).

Cyanobacteria ecotype and physiology in the system of study

The system of study in this thesis is the hypereutrophic Upper Klamath Lake (UKL) and Agency Lake, which are in southern central Oregon (see Study Site section for more details). The dominant cyanobacterium since European American settlement and $20^{\text {th }}$ century eutrophication has been APFA (Eilers et al. 2004), and there are no reports that the APFA present in UKL produces toxins (Eldridge et al. 2013). The microcystin- 
producing MSAE is also present in the lake, and can increase following a decline in an earlier APFA bloom due to an increase in phosphorous and nitrogen availability (Lindenberg et al. 2009). A key to understanding how competition between these two buoyant cyanobacteria could change under climate change is to understand how weather currently impacts algal productivity in UKL and how the lake specific ecotypes of the cyanobacteria is impacted by warm weather.

Productivity in UKL and Agency Lake is high, and is often favorably and quickly impacted by weather. USGS continuously monitored water-quality variables $(\mathrm{pH}, \mathrm{DO}$, specific conductance and water temperature) and found significant variability on time scales of 6-7 days (Eldridge et al. 2014). They concluded that photosynthetically driven water quality variables are highly influenced by weather. Eldridge et al. (2014) also found increases in blooms were positively correlated with increases in air temperature and decreases in wind speed within 1-4 days. Blooms increased when the water column was stable during the day and mixed overnight within 1-2 days. These findings underscore the importance of short-term weather patterns on cyanobacteria bloom production in UKL. The algal ecotypes present in Upper Klamath Lake are well adapted to warm weather, and climate change could exacerbate the problem of high productivity.

The sensitivity of cyanobacteria to temperature varies with regional ecotypes (Paerl and Otten 2016) and competitive advantage is only exploited at the upper and lower end of a cyanobacteria's tolerance. Paerl and Otten (2016) analyzed a 14-year 
dataset (collected as part of the Klamath Hydroelectric Settlement Agreement) and found the APFA in UKL reached peak dominance at water temperatures of around $24^{\circ} \mathrm{C}$, while the MSAE population showed no indication of peaking at the maximum water temperature that was observed $\left(26.5^{\circ} \mathrm{C}\right)$. For comparison, Wu et al. (2015) observed rapidly forming APFA blooms in Dianchi Lake, China at $15^{\circ} \mathrm{C}$, and MSAE blooming at around $18^{\circ} \mathrm{C}$. Reynolds (2006) recorded the temperature of maximum replication rates for APFA at $20^{\circ} \mathrm{C}$ and at $28^{\circ} \mathrm{C}$ for MSAE. If climate change results in warmer temperatures around UKL, the existing cyanobacterial ecotypes are well situated to exploit the altered hydrodynamics of the lake (see Figure 1-2 for summary of hydrodynamic changes).

The effects of climate change will be regionally variable, which require localscale downcasting of climate change models to sharpen our understanding of the meteorological impacts on specific lakes, such as UKL. Climate change predictions for the Klamath Basin include increases in air temperature and decrease in summer precipitation (Barr et al. 2010). There is a high degree of uncertainty in forecasting the effects of climate change on species interactions (Winder and Schindler 2004), which compounds the difficulty of predicting the competition between buoyant cyanobacteria species in UKL. It is important to consider a physiological approach to investigating competition mechanisms between species. In general, plankton physiological adaptions can confound water quality improvement and algal management efforts in impaired 
hypereutrophic lakes, especially when taking into consideration the ecosystem's response to climate change.

In hypereutrophic lakes, nutrient reduction is an essential, long-term management strategy for reducing algal biovolume in lakes (Paerl et al. 2001; Paerl et al. 2001; Paerl and Otten 2016). In over-enriched lakes, cyanobacteria often dominate the algal community because cyanobacteria have exhibited several physiological strategies that improve their nutrient absorption and assimilation (Fogg 1969; Reynolds 1987). Nutrient enrichment is a known problem in UKL, and there are several management techniques (such as wetland creation and restoration and sediment removal) that are currently being explored which are focused on long-term nutrient reductions to reduce cyanobacteria growth (Stillwater Sciences Technical Memo 2013). In contrast, shortterm management techniques, such as mechanical aeration and hydrologic manipulation focus on short-term suppression of blooms and have an immediate impact on algae biovolume (Bailey-Watts et al. 1987; Huisman et al. 2004; Lehman et al. 2009). Physical mixing can suppress and disperse cyanobacteria accumulations within a water column by decreasing the influence of the physiological adaption of buoyancy regulation (Reynolds and Walsby 1975; Paerl et al. 2001; Morento-Ostos et al. 2009). The focus of this thesis will be on how mixing and buoyancy influence algal community composition (instead of biovolume), and how this might suggest some new short-term management strategies. 


\section{Thesis objectives}

The objective of this study is to model how weather patterns and algal buoyancy regulation influence the competition and growth of two bloom-forming buoyant cyanobacteria species (APFA and toxin-forming MSAE) in UKL, Oregon. Sudden changes in weather patterns can quickly impact lake thermal structure, which can rapidly influence the competition between buoyancy regulating cyanobacteria. The intention of the study is not to predict long-term changes in cyanobacteria biomass or to predict the occurrence of blooms; the analysis is meant to investigate how buoyancy impacts competition under a changing climate regime. By modeling competition, I plan to address how altered climate could shift the competitive advantage from the current cyanobacterium to a toxic-producing, bloom-forming cyanobacterium.

I modified a coupled one-dimensional hydrodynamic and algal competition model, with lake specific physiological parameters pioneered by Huisman et al. (2004). The hydrodynamic model is driven by meteorological variables, and is a system of four partial differential equations, which describe the mechanics of momentum, heat transfer, turbulent kinetic energy, and turbulent dissipation rate (Joehnk et al. 2008). The hydrodynamic model is one-dimensional because it models mixing of one column of water instead of an entire lake. The algal competition model also only considers a vertical column of water and the growth and competition of each species relative to each other. The vertical mixing and light environment determined by the 1D model will be used to drive the competition model. This thesis investigated the sensitivity of lake 
thermal regimes to various weather scenarios, and how this can reassemble algal community structure and influence the competition for light between two species of cyanobacteria. The coupled biological-physical model (similar to Joehnk et al. 2008) was built in STELLA ${ }^{\mathrm{TM}}$ version 10.0.6, which allowed for the investigation of how the structure and sensitivity of parameters interacted between variables under different lake turbulence structures. To increase accuracy of model physiological parameters, APFA buoyancy rates were measured from in-lake specimens. Due to a lack of MSAE specimens from in-lake samples, MSAE buoyancy rates were not directly measured in this study.

\section{Hypotheses}

Weather patterns play a large role in the outcome of competition between cyanobacteria in UKL, and even short-term changes can create dramatic shifts in species composition. The difference between the relative buoyancy between APFA and MSAE could be a key physiological mechanism for better understanding the outcome of this competition.

Planktonic cyanobacteria species have differing buoyancy rates and this can confer distinct advantages or disadvantages under certain mixing regimens. To elucidate the advantages one species can have over another during small-scale local competition, I have formulated two hypotheses: 
- Hypothesis 1: MSAE will dominate under conditions of high water temperature due to its high optimum growth temperature.

- Hypothesis 2: Fast buoyancy rates can shift the outcome of competition in favor of the less physiologically fit (i.e. not as well adapted to the physical conditions of the water column) species due to quick accumulation near the surface that shades out the "fitter" competitor.

\section{Potential study significance}

Restoration and management efforts that take for granted the status quo could be blindsided by significant cascading ecological responses to climate change. Currently, the non-toxin-forming cyanobacteria APFA dominate UKL, but MSAE is present and has been known to bloom. There is concern that shifting weather patterns could change the current algal competition in favor of the toxin-forming species, MSAE. This is significant because UKL is home to two endangered fish species of suckers (that have legal protection and cultural significance to native tribes) and is the headwaters to an important river for anadromous fish migration. While succession between species in the cyanobacteria genera is poorly understood, it has been hypothesized that temperature is the most influential factor governing the succession and competition between APFA and MSAE (McDonald and Lehman et al. 2013; Wu et al. 2015). Since climate change will most likely increase temperature in the Klamath region, the concern about cyanobacteria succession is justified and should be explored further. My thesis seeks to 
identify certain weather scenarios that could lead to dangerous accumulations of MSAE (hot calm days, or hot windy days), and identify if buoyancy regulation and/or optimum growth curves impact algal competition in UKL. 


\section{Figures Chapter 1}

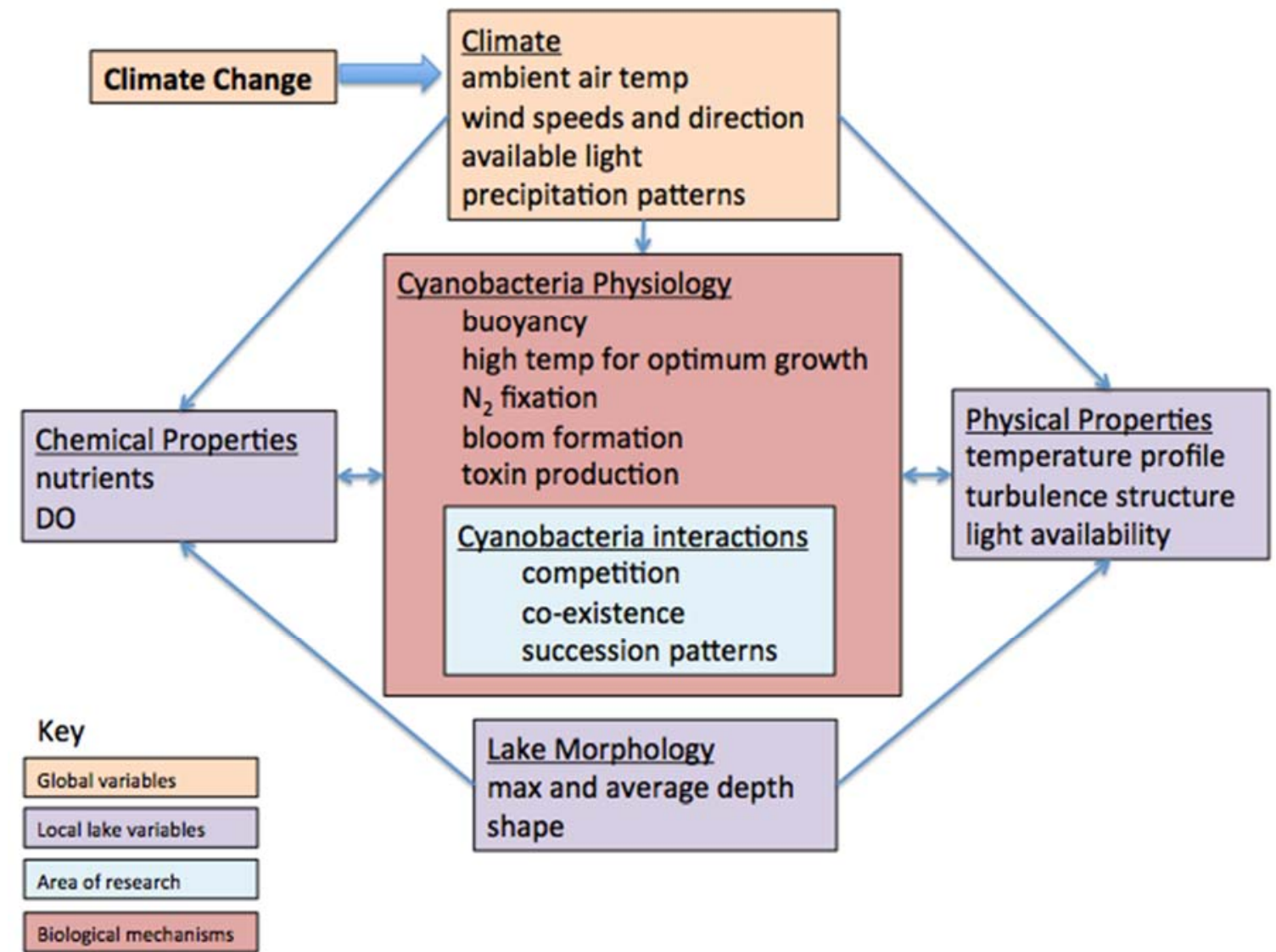

Figure 1-1 Conceptual diagram of the factors that impact cyanobacteria physiology and species interactions (temp $=$ temperature, $\mathrm{DO}=$ dissolved oxygen). 


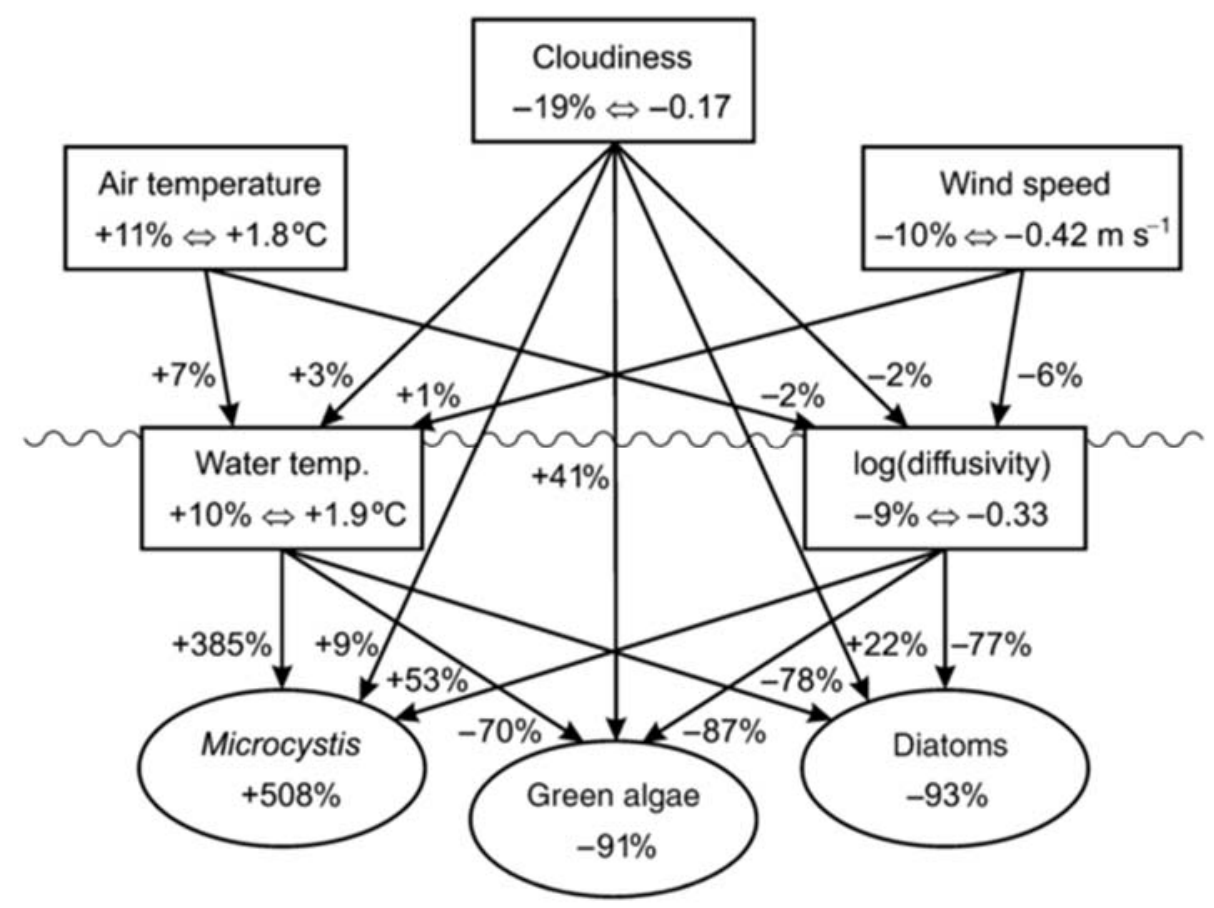

Figure 1-2 Summary of effects of summer heatwaves on phytoplankton biomass (reprinted from Joehnk et al. 2008). Three meteorological variables (air temperature, cloudiness, and wind speed) affect water temperature and turbulent diffusion in the water column. The numbers inside the boxes represent the relative (left) and absolute (right) differences between the summer heatwave of 2003 in Lake Nieuwe Meer and an average summer. The phytoplankton functional groups are represented in the circles and show the relative increase or decrease in biovolume due to changes in water temperature and diffusivity 


\section{Chapter 2. Modeling water column mixing in Upper Klamath Lake}

\section{Introduction}

Understanding how heat is distributed through the water column is of prime importance to ecologists and lake managers because temperature affects the growth rate of all aquatic species (Losordo and Piedrahita 1991). Key physical properties, such as water column temperature, density, stability, and light availability are interrelated and are dependent on meteorological variables such as: air temperature, wind speed and direction, and solar irradiance (Edinger et al. 1968; Dodson 2005). High air temperatures increase the stability of the water column, thereby reducing vertical turbulent mixing (Sundaram and Rehm 1973). Water column stability is impacted in part because the density of water is dependent on temperature. In stratified lakes, warmer lighter water at the top of the water column is effectively segregated from the denser cooler water at the bottom. This density gradient acts as a barrier for some aquatic species (Sundaram and Rehm 1973; Reynolds et al. 1987). Convective cooling of surface water causes increased vertical mixing, which can break down this density gradient (Dodson 2005). Water column stratification can happen on a seasonal basis, and nighttime convective cooling is one physical mechanism that can cause thermal stratification to break down (Livingstone 2003). Water column mixing can occur when the kinetic energy input from the wind is sufficient to overcome the water column's resistance to mixing (Losordo and Piedrahita 1991; Reynolds 1997). Thus, meteorological variables impact how heat energy diffuses through a column of water. 
There are five main physical mechanisms through which the heat balance of a lake is influenced (Edinger et al. 1968): i) absorption of atmospheric long-wave radiation, ii) emission of long-wave radiation from the lake's surface, iii) absorption of direct and diffuse short-wave solar radiation, iv) exchange of latent heat of evaporation and condensation, and v) the convective exchange of sensible heat. Hydrodynamic models have been created to simulate lake turbulence structure by calculating these empirical physical mechanisms.

Hydrodynamic models that incorporate heat diffusion equations are common in the literature and is often called a one-dimensional (1D) k- $\varepsilon$ turbulence model (Losordo and Piedrahita 1991; Rodi 1993; Mohammadi and Pironneau 1994; Joehnk and Umlauf 2001; Hutter and Joehnk 2004; Joehnk et al. 2008). $k$ is the coefficient of the turbulent eddy diffusion of heat, and $\varepsilon$ is the molecular diffusivity of heat. These terms are often combined into one term called the effective diffusion coefficient $\left(E_{z}\right)$, which is greatest at the water surface and decreases with depth to a minimum at the thermocline (Losordo and Piedrahita 1991). The success or failure of a diffusion-type model often hinges on the accuracy of estimating $E_{z}$ when a lake has a long residence time (Hurley 1977). With a diffusion model, heat is transferred through the water column by turbulent mixing, which is a function of the temperature gradient and the diffusion coefficient. The value of the diffusion coefficient varies over time and is a function of the meteorological variables discussed above (wind speed, temperature, solar irradiance). A one-dimensional k- $\varepsilon$ turbulence model was created for Upper Klamath Lake (UKL) to 
simulate mixing regimes under contrasting weather conditions by adapting the work of Losordo and Piedrahita (1991) and Losordo (1988).

The objective of modeling the hydrodynamic properties of UKL was to establish mixing rates throughout a water column under varying weather conditions. A meteorological station and two arrays of water temperature logger data were collected for the model data inputs and verification, respectively. Four representative days were selected for modeling: hot windy, hot calm, cool windy and cool calm. The resulting mixing regime outputs were used as inputs for the algal competition model (see Chapter $3)$.

\section{Methods}

Study site

UKL is a large $\left(232 \mathrm{~km}^{2}\right)$, shallow (average depth of $2.8 \mathrm{~m}$ ) lake located in southcentral Oregon (Lindenberg et al. 2009). This natural lake is in a sizeable watershed $\left(9,415 \mathrm{~km}^{2}\right)$, and a dam down river controls the height of the lake. Agency Lake is located north of UKL and is connected to UKL via a shallow channel, and adds about 38 $\mathrm{km}^{2}$ of surface area to the UKL total surface area (Johnson 1985). The lakes are connected by a channel and more recently through The Nature Conservancy project where the levees were removed and lake water could move across the property. Both lakes are hypereutrophic and have annual blooms of APFA. The prevailing winds at UKL are westerly over the northern part of the of the lake and northwesterly over the 
southern two-thirds of the lake (Lindenberg et al. 2009).

A meteorological station and data loggers were deployed on the Nature Conservancy's property in Agency Lake (Figure 2-1), connected to and located north of UKL. The meteorological station was launched on a levee remnant that is surrounded by lake water (called the "turn around"). Two water temperature arrays were launched due north of the meteorological station in a section of the lake that had an approximate depth of $90 \mathrm{~cm}$. This area is behind a locked gate with no public access however we were granted access by The Nature Conservancy.

\section{Data collection and selection}

A meteorological station and data loggers were deployed from September 1-23, 2016. The meteorological recorded data every ten minutes and collected the following variables: air temperature $\left({ }^{\circ} \mathrm{C}\right)$, photosynthetically active radiation $(\mathrm{PAR}, \mu \mathrm{E})$, relative humidity (\%), wind speed $\left(\mathrm{m} \mathrm{s}^{-1}\right)$, gust speed $\left(\mathrm{m} \mathrm{s}^{-1}\right)$, and wind direction (degrees). All data were averaged to an hourly time step for the 1D model inputs. Water temperature was recorded via two data logger arrays. The data loggers recorded temperature and lux at a ten-minute time step. All data were averaged to an hourly time step for model validation and interpolation. The loggers were placed on the array at the following depths $(\mathrm{cm}): 0,2.5,5,15,35$, and 60 . In addition, one array recorded sediment temperature and lux $(90 \mathrm{~cm})$. 
Four day clips were selected for modeling based on the average day's temperature and wind conditions. Days were categorized as: hot and windy, hot and calm, cool and windy, and cool and calm. Each day was compared to the average daily temperature, maximum daily temperature, average daily wind speed, and max daily gust speed to categorize a day as hotter than average, windier than average.

\section{Hydrodynamic model}

The hydrodynamic model is driven by meteorological variables, and calculates the energy exchanges between the atmosphere and the lake surface, and between each layer of water. The model simulates mixing and temperatures between six layers of water: $0-5 \mathrm{~cm}, 5-20 \mathrm{~cm}, 20-40 \mathrm{~cm}, 40-60 \mathrm{~cm}, 60-80 \mathrm{~cm}$, and $80 \mathrm{~cm}$ to the sediment (Figure

2-2). The hydrodynamic model was based from work by Losordo and Piedrahita (1991). Losordo and Piedrahita (1991) simplify calculations by using a Fickian diffusion equation to express turbulent eddy transport of heat:

$$
J_{s z}=-K_{s z} \partial s / \partial
$$

$\mathrm{J}_{\mathrm{sz}}$ is the flux of heat in the $\mathrm{z}$ direction. $\mathrm{K}_{\mathrm{sz}}$ is the coefficient of the turbulent eddy diffusion of heat $(s)$ in the $z$ direction. This means $K_{s z}$ is a measure of the rate of mixing from one volume element to another. A one-dimensional (i.e. vertical) equation for heat can be used to calculate the change in temperature in a water body: 


$$
\frac{\partial T_{w c}}{\partial t}=\frac{\partial}{\partial z}\left[\left(\varepsilon+K_{z}\right) \partial T_{w c}\right]+\left(\frac{\partial \phi}{\partial z}\right) /\left(\rho_{w} c_{p w}\right)
$$

where

$\mathrm{T}_{\mathrm{wc}}$ is the temperature $\left({ }^{\circ} \mathrm{C}\right)$ of water, and $\mathrm{t}$ is time (seconds).

$\varepsilon$ is the molecular diffusivity of heat $\left(\mathrm{m}^{2} \mathrm{~s}^{-1}\right)$

$K_{z}$ is coefficient of the turbulent eddy diffusion of heat at depth $z\left(\mathrm{~m}^{2} \mathrm{~s}^{-1}\right)$.

$\Phi$ is direct radiative heat flux $\left(\mathrm{J} \mathrm{m}^{-2} \mathrm{~s}^{-1}\right)$.

$\rho_{\mathrm{w}}$ is density of water $\left(\mathrm{kg} \mathrm{m}^{-3}\right)$.

$C_{p w}$ is heat capacity of water $\left(\mathrm{J} \mathrm{kg}^{-10} \mathrm{C}^{-1}\right)$.

It is common to combine $\varepsilon$ and $K_{z}$ into one term called the effective diffusion coefficient $\left(E_{z}\right)$. In general, $E_{z}$ is greatest at the water surface and decreases with depth to a minimum at the thermocline.

The model heat transfer equations can be subdivided into surface (layer 1 ), water column (layers 2-5) and sediment (layer 6). All equations come from Losordo and Piedrahita (1991), unless otherwise noted.

Energy exchange at surface layer 
The net flow of energy from the atmosphere and the surface of the water column can be represented as:

Net energy flow: $\phi_{n e t}=\phi_{s n}+\phi_{a t}-\phi_{w s}-\phi_{e} \pm \phi_{c}$

where

$\phi_{s n}=$ penetrating short-wave solar irradiance

$\phi_{a t}=$ atmospheric radiation

$\phi_{w s}=$ water surface back radiation

$\phi_{e}=$ evaporative heat transfer

$\phi_{c}=$ sensible heat transfer

All terms are in $\mathrm{kJ} \mathrm{m}^{-2} \mathrm{~h}^{-1}$ units. What follows next is a description of each term in the net energy flow for surface layer equations.

Penetrating short-wave solar irradiance: $\phi_{s n}=\phi_{s}-\phi_{r}$ where

$\phi_{s n}=$ penetrating short-wave solar irradiance

$\phi_{s}=$ short-wave solar irradiance

$\phi_{r}=$ reflected short-wave solar irradiance 
The following is all for calculating $\phi_{r}$.

When short-wave $(400-1100 \mathrm{~nm})$ solar radiation hits the water surface, the energy is either reflected or penetrates the surface. The reflection of solar radiation depends on the angle of incidence of the incoming radiation, characteristics of the water surface (i.e. roughness), local atmospheric conditions, and the topography of the surrounding region (Wetzel 1983). Water Resources Engineers (WRE 1968), created the following equation to approximate reflectivity of incoming solar radiation:

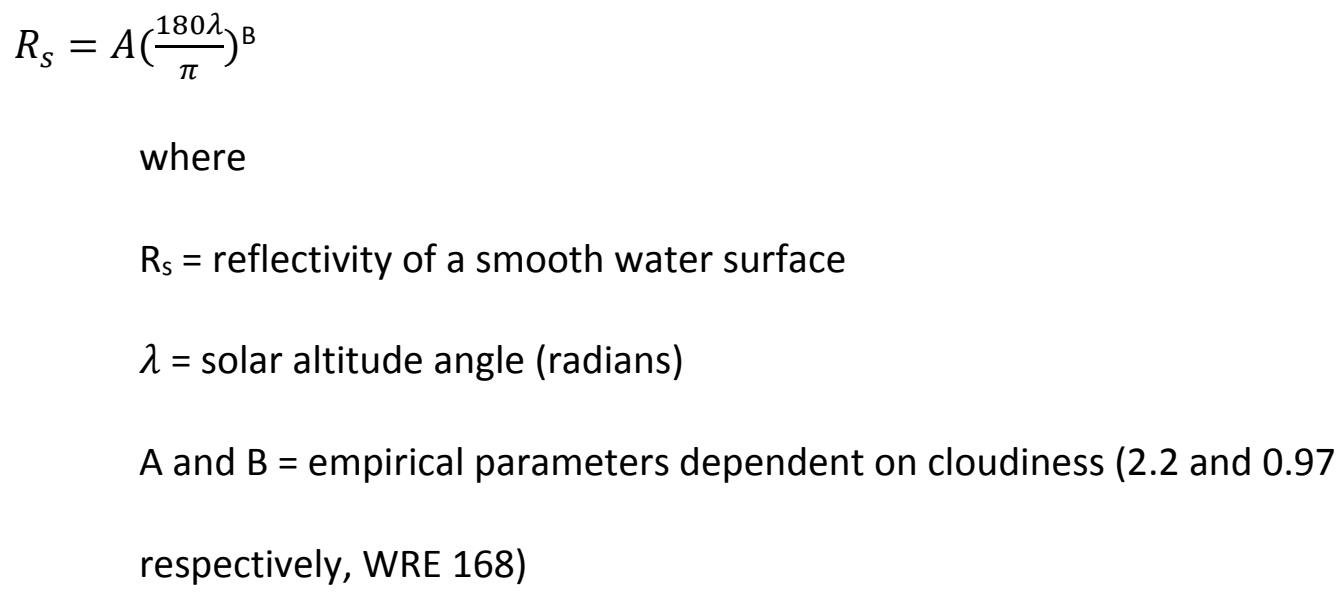




$$
\mathrm{W}_{\mathrm{z}}=\text { wind velocity at height } \mathrm{z}\left(\mathrm{m} \mathrm{s}^{-1}\right)
$$

Pulling this all together, the reflected short-wave solar irradiance is calculated by:

$\phi_{r}=\phi_{s} R$

Atmospheric radiation: $\phi_{a t}$

Atmospheric radiation is the emission of absorbed solar radiation by water vapor, carbon dioxide, and ozone (WRE 1968). Atmospheric radiation is calculated (Hurley 1977) by:

$\phi_{a t}=(1-r) e \sigma\left(T_{a K}\right)^{4}$

where

$r=$ reflectance of the water surface to long-wave radiation (0.03)

$\sigma=$ Stefan-Boltmann constant $\left(2.04 \times 10^{-7} \mathrm{~kJ} \mathrm{~m}^{-2} \mathrm{~h}^{-1}\right)$

$\mathrm{T}_{\mathrm{aK}}=$ absolute air temperature $2 \mathrm{~m}$ above the water surface $(\mathrm{K})$

$\mathrm{e}=$ average emittance of the atmosphere (dimensionless). Can be calculated as:

$$
\mathrm{e}=0.398 \times 10^{-5}\left(\mathrm{~T}_{\mathrm{aK}}\right)^{2.148}
$$

Water surface back radiation: $\phi_{w s}$ 
Water has an emissivity of approximately 0.97 , so it is not a perfect blackbody radiator. Thus, water losses energy, and this long-wave radiation loss can be estimated (Hurley 1977) by:

$\phi_{w s}=0.97 \sigma\left(T_{w K}\right)^{4}$

where

$\mathrm{T}_{\mathrm{wK}}=$ absolute water temperature $(\mathrm{K})$

Evaporative heat transfer: $\phi_{e}$

Evaporative heat loss is a diffusive process that follows Fick's fist law (Dingman 2002). Evaporative heat loss occurs when the state of water changes from a liquid to a gas (water vapor) and the associated loss of heat due to the latent heat of vaporization (Orlob 1981). Evaporative heat transfer can be calculated as:

$\phi_{e}=N W_{2}\left(e_{s}-e_{a}\right)$

where

$\mathrm{N}=$ empirical coefficient, aka Hefner formula $\left(5.0593 \mathrm{~kJ} \mathrm{~m}^{-2} \mathrm{~km}^{-1} \mathrm{~mm} \mathrm{Hg}^{-1}\right.$ )

$W_{2}=$ wind speed at $2 \mathrm{~m}$ above the water surface $\left(\mathrm{km} \mathrm{h}^{-1}\right)$

$\mathrm{e}_{\mathrm{s}}=$ saturated vapor pressure at $\mathrm{T}_{\mathrm{wc}}(\mathrm{mm} \mathrm{Hg})$. Can be calculated by: 


$$
e_{S}=25.374^{\left(17.62-\frac{5271}{T_{w C}}\right)}
$$

$\mathrm{e}_{\mathrm{a}}=$ water vapor pressure above water surface $(\mathrm{mm} \mathrm{Hg})$. Can be calculated by:

$$
e_{a}=R H x 25.374^{\left(17.62-\frac{5271}{T_{a C}}\right)}
$$

$\mathrm{T}_{\mathrm{aC}}=$ air temperature above the water surface $\left({ }^{\circ} \mathrm{C}\right)$

$\mathrm{T}_{\mathrm{wC}}=$ water surface temperature $\left({ }^{\circ} \mathrm{C}\right)$

Sensible heat transfer: $\phi_{c}$

The sensible addition or removal of heat from water surfaces is a function of wind speed, atmospheric pressure, and the temperature gradient of the over lying air (WRE 1968). Fritz et al. (1980) estimated sensible heat transfer as:

$$
\phi_{c}=1.5701 W_{2}\left(T_{w C}-T_{a C}\right)
$$

\section{Energy exchange within the water column}

The transmittance of short-wave solar irradiance and the process of turbulent diffusion are the mechanisms through which Losordo and Piedrahita (1991) calculate the transport of heat between volume elements within the water column. Convective mixing also occurs when density instabilities exist, and this needs to be account for when periods of net cooling of the water body occurs.

Heat transfer by turbulent diffusion: $E_{z}$ 
The effective diffusion coefficient $\left(E_{z}\right)$ is a function of: wind speed, water column depth, and the water density gradient. The value of a neutrally buoyant effective diffusion coefficient $\left(E_{\theta, z}\right)$ needs to be calculated first, then adjusted for the water column density gradient and according to local wind speed. Henderson-Sellers (1984) calculated $\mathrm{E}_{\theta, \mathrm{z}}$ by:

$$
E_{\theta, z}=\left[\frac{\left(W^{*}\right)^{2}}{u_{s} k^{*}}\right] \exp \left(-k^{*} z\right)
$$

where

$\mathrm{W}^{*}=$ frictional velocity from wind stress $\left(\mathrm{m} \mathrm{s}^{-1}\right)$. Can be calculated by:

$$
\begin{aligned}
& W^{*}=\left(\frac{\tau_{0}}{\rho_{w}}\right)^{1 / 2} \\
& \rho_{w}=\text { density of water }\left(\mathrm{kg} \mathrm{m}^{-3}\right) \\
& \tau_{0}=\text { shear stress at the surface, caused by wind }\left(\mathrm{N} \mathrm{m}^{-2}\right) \text { and is calculated }
\end{aligned}
$$

as:

$$
\begin{aligned}
& \qquad \tau_{0}=\rho_{a} C_{z}\left(W_{z}\right)^{2} \\
& \rho_{a}=\text { density of air }\left(\mathrm{kg} \mathrm{m}^{-3}\right) \\
& \mathrm{C}_{\mathrm{z}}=\text { coefficient of aerodynamic resistance } \\
& \mathrm{W}_{\mathrm{z}}=\text { wind velocity at } \mathrm{z} \text { height above the water surface }\left(\mathrm{m} \mathrm{s}^{-1}\right) \\
& \mathrm{k}^{*}=\text { empirical decay coefficient }\left(\mathrm{m}^{-1}\right) \text { and is calculated by: } \\
& \mathrm{k}^{*}=6 \mathrm{~W}_{\mathrm{z}}^{-1.84}
\end{aligned}
$$




$$
\begin{gathered}
\mathrm{u}_{\mathrm{s}}=\text { drift velocity }\left(\mathrm{m} \mathrm{s}^{-1}\right) \text { and is calculated by: } \\
\mathrm{u}_{\mathrm{s}}=30\left(\mathrm{~W}^{*}\right)
\end{gathered}
$$

The neutrally buoyant effective diffusion coefficient needs to be adjusted for the density gradient in the water column at each depth. Assuming $z=2$ :

$$
E_{z, 2}=\left(E_{\theta, 2}\right)\left(\sigma R i_{z, 2}\right)^{-1}
$$

where

$E_{z, 2}=$ effective diffusion coefficient at depth $z_{2}$, adjusted for density gradient $\left(\mathrm{m}^{2}\right.$

$\left.h^{-1}\right)$

$\sigma=$ empirical coefficient, which is 0.05

$\mathrm{Ri}_{z, 2}=$ Richardson number. Per Sundaram and Rehm (1973), this is calculated by:

$$
R i_{z, 2}=a_{v} g z^{2} /\left(W^{*}\right)^{2}\left(\frac{\Delta T}{\Delta z}\right)
$$

where

$a_{v}=1.5 \times 10^{-5}\left(T_{a v}-277\right)-2.0 \times 10^{-7}\left(T_{a v}-277\right)^{2}$

$\mathrm{T}_{\mathrm{av}}=$ the average water temperature of the two adjacent volume

elements

$\Delta T=$ temperature difference $(\mathrm{K})$ between the adjacent volume elements

$\left(T_{1}-T_{2}\right)$

$\Delta \mathrm{z}=$ distance between the centers of each adjacent volume elements $\mathrm{g}=$ gravitational acceleration $\left(\mathrm{m} \mathrm{s}^{-2}\right)$ 
To calculate the rate of heat transfer due to the effective diffusion of heat from one volume element $\left(V_{1}\right.$, with a center at depth $\left.z_{1}\right)$ to the next volume element $\left(V_{2}\right.$, with a center at depth $z_{3}$ ) (see Figure 2-2):

$$
\begin{aligned}
\phi_{d, 2}= & \rho_{w} c_{\rho w} E_{z, 2}\left(T_{1}-T_{2}\right) /\left(z_{1}-z_{3}\right) \\
& \text { where } \\
& \phi_{d, 2}=\text { heat transferred from } \mathrm{V}_{1} \text { to } \mathrm{V}_{2}\left(\mathrm{~kJ} \mathrm{~m}^{-2} \mathrm{~h}^{-1}\right) \\
& E_{z, 2}=\text { effective diffusion coefficient at depth } \mathrm{z}_{2}\left(\mathrm{~m}^{2} \mathrm{~h}^{-1}\right) \\
& \mathrm{T}_{1} \text { and } \mathrm{T}_{2}=\text { temperature at } \mathrm{z}_{1} \text { and } \mathrm{z}_{3} \text {, respectively }\left({ }^{\circ} \mathrm{C}\right) \\
& \mathrm{C}_{\mathrm{pw}}=\text { heat capacity of water }\left(\mathrm{J} \mathrm{kg}^{-10} \mathrm{C}^{-1}\right)
\end{aligned}
$$

For all of the equations that use wind speed, it is important to adjust the wind speed data to the reference height. At UKL, the anemometer height was $2.5 \mathrm{~m}$. The equation to adjust wind speed is:

$$
\begin{aligned}
& W_{\text {adj }}=W_{z}\left(z / z_{r}\right)^{p} \\
& \text { where } \\
& W_{\text {adj }}=\text { adjusted wind speed for height }\left(\mathrm{m} \mathrm{s}^{-1}\right) \\
& W_{z}=\text { wind speed at height } \mathrm{z}_{\mathrm{r}}\left(\mathrm{m} \mathrm{s}^{-1}\right) \\
& \mathrm{z}_{\mathrm{r}}=\text { reference height of anemometer }(2.5 \mathrm{~m} \text { for UKL meteorological station) } \\
& \mathrm{p}=\text { calibrated constant (dimensionless) }
\end{aligned}
$$




\section{Convective mixing:}

During periods of net cooling in a water body, convective mixing can surpass turbulent diffusion as the dominant source of vertical mixing. In this model the issue of density instability (which results in convective transport) was explained by setting $E_{z}$ to maximum value $\left(E_{\max }\right)$ when density instabilities occurred. For this model, $E_{\max }$ was set to $3,000 \mathrm{~m}^{2} \mathrm{~h}^{-1}$.

\section{Energy exchange at the sediment}

The two main physical processes to account for when modeling the energy exchange at the sediment is the conductive heat exchange between the sediment and bottom volume element, and the heat loss from the sediment volume element to the ground water table. Heat transfer between the bottom volume element and the sediment was calculated as:

$$
\begin{aligned}
& \phi_{\text {sed }}= k_{\text {sed }}\left(\frac{T_{3}-T_{S}}{\Delta_{z}}\right) \\
& \text { where } \\
& \phi_{\text {sed }}=\text { heat transfer between the bottom volume element and the sediment ( } \mathrm{kJ} \\
&\left.\mathrm{m}^{-2} \mathrm{~h}^{-1}\right) \\
& k_{\text {sed }}=\text { thermal conductivity coefficient for the sediment }\left(\approx 2.53 \mathrm{~kJ} \mathrm{~m}^{-2} \mathrm{~h}^{-1}{ }^{\circ} \mathrm{C}^{-1}\right) \\
& \mathrm{T}_{3}=\text { temperature of the bottom element }\left({ }^{\circ} \mathrm{C}\right) \\
& \mathrm{T}_{\mathrm{s}}=\text { temperature of the sediment }\left({ }^{\circ} \mathrm{C}\right) \\
& \Delta_{z}=\text { distance between the centers of the elements }
\end{aligned}
$$


The equation used to calculate the heat loss from the sediment to the ground water table was:

$$
\begin{aligned}
& \phi_{g w}=k_{e}\left(\frac{T_{s}-T_{g w}}{\Delta_{z}}\right) \\
& \text { where } \\
& \phi_{g w}=\text { heat loss from the sediment to the water table }\left(\mathrm{kJ} \mathrm{m}^{-2} \mathrm{~h}^{-1}\right) \\
& k_{e}=\text { thermal conductivity coefficient for the earth }\left(\approx 2.53 \mathrm{~kJ} \mathrm{~m}^{-2} \mathrm{~h}^{-1}{ }^{\circ} \mathrm{C}^{-1}\right) \\
& \mathrm{T}_{\mathrm{s}}=\text { temperature of the sediment }\left({ }^{\circ} \mathrm{C}\right) \\
& \mathrm{T}_{\mathrm{gw}}=\text { temperature of the ground water table }\left(\approx 20{ }^{\circ} \mathrm{C}\right) \\
& \Delta_{z}=\text { distance between the sediment and the ground water table }(\approx 5 \mathrm{~m})
\end{aligned}
$$

Heat balance calculations

The net flux of heat for a specific volume element is needed first in order to determine the resulting temperature of the volume element. Like the equations above, the heat balance equations are subdivided into surface, in-water column, and sediment heat balance equations.

Surface heat balance for volume element 1 is determined as:

$$
\begin{aligned}
& \frac{d H_{v 1}}{d t}=\left(\phi_{n e t}-\phi_{s n, 2}-\phi_{d, 2}\right) A_{v} \\
& \text { where } \\
& \quad \mathrm{H}_{\mathrm{v} 1}=\text { heat energy stored in volume element } 1(\mathrm{~kJ})
\end{aligned}
$$




$$
\begin{aligned}
& A_{v}=\text { volume element surface area }\left(\mathrm{m}^{2}\right) \\
& \phi_{n e t}=\text { net energy flow } \\
& \phi_{s n, 2}=\text { penetrating short-wave solar irradiance at depth } \mathrm{z}_{2} \\
& \phi_{d, 2}=\text { effective diffusion of hear at depth } \mathrm{z}_{2}
\end{aligned}
$$

$\underline{\text { Mid-depth volume element heat balance was calculated as: }}$

$\frac{d H_{v 2}}{d t}=\left(\phi_{s n, 2}-\phi_{s n, 4}+\phi_{d, 2}-\phi_{d, 4}\right) A_{v}$

$\mathrm{H}_{\mathrm{v} 2}$ is the heat stored in volume element $2(\mathrm{~kJ})$.

Bottom volume element heat balance was calculated as:

$\frac{d H_{v 3}}{d t}=\left(\phi_{s n, 4}-\phi_{s n, 6}+\phi_{d, 4}-\phi_{s e d}\right) A_{v}$

$\underline{\text { Sediment volume element heat balance was calculated as: }}$

$\frac{d H_{v s}}{d t}=\left(\phi_{s n, 6}+\phi_{s e d}-\phi_{g w}\right) A_{v}$

\section{Temperature calculations}

The temperature for all volume elements were calculated the same. For volume element $V_{i}$ at time $t$, the equation was: 


$$
\begin{aligned}
& T_{V i, t}= T_{V i, 0}+\left(H_{V i, t-1}+\left(\frac{d H_{V i}}{d t}\right) d t\right) /\left(\rho_{w} c_{p w} v_{i}\right) \\
& \text { where } \\
& \mathrm{T}_{\mathrm{Vi}, \mathrm{t}}=\text { the temperature of } \mathrm{V}_{\mathrm{i}} \text { at time } t\left({ }^{\circ} \mathrm{C}\right) \\
& \mathrm{T}_{\mathrm{Vi}, 0}=\text { the temperature of } \mathrm{V}_{\mathrm{i}} \text { at time } t=0\left({ }^{\circ} \mathrm{C}\right) \\
& \mathrm{HVi,t}-1=\text { heat stored in } \mathrm{Vi} \text { at time } \mathrm{t}-1(\mathrm{~kJ})
\end{aligned}
$$

\section{Model implementation}

At the beginning of each day's simulation, the initial temperatures recorded with the data loggers were used for each volume element. A time-step of one and a half minutes was selected for simulation. At each time step the net flux of heat for each volume element was calculated using the above heat balance equations, and the temperature was calculated. The 1D hydrodynamic model was built to simulate temperatures and effective diffusion rates volume elements $(\mathrm{cm}) 5,20,40,60,80$, and 100. Data logger placement was at (cm) $2.5,5,15,35,60$, and at the sediment (90). Light attenuation coefficients were manually calibrated. Model temperature outputs were linearly interpolated to the depths of the data loggers to compare model simulations to actuals in the model verification step, and resulting temperature with depth curves were checked for reasonability.

For model diagram and code see Appendix A. Model outputs are available at http://www.cyanolab.research.pdx.edu/. 
Model verification

The 1D hydrodynamic model used meteorological data to calculate turbulent mixing rates and temperature throughout the water column. The direct water temperature recorded by the data logger arrays was compared to the model's calculated temperature to check the models performance and for validation. The predicted water temperature from the model was plotted against the observed water temperature from the data loggers to see how far points deviated from a 1:1 line. The root mean square deviation (RMSD) was calculated for each modeled day. To interpret the relative magnitude of the deviation, the coefficient of variation (CV) was also calculated for each day. Absolute difference between the model's predicted temperature and the observed temperature was also investigated for each depth and on each modeled day.

\section{Results}

Model day selection

The days selected for modeling were September $16^{\text {th }}, 18^{\text {th }}, 22^{\text {nd }}$, and $23^{\text {rd }}$ (categorized as hot calm $(\mathrm{HC})$, hot windy $(\mathrm{HW})$, cool windy $(\mathrm{CW})$, and cool calm (CC), respectively; Table 1, Figure $2-3$ ). September $22^{\text {nd }}$ and $23^{\text {rd }}$ were the two coolest days in the dataset, and were $5.3{ }^{\circ} \mathrm{C}$ and $6.4^{\circ} \mathrm{C}$ cooler than the average day, respectively. September $22^{\text {nd }}$ was one of the windiest days at $1.6 \mathrm{~m} \mathrm{~s}^{-1}$ faster than the average day. 
The wind on September $23^{\text {rd }}$ was $1.2 \mathrm{~m} \mathrm{~s}^{-1}$ slower than the average day. September $16^{\text {th }}$ and $18^{\text {th }}$ were $2.4^{\circ} \mathrm{C}$ and 4.3 hotter ${ }^{\circ} \mathrm{C}$ than the average day, respectively. September $16^{\text {th }}$ was one of the calmest days on record, and wind speed was $1.1 \mathrm{~m} \mathrm{~s}^{-1}$ calmer than the average day. Wind on September $18^{\text {th }}$ was $0.5 \mathrm{~m} \mathrm{~s}^{-1}$ faster than the average day, and the maximum gust speed was $1 \mathrm{~m} \mathrm{~s}^{-1}$ faster than the average maximum (Table 2-1). Initial temperatures throughout the water were mostly isothermal (within $0.1^{\circ} \mathrm{C}$ ) for the hot days. Cool days initial temperatures were coldest at the water surface $\left(\mathrm{CC}\right.$ was $0.8^{\circ} \mathrm{C}$ cooler at the surface and $\mathrm{CW}$ was $.5^{\circ} \mathrm{C}$ cooler at the surface). The average temperature difference between the top and bottom of the water column was larger on calm days $\left(0.28^{\circ} \mathrm{C}\right.$ for $\mathrm{CC}$, and $0.27^{\circ} \mathrm{C}$ for $\left.\mathrm{HC}\right)$, while the difference was less and more varied more on windy days, depending on ambient air temperature $\left(0.09^{\circ} \mathrm{C}\right.$ for $\mathrm{CW}$, and $0.16{ }^{\circ} \mathrm{C}$ for $\mathrm{HW}$;). Complete temperature and wind speed data set can be found in Figure 2-4.

\section{Model predicted temperature validation}

None of the observed versus predicted plots followed a 1:1 line (Figure 2-5 to Figure 2-8). The RMSD was relatively even throughout the water column on each modeled day (Table 2-3). The hot windy (HW) day had the overall lowest RMSD and the cool windy (CW) day had the highest overall RMSD. The smallest RMSD for a single depth was modeled at $35 \mathrm{~cm}$ depth for the HW modeled day (RMSD $=0.54)$. The largest single RMSD was at $5 \mathrm{~cm}$ on the $\mathrm{CW}$ modeled day (RMSD = 1.29). The average spread relative to the mean was $7.38 \%$ for the cool calm (CC) day, $9.61 \%$ for the cool windy 
(CW) day, $6.34 \%$ for the HC day, and 3.41\% for the HW day (Table 2-4). The averaged absolute difference between the predicted and observed temperature was lowest on $\mathrm{HW}\left(0.5^{\circ} \mathrm{C}\right)$, and was highest on $\mathrm{CW}\left(1.0^{\circ} \mathrm{C}\right.$; Table $\left.2-5\right)$. The overall difference between the predicted and observed temperatures for all four modeled days was $0.8^{\circ} \mathrm{C}$.

Similarly, the average temperature range between the modeled temperature and the linearly interpolated temperatures were small (average of $0.09{ }^{\circ} \mathrm{C}$; Figure 2-9).

Model effective diffusion rates

Effective diffusion at the surface was nearly twice as high for windy days than calmer days (Table 2-6). The day with the highest diffusion rates was cool windy, followed by hot windy. Cool days saw relatively lower effective diffusion rates at $60 \mathrm{~cm}$. All days had nearly identical diffusion rates at the sediment. In addition, the cool windy day saw a second diffusion rate maximum at 70cm (Figure 2-10).

\section{Discussion}

One-dimensional models can adequately predict the water column dynamics of small, well mixed water bodies (WRE 1968). While UKL is large, this model focused on small-scale local water quality conditions and was well mixed on all simulated days. The accuracy of the 1D model's predicted temperature gradients varied between contrasting weather scenarios. The variability of the model's predicted temperature gradient was similar for calm and windy days (CV $6.86 \%$ vs. $6.51 \%$, respectively), but there was a 
larger difference between cool and hot days (CV\% $8.49 \%$ vs. $4.87 \%$, respectively). This indicates that while the model performs similarly between contrasting windy conditions, it does not perform similarly in contrasting temperature conditions. While the model was not as accurate in predicting the temperature variations on cool days than on hot days, the difference between the actuals and predicted temperatures was often less than $1^{\circ} \mathrm{C}$.

Losordo and Piedrahita (1991) considered the simulated temperatures generally accurate when the results were within $0.5^{\circ} \mathrm{C}$ of actual measured temperatures, while some of their results had temperature differences of $1.5^{\circ} \mathrm{C}$. Losordo and Piedrahita's (1991) study objective was to estimate turbulent vertical heat transfer in a small, shallow aquaculture pond. Similarly, Bonnet et al. (2000) reported a low 1D model mean square error of $0.57^{\circ} \mathrm{C}$ during lake warm-up period (June to early July), but large discrepancies during times of steep temperature gradients (July to early September). The average difference between the observed and the 1D model predicted temperatures ranged from $0.5^{\circ} \mathrm{C}$ to $1.0^{\circ} \mathrm{C}$. The hot windy and cool calm had the two lowest absolute differences between the predicted temperatures and observed. As mentioned above, the model did a slightly better job predicting the temperature gradient on hot days than on cool days, however the average difference in absolute degrees was negligible $\left(0.85^{\circ} \mathrm{C}\right.$ for cool days and $0.68^{\circ} \mathrm{C}$ for hot days). There was no indication that the model performed considerably better in any one weather scenario. Given no systematic bias for one weather scenario over another, and a similar 
difference in predicted versus actuals as Bonnet et al. (2000) and Losordo and Piedrahita (1991), the results of this 1D model is considered accurate enough for the model's objective (which is to calculate effective diffusion coefficients for different weather scenarios).

The pattern of effective diffusion coefficient with depth followed an expected pattern. The windy modeled days had higher effective diffusion coefficients at the surface depths than calm days. Diffusion rates were similar for all days at the bottom of the water column. The lowest effective diffusion coefficients occurred on the calm days, which signify greater thermal stability than windy days. The diffusion rates on the cool windy day were higher than the rates on the hot windy day, which indicates that warm days in UKL can sufficiently increase the thermal stability on the water column to resist wind induced mixing. There are limitations and assumptions built into this type of 1D turbulence models.

One-dimensional hydrodynamic models assume that the horizontal variation in water temperature at any given depth was negligible compared to the vertical variation. The two data logger arrays were located within $1 \mathrm{~m}$ of each other, and showed similar temperatures with depth, however, this assumption would not hold for an entire lake. The scale of a 1D hydrodynamic model cannot be applied to an entire lake, and are often used for developing theoretical competition theory (Huisman and Sommeijer 2002; Huisman et al. 2004; Joehnk et al. 2008), or for predicting stratification events in small shallow agricultural ponds (Losordo and Piedrahita 1991). In this application, the 
1D model was used to demonstrate how weather patterns could influence small-scale local mixing patterns by estimating the effective diffusion rates from UKL that could be used in a model that contains vertical buoyancy rates.

\section{Conclusion}

Temperature and effective diffusion coefficients can be simulated to within one ${ }^{\circ} \mathrm{C}$ using a mechanistic heat diffusion model. This 1D hydrodynamic model can be used for simulating water temperature and turbulent mixing on a single vertical plain. While the model was slightly more accurate in predicting the water column temperature structure on hot days vs. cool days, the difference in absolute degrees was relatively small. Model inputs include weather conditions, such as hourly air temperature, wind speed and direction, PAR, and relative humidity. Outputs are hourly temperature and turbulent mixing with depth over time. 


\section{Tables and Figures Chapter 2}

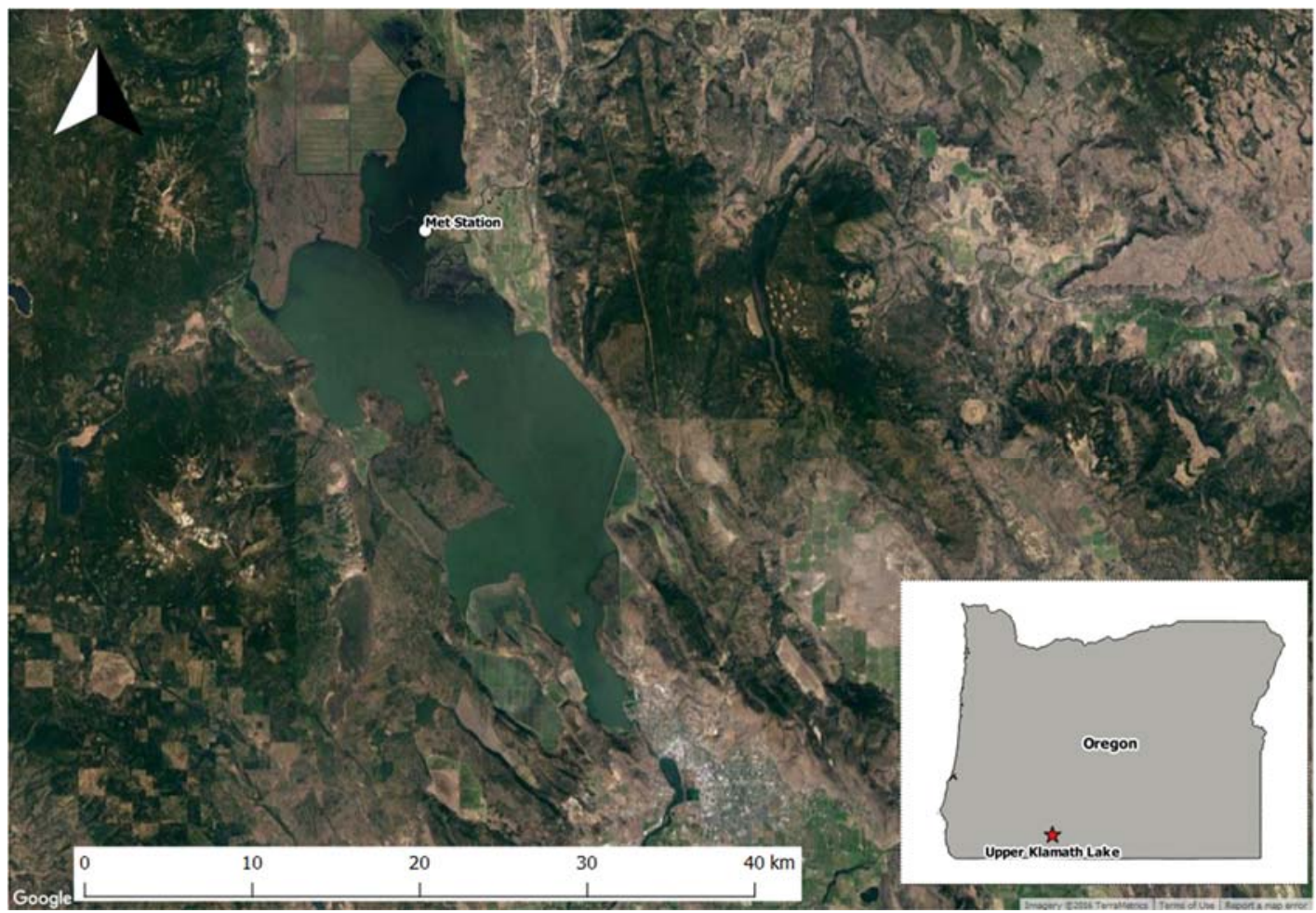

Figure 2-1 Map of the location of the meteorological station and temperature loggers in Upper Klamath Lake.

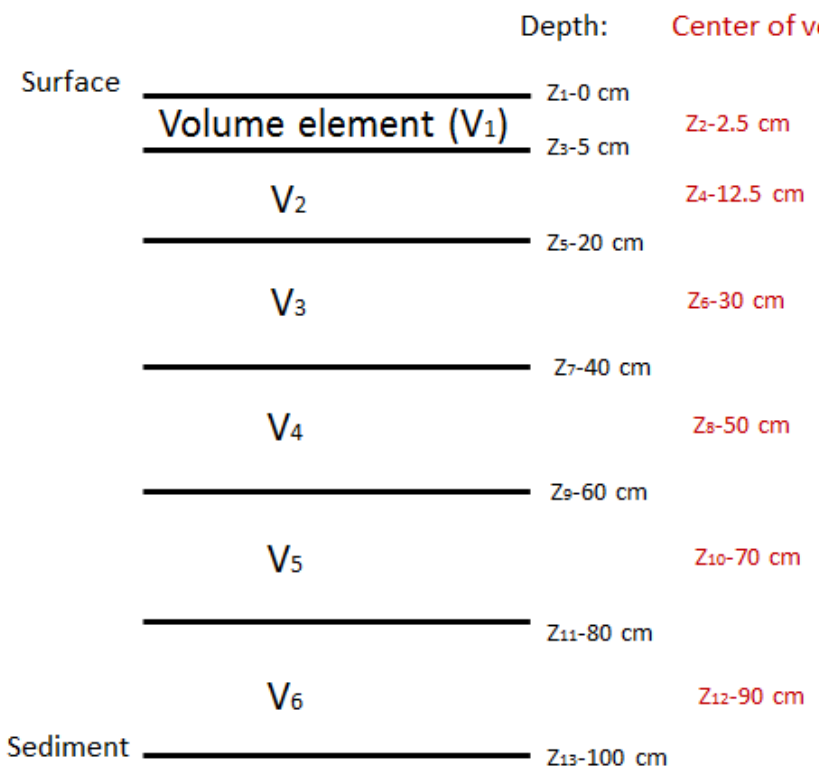

Figure 2-2 A schematic diagram showing how the water column was divided into volume elements for modeling. Depth $(z)$ is shown at the boundaries and in the center of each volume element. 


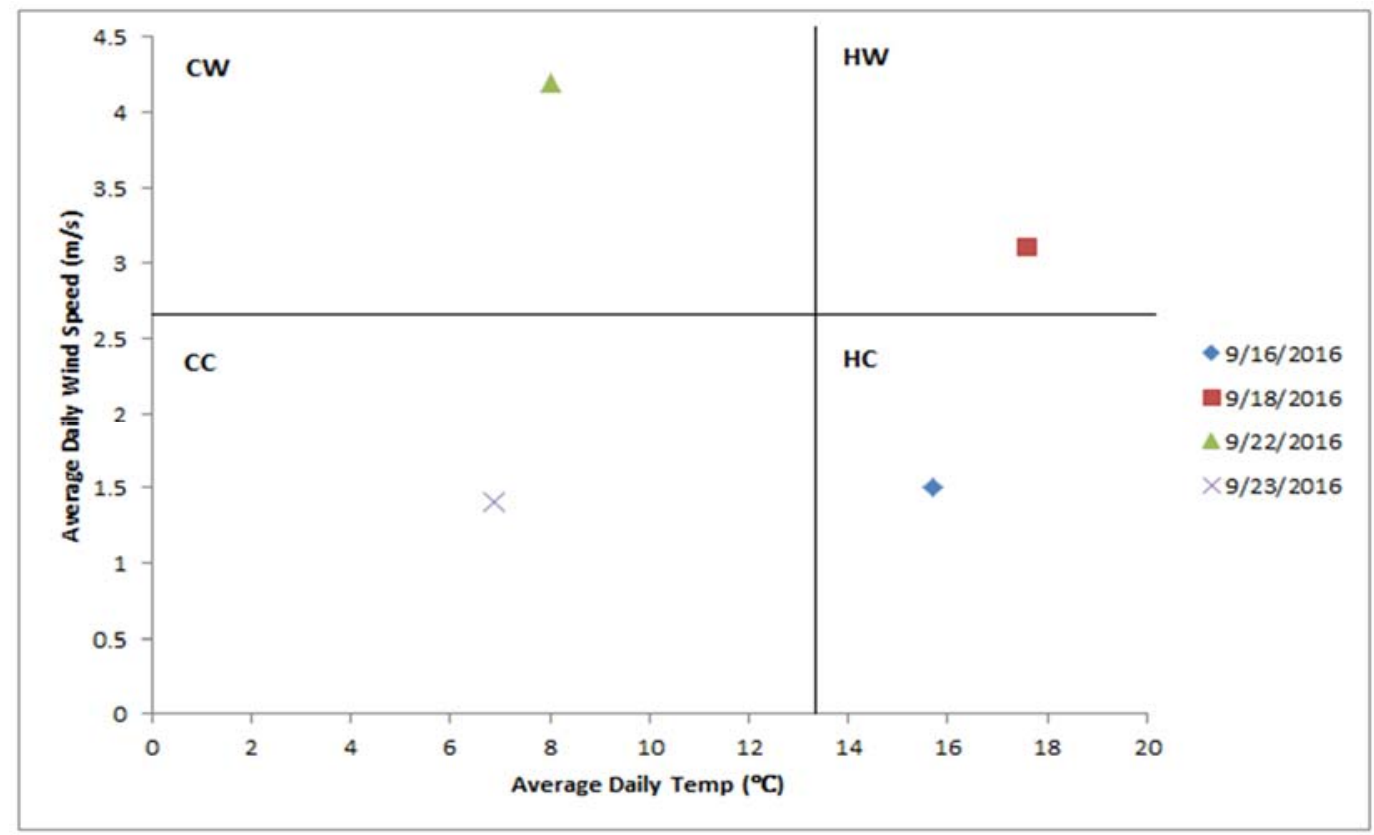

Figure 2-3 The selected modeled days are plotted against daily average wind speed (m s${ }^{-1}$ ) and daily average air temperature $\left({ }^{\circ} \mathrm{C}\right)$. The average temperature and average wind speed for the entire data set are plotted as vertical and horizontal lines, respectively. Categories are: $\mathrm{CW}=$ cool windy, $\mathrm{HW}=\mathrm{hot}$ windy, $\mathrm{CC}=$ cool calm, $\mathrm{HC}=$ hot calm.

Table 2-1 Daily average and max air temperatures and wind speed at UKL. Asterisked dates represent days selected for modeling.

$\begin{array}{lllll}\text { Date } & \text { Average } & \text { Max Temp } & \text { Average } & \text { Max Gust } \\ & \text { Temp }\left({ }^{\circ} \mathrm{C}\right) & \left({ }^{\circ} \mathrm{C}\right) & \begin{array}{l}\text { Wind Speed } \\ \left(\mathrm{m} \mathrm{s}^{-1}\right)\end{array} & \text { Speed }\left(\mathrm{m} \mathrm{s}^{-1}\right) \\ & & \end{array}$

\begin{tabular}{|l|cccc|}
\hline $9 / 1 / 16$ & 14.2 & 21.0 & 2.2 & 10.8 \\
$9 / 2 / 16$ & 13.7 & 20.2 & 2.5 & 10.3 \\
$9 / 3 / 16$ & 12.6 & 21.2 & 3.7 & 11.3 \\
$9 / 4 / 16$ & 11.2 & 18.1 & 2.6 & 10.1 \\
$9 / 5 / 16$ & 12.0 & 21.8 & 2.5 & 8.6 \\
$9 / 6 / 16$ & 11.4 & 19.5 & 2.3 & 11.1 \\
$9 / 7 / 16$ & 14.2 & 23.3 & 1.8 & 6.3 \\
$9 / 8 / 16$ & 16.4 & 26.6 & 1.9 & 7.8 \\
$9 / 9 / 16$ & 16.6 & 26.3 & 3.2 & 7.8 \\
$9 / 10 / 16$ & 18.1 & 28.3 & 2.3 & 7.3 \\
$9 / 11 / 16$ & 15.7 & 23.9 & 2.5 & 11.3 \\
$9 / 12 / 16$ & 11.5 & 17.6 & 5.1 & 12.8 \\
$9 / 13 / 16$ & 11.7 & 19.3 & 3.4 & 10.1
\end{tabular}




\begin{tabular}{|l|cccc|}
\hline 9/14/16 & 12.6 & 21.2 & 1.7 & 8.3 \\
$9 / 15 / 16$ & 14.1 & 23.9 & 1.5 & 4.8 \\
$9 / 16 / 16^{*}$ & 15.7 & 26.0 & 1.5 & 7.8 \\
$9 / 17 / 16$ & 15.3 & 24.3 & 1.7 & 9.6 \\
$9 / 18 / 16^{*}$ & 17.6 & 22.8 & 3.1 & 10.6 \\
$9 / 19 / 16$ & 14.0 & 24.8 & 1.6 & 9.8 \\
9/20/16 & 12.8 & 19.2 & 3.8 & 11.1 \\
9/21/16 & 10.1 & 17.0 & 3.4 & 10.8 \\
9/22/16* & 8.0 & 11.4 & 4.2 & 14.9 \\
9/23/16* & 6.9 & 12.3 & 1.4 & 6.8 \\
Average Day & 13.3 & $\mathbf{2 1 . 3}$ & $\mathbf{2 . 6}$ & $\mathbf{9 . 6}$ \\
\hline
\end{tabular}

Table 2-2 The average measured temperature with depth for the four modeled days.

\begin{tabular}{rcccc}
\hline Depth (cm) & Avg ${ }^{\circ} \mathbf{C}: \mathbf{C C}$ & Avg ${ }^{\circ} \mathbf{C}: \mathbf{C W}$ & Avg $^{\circ} \mathbf{C}: \mathbf{H C}$ & Avg ${ }^{\circ} \mathbf{C}: \mathbf{H W}$ \\
\hline $\mathbf{5}$ & 11.14 & 13.04 & 17.58 & 17.76 \\
$\mathbf{1 5}$ & 11.17 & 13.06 & 17.64 & 17.77 \\
$\mathbf{3 5}$ & 11.10 & 13.03 & 17.54 & 17.69 \\
$\mathbf{6 0}$ & 10.84 & 12.87 & 17.23 & 17.53 \\
$\mathbf{9 0}$ & 10.86 & 12.95 & 17.31 & 17.60 \\
& 0.28 & 0.09 & 0.27 & 0.16 \\
$\begin{array}{l}\text { Difference } \\
\text { between top } \\
\text { and bottom }\end{array}$ & & & & \\
\hline
\end{tabular}

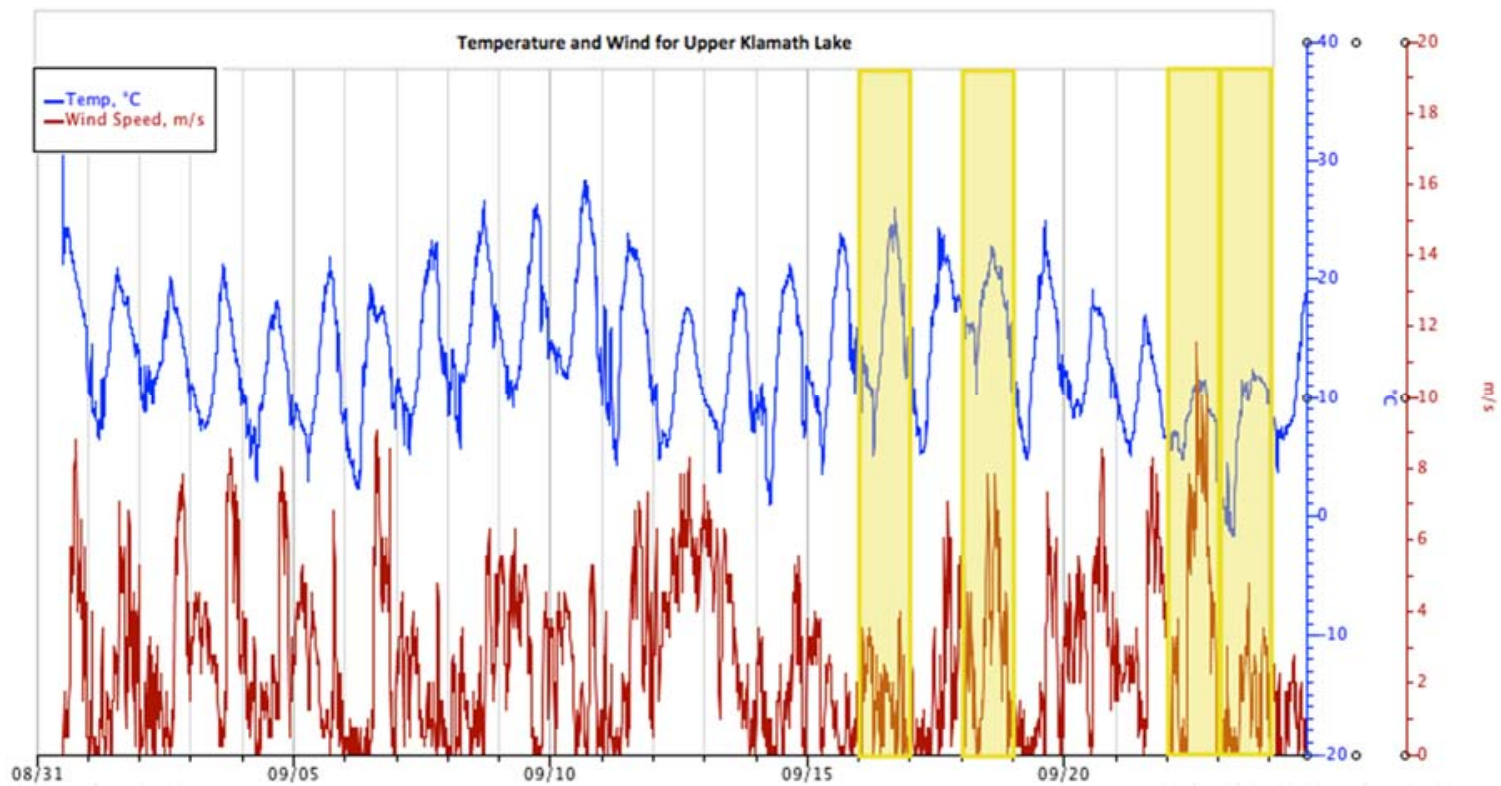

Figure 2-4 Temperature and wind speed data for Upper Klamath Lake. Days highlighted in yellow were selected for modeling the water column's turbulence structure. 
Depth $5 \mathrm{~cm}$

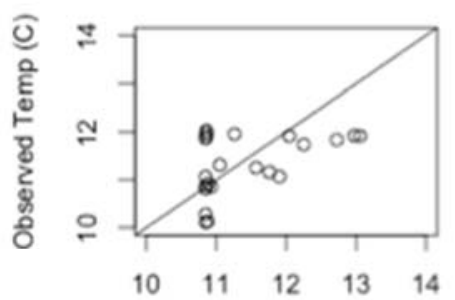

Predicted Temp (C)

Depth $35 \mathrm{~cm}$

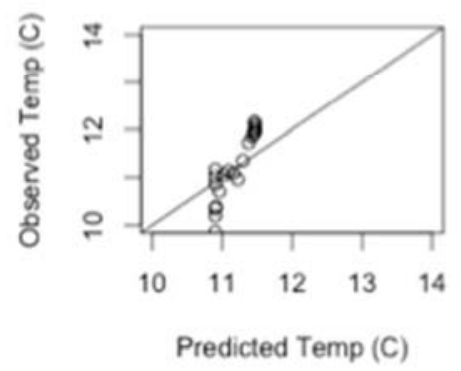

Depth $15 \mathrm{~cm}$

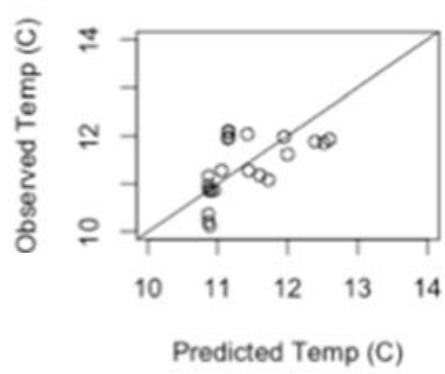

Depth $60 \mathrm{~cm}$

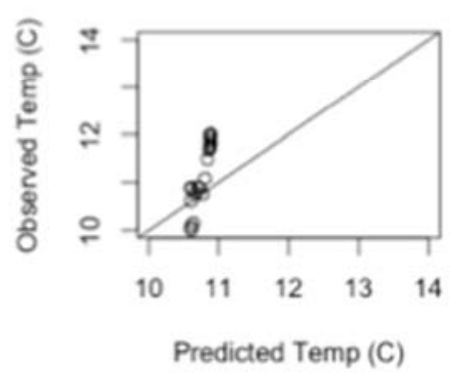

Depth $90 \mathrm{~cm}$

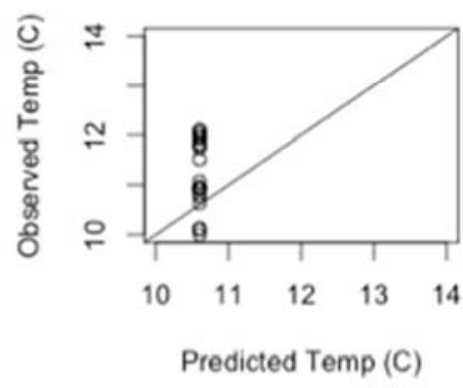

Figure 2-5 1:1 line graphs of observed temperatures versus model predicted temperatures at all depths for the modeled cool calm day. 
Depth $5 \mathrm{~cm}$

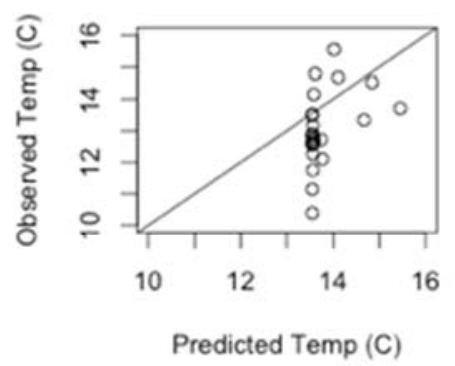

Depth $35 \mathrm{~cm}$

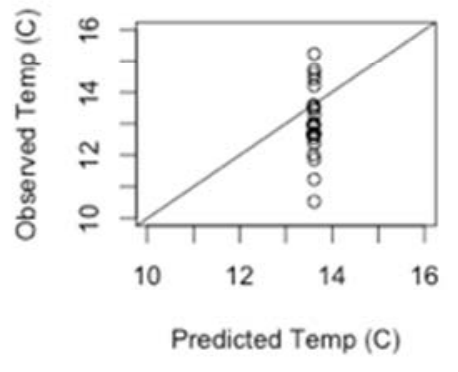

Depth $15 \mathrm{~cm}$

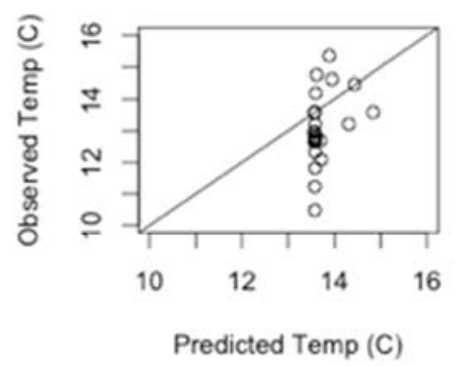

Depth $60 \mathrm{~cm}$

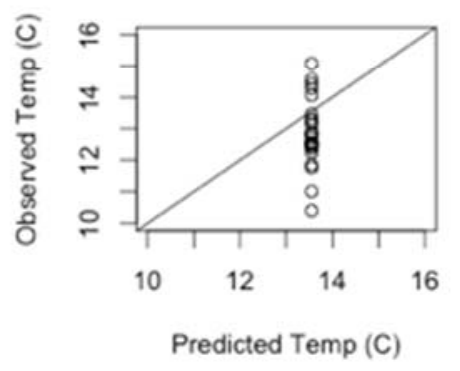

Depth $90 \mathrm{~cm}$

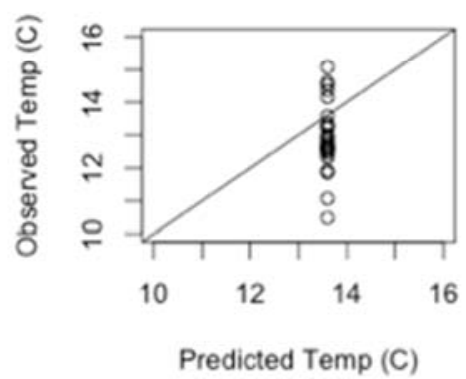

Figure 2-6 1:1 line graphs of observed temperatures versus model predicted temperatures at all depths for the modeled cool windy day. 

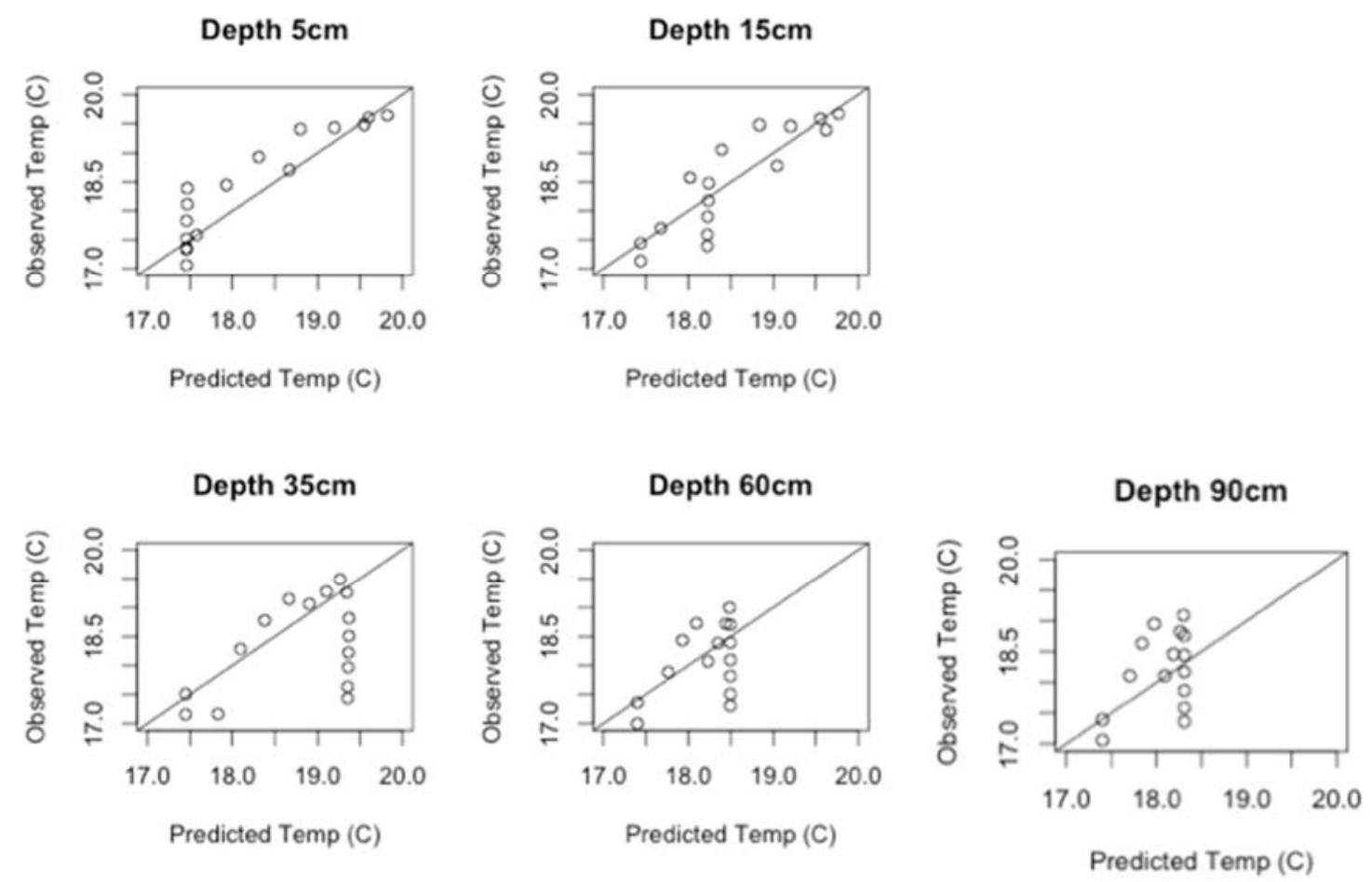

Figure 2-7 1:1 line graphs of observed temperatures versus model predicted temperatures at all depths for the modeled hot calm day.

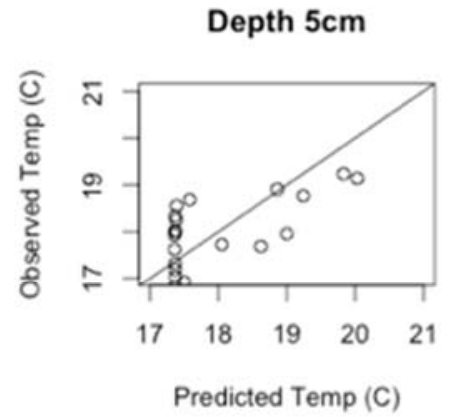

Depth $35 \mathrm{~cm}$

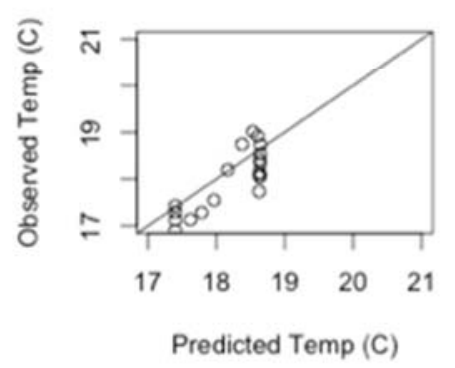

Depth $15 \mathrm{~cm}$

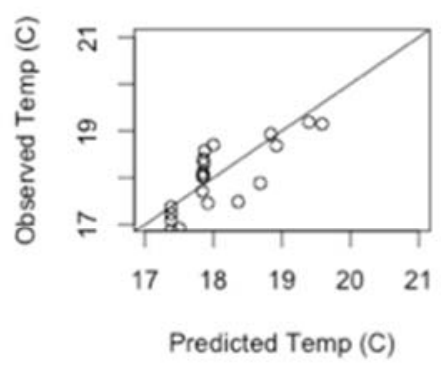

Depth $60 \mathrm{~cm}$

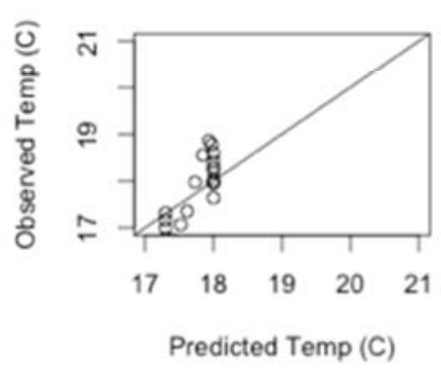

Depth $90 \mathrm{~cm}$

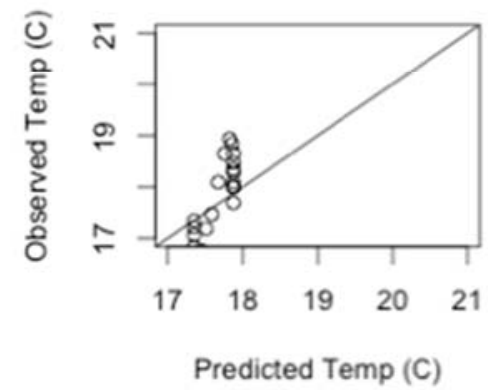


Figure 2-8 1:1 line graphs of observed temperatures versus model predicted temperatures at all depths for the modeled hot windy day.

Table 2-3 Model root mean square deviations (RMSD) by depth and modeled day.

\begin{tabular}{rcccc}
\hline Depth $(\mathbf{c m})$ & CC & CW & HC & HW \\
\hline $\mathbf{5}$ & 0.83 & 1.29 & 1.04 & 0.73 \\
$\mathbf{1 5}$ & 0.70 & 1.22 & 1.00 & 0.54 \\
$\mathbf{3 5}$ & 0.65 & 1.21 & 1.20 & 0.53 \\
$\mathbf{6 0}$ & 0.85 & 1.27 & 1.17 & 0.58 \\
$\mathbf{9 0}$ & 1.03 & 1.25 & 1.12 & 0.63 \\
\hline
\end{tabular}

Table 2-4 Coefficient of variation (CV\%) by depth and modeled day.

\begin{tabular}{rrccc}
\hline Depth (cm) & CC & CW & HC & HW \\
\hline $\mathbf{5}$ & $7.45 \%$ & $9.89 \%$ & $5.92 \%$ & $4.11 \%$ \\
$\mathbf{1 5}$ & $6.26 \%$ & $9.34 \%$ & $5.67 \%$ & $3.04 \%$ \\
$\mathbf{3 5}$ & $5.85 \%$ & $9.29 \%$ & $6.84 \%$ & $3.00 \%$ \\
$\mathbf{6 1}$ & $7.84 \%$ & $9.87 \%$ & $6.79 \%$ & $3.31 \%$ \\
$\mathbf{9 0}$ & $9.48 \%$ & $9.65 \%$ & $6.47 \%$ & $3.58 \%$ \\
Average & $7.38 \%$ & $9.61 \%$ & $6.34 \%$ & $3.41 \%$ \\
\hline
\end{tabular}

Table 2-5 The absolute difference between the model predicted temperature and observed temperature was averaged at each depth for each modeled day.

Average Difference Between Predicted and Observed

\begin{tabular}{lrrlll}
\hline Depth (cm) & & CC & CW & HC & HW \\
& $\mathbf{5}$ & 0.7 & 1.1 & 0.7 & 0.7 \\
& $\mathbf{1 5}$ & 0.6 & 1.0 & 0.7 & 0.5 \\
& $\mathbf{3 5}$ & 0.5 & 1.0 & 1.0 & 0.5 \\
& $\mathbf{6 0}$ & 0.7 & 1.1 & 0.9 & 0.5 \\
& $\mathbf{9 0}$ & 0.9 & 1.0 & 0.9 & 0.5 \\
& Average & 0.7 & 1.0 & 0.8 & 0.5 \\
\hline
\end{tabular}

Table 2-6 The daily average effective diffusion coefficient for each modeled day with depth.

\begin{tabular}{rrrrrr}
\hline & \multicolumn{5}{c}{ Daily Average Effective Diffusion Coefficient $\left(\mathbf{m}^{\mathbf{2}} \mathbf{h}^{-\mathbf{1}}\right)$} \\
\hline Depth (cm) & & CC & CW & HC & HW \\
& $\mathbf{5}$ & 0.57 & 0.77 & 0.47 & 0.67 \\
& $\mathbf{1 5}$ & 0.45 & 0.69 & 0.44 & 0.58 \\
& $\mathbf{2 5}$ & 0.21 & 0.51 & 0.39 & 0.39 \\
\hline
\end{tabular}




\begin{tabular}{lllll}
\hline $\mathbf{3 5}$ & 0.09 & 0.42 & 0.29 & 0.29 \\
$\mathbf{4 5}$ & 0.09 & 0.41 & 0.14 & 0.28 \\
$\mathbf{5 5}$ & 0.08 & 0.51 & 0.07 & 0.27 \\
$\mathbf{6 5}$ & 0.07 & 0.70 & 0.06 & 0.26 \\
$\mathbf{7 5}$ & 0.18 & 0.71 & 0.19 & 0.31 \\
$\mathbf{8 5}$ & 0.40 & 0.52 & 0.44 & 0.41 \\
$\mathbf{9 0}$ & 0.51 & 0.43 & 0.57 & 0.46 \\
\hline
\end{tabular}

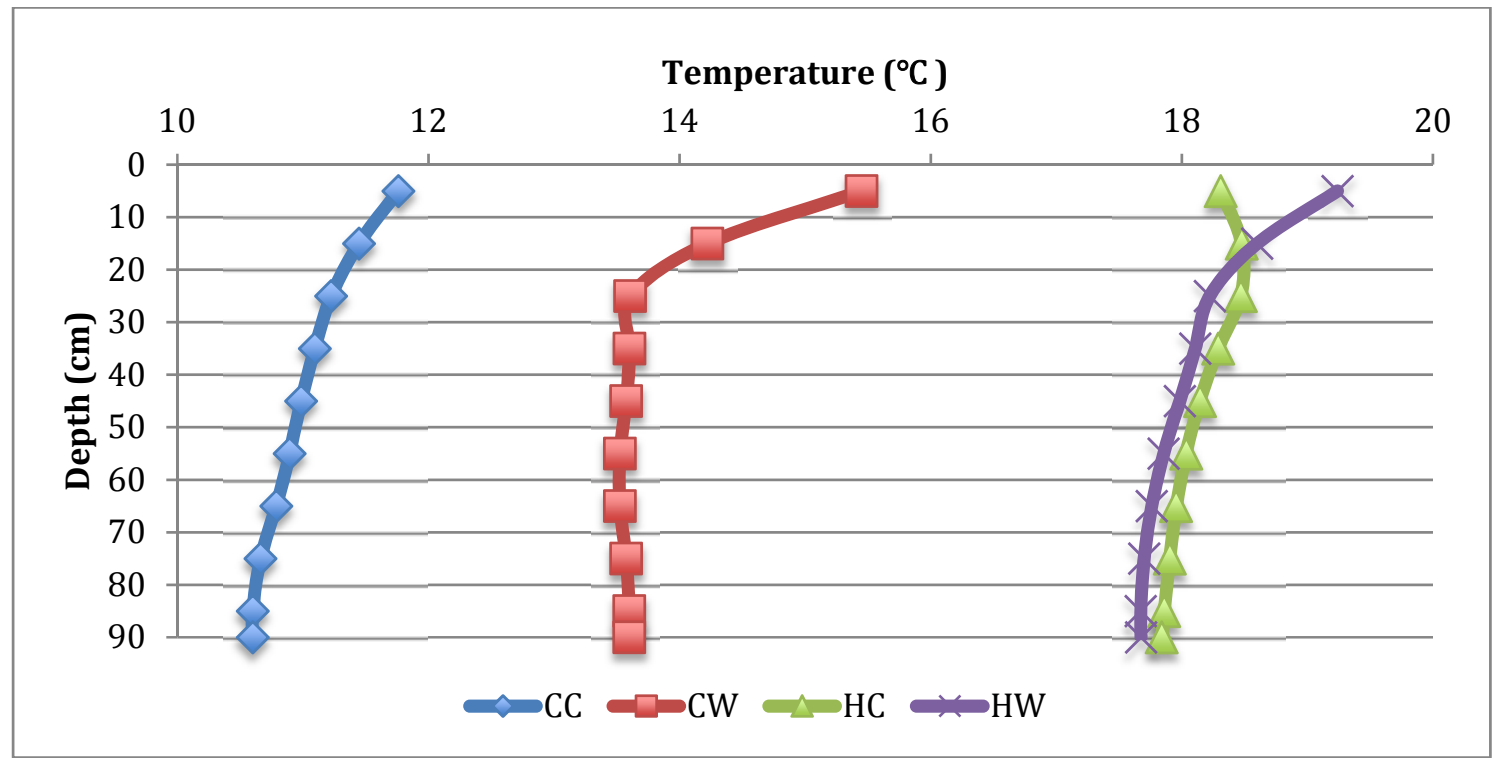

Figure 2-9 Temperature with depth profile for all modeled days. The plotted values include modeled and interpolated temperatures at $12 \mathrm{pm}$ on each modeled day. 


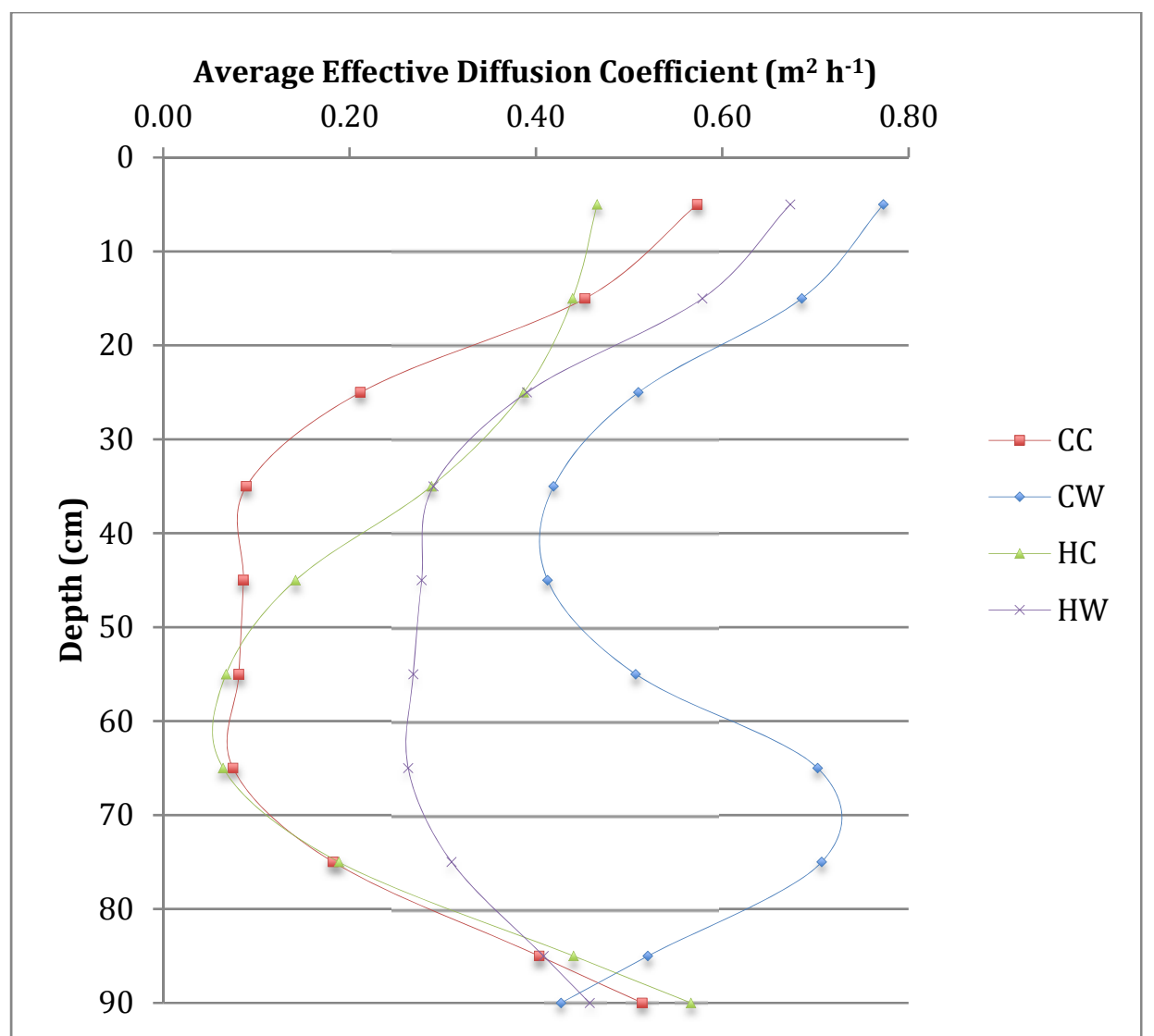

Figure 2-10 The average effective diffusion coefficient with depth for all modeled days. 


\section{Chapter 3. Modeling the competition of cyanobacteria and the sensitivity of competition to buoyancy}

\section{Introduction}

The impact of lake physical mixing and buoyancy regulation on species interactions and competition is important in the context of human drivers and climate change. Several theories have been developed to predict how changes in turbulent mixing shifts competition for light between sinking and floating species of phytoplankton. Competition theory developed by Huisman et al. (2004) predicts buoyant algae dominate competition under low turbulent diffusivity, while sinking species succeed under high turbulent diffusivity. Game theory developed by Klausmeier and Litchman (2001) incorporates nutrient limitations into predictions of competition. Under low nutrient conditions and low light attenuation, the evolutionarily stable strategy is for a benthic layer of algae to form; and at high nutrient levels, a surface scum is more evolutionarily stable (Klausmeier and Litchman 2001). In both ecological theories, the conditions of nutrient supply, light availability, and physical turbulence levels are used to explain the physiological adaptions of phytoplankton and link them to competition between phytoplankton functional groups (i.e. sinking species and buoyant species). However, extending these theories to explain competition between species with similar physiological adaptions proves difficult. 
Early competition models used differential equations to describe key physical, chemical, and biological processes in aquatic ecosystems (Chen 1970). These models were simple descriptions of aquatic systems that helped elucidate the interactions between nutrients, organic matter, and functional groupings such as phytoplankton and zooplankton (Steele 1974; Wroblewski et al. 1988; Anderson 2005). Competition models can satisfactorily predict outcomes at higher aggregation levels such as phytoplankton community level (McCauley and Murdoch 1987), however this level of aggregation can be an unreliable indicator of structural ecosystem shifts (Schindler 1990). Increasing complexity has been integrated into simple community-level models in order to explore complicated ecological interactions.

Competition models are increasingly representing multiple biogeochemical cycles at a time, with multiple biotic communities and their interactions (Van Nes and Scheffer 2005). Some researchers have argued that complex models can have misleading results due to the poorly understood ecology of the systems in question, a lack of data, and the sensitivity of the results to model parameterizations (Anderson 2005; Shimoda and Arhonditsis 2016). Anderson (2005) and Shimoda and Arhonditsis (2016) recommend gradual incorporation of complexity, skepticism of model outputs, an objective assessment of the parameters, use of empirical alternatives to dynamic representation of parameters, and an open dialogue on how to mathematically depict complex interconnections. Thus, it is important to compare mathematical equations and parameters used between models. 
Competition models have been used to develop ecological theory and to explore abiotic and biotic interactions. Theoretical competition modeling has investigated interactions such as: the competition for light and nutrients (Klausmeier and Litchman 2001), turbulent mixing and competition for light between buoyant and sinking phytoplankton (Huisman et al. 1999; Huisman et al. 2004), influence of vertical mixing on competition (Bengfort and Malchow 2016), influence of climate change on phytoplankton assemblage (Joehnk et al. 2008), and competition between invasive and native phytoplankton under various light and temperature conditions (Mehnert et al. 2010). The goals of models used in the context of water quality management are to predict harmful algal blooms and to deduce the physiological traits of cyanobacteria that render competitive capacity and induce shifts in species composition. Important physiological traits include higher temperature optima, buoyancy regulation, low lightenergy requirements, resistance to zooplankton grazing, nitrogen fixation, high affinity for and ability to store phosphorus, and superior kinetics for different nitrogen forms (Lampert 1981; Paerl and Huisman 2009; Carey et al 2012; O’Neil et al. 2012; Chung et al. 2014). It is common for studies to focus on one physiological trait at a time, so in studies that investigate buoyancy regulation, nutrients are assumed to be not limiting to simplify model parameters (Huisman et al. 1999; Huisman and Sommijer 2002; Huisman et al. 2004; Joehnk et al. 2008). The competition model used in this study was developed to explore the role of buoyancy regulation in the competition between two buoyant cyanobacteria (Aphanizomenon flos-aquae (APFA) and Microcystis aeruginosa 
(MSAE)) in Upper Klamath Lake (UKL). In order to make the assumption that nutrient limitation is not a factor in the competition, the role of nutrients in UKL must be explored over an annual cycle.

There is a seasonal pattern in total nutrients in UKL, but exactly how nutrients impact the interactions between species is unclear. Eldridge et al. (2013) reviewed toxic microcystins, nutrient dynamics and environmental variables in 2009. They found that from May to October, total nitrogen (TN) and total phosphorous (TP) generally increased, while the TN: TP ratios decreased. Dissolved inorganic nitrogen and dissolved inorganic phosphorous peaked in late July, and declined right after. This peak roughly coincides with the first APFA bloom, which occurred in June and July. After the first APFA bloom declined, nitrogen and phosphorous concentrations increased, which coincided with MSAE concentration increase. This has been interpreted as a causal relationship (Eldridge et al. 2013), where early APFA blooms "feed" nitrogen to the non$\mathrm{N}_{2}$ fixing MSAE, however a mechanism has not been demonstrated. Microcystin concentration peaks in mid-August, which means there is sufficient dissolved inorganic nitrogen that can support MSAE growth into late summer. Unique nutrient physiological traits allow cyanobacteria to maintain high growth rates when the epilimnetic ratio of TN:TP is below 29:1 by weight (Smith 1983). MSAE has a high affinity for dissolved inorganic nitrogen, and the ability to store large amounts of phosphorous (Jacobson and Halmann 1982; Takamura et al. 1987), and APFA can fix atmospheric nitrogen (Paerl et al. 2001). All UKL sampling sites reported TN:TP ratios of less than 29 for all of 2006, 
which indicates that the appropriate conditions existed to establish cyanobacteria dominance over other phytoplankton (Lindenberg et al. 2009). The present study focused on time (late summer) when nitrogen concentration is sufficient for MSAE growth. In addition, the competition model in this study has a limited temporal scope (5 days), which further reduces the need to consider seasonal nutrient dynamics. The focus of this competition model will be to explore the sensitivity of competition to physiological algal buoyancy rates and the physical mixing process in UKL.

The ability to regulate buoyancy confers several ecological benefits to the cyanobacteria species that are able to create gas vesicles. The primary benefit of buoyancy regulation is increased fitness in the competition for light (Walsby 1994). Buoyant cyanobacteria can overcome steep thermal density gradients in order to spend more time near the water surface and receive more light than sinking species of phytoplankton (Reynolds and Walsby 1975; Humphries and Lyne 1988; Ibelings et al. 1991). This allows the buoyant cyanobacteria, like MSAE and APFA, to effectively act as a canopy species: they shade out competitors, which essentially denies other phytoplankton of the light needed to photosynthesize (Ganf et al. 1989). Other secondary advantages of occupying surface waters are the increased availability of free $\mathrm{CO}_{2}$ during times of depletion (Booker and Walsby 1981; Paerl and Ustach 1982), and atmospheric fixed nitrogen (Lewis 1983). Buoyancy regulation allows cyanobacteria to quickly recover water surface location after a high wind event causes mixing; in one deep Spanish reservoir, APFA was able to recover surface position within 80 minutes of 
a wind event (Moreno-Ostos et al. 2009). Buoyancy regulation also allows cyanobacteria to escape the surface during periods of high irradiance, which can help them avoid photo-oxidative damage (Reynolds and Walsby 1975; Reynolds 1987). However, buoyancy regulation can fail: during blooms, photosynthetic activity is restricted to the first few millimeters of the water surface, and cells are kept at the surface by a blanket of buoyant colonies below them (Ibelings and Mur 1992). Buoyancy regulation confers ecological advantages to cyanobacteria over sinking phytoplankton, however the role of buoyancy on competition between buoyant cyanobacteria is not well understood and depends on the species involved and the physical turbulence and thermal density gradients of the water column.

Many species of cyanobacteria, including MSAE and APFA, have the ability to regulate buoyancy, which helps them avoid conditions that are not conducive for growth (Chung et al. 2014), however there are differences between the two species physiological parameters. MSAE exhibits both seasonal and diurnal vertical migration patterns, which are adaptive mechanisms that enable it to acquire adequate sunlight and nutrients for growth (Reynolds et al. 1987; Ibelings et al. 1991; Walsby 1994). Field observations of APFA also reveal a daily migration pattern (Reynolds et al. 1987). MSAE has the ability to form quasi-spherical colonies of varying size (up to $1 \mathrm{~mm}$ in diameter) by embedding cells in mucilage (Reynolds and Walsby 1975; Carey et al. 2012). MSAE colony size plays a role in both vertical distribution and buoyancy regulation, since larger colonies are less affected by mixing and experience more rapid vertical velocities than 
smaller colonies (Kromkamp and Walsby 1990; Wallace et al. 2000; Wu and Kong 2009). The trichomes of APFA aggregate into rafts of 100 or more filaments that can measure up to $500 \times 50 \mu \mathrm{m}$ (Reynolds and Walsby 1975). MSAE vertical flotation velocity has been calculated at $0.5 \mathrm{~m} \mathrm{~h}^{-1}$ (Huisman et al. 2004; Joehnk et al. 2008). APFA vertical velocity has been calculated to be $0.9+/-0.5 \mathrm{~m} \mathrm{~h}^{-1}$ (Walsby et al. 1995). There exists variability in buoyancy, with turgor pressure, gas vesicle volume, cell ballast, light intensity and light and nutrient history impacting a cells buoyancy response (Reynolds and Walsby 1975; Brookes and Ganf 2001). The addition of gas vesicles helps cells achieve positive buoyancy, and levels of irradiance impact cyanobacteria species differently. Optimal photon irradiance for production of new gas vesicles is $35 \mu \mathrm{mol} \mathrm{m} \mathrm{m}^{-2}$ $\mathrm{s}^{-1}$ for MSAE and around 13-22 $\mu \mathrm{mol} \mathrm{m} \mathrm{m}^{-2} \mathrm{~s}^{-1}$ for APFA (Walsby 1994). This indicates MSAE can regulate its buoyancy better in high irradiance conditions than APFA. The physiological characteristics of buoyant cyanobacteria interact with and are impacted by the physical and chemical properties of the lake they inhabit.

Many of the physical lake properties that are advantageous for buoyant cyanobacteria are present in UKL. During the peak bloom season (May to November) between $90-100 \%$ of phytoplankton biomass is APFA, while MSAE is <1\% (Kann 1998). Typical summers are dry and hot in the Upper Klamath Basin, and wind speeds are relatively low with average daily wind speeds less than $5 \mathrm{~m} \mathrm{~s}^{-1}$ from June to August (Lindenberg et al. 2009). UKL is shallow and mixes on an almost daily basis, so it is likely that the vertical migration pattern of buoyant cyanobacteria is controlled by the 
physical turbulence and thermal density gradients of the water column, in addition to light availability (Wood and Gartner 2010). Wood and Gartner (2010) found daily suspended solids (which includes organic matter like APFA rafts and inorganic matter) migration showed a near surface maximum during times of peak thermal stability (afternoon), and exhibited a uniform distribution throughout the water column when temperature stability was at its lowest (late night to mid-morning). They measured positive velocities of $0.1 \mathrm{~cm} \mathrm{~s}^{-1}$ from these suspended solids concentration. While resuspended bed material would be expected to be included in this velocity calculation, Wood and Gartner (2010) argued that by selecting the deep trench in UKL, in combination with high lake levels and low wind speed, low levels of re-suspended bed materials were expected in the velocity calculation. While APFA colonies were suspected to be in the suspended solids concentration (and thus subject to the velocity calculation), this could not be verified. UKL is a dynamic, large and fast moving system, and how fast cyanobacteria can move through this system could influence algal competition and bloom dynamics.

Previous studies often treat buoyancy regulation as either present or absent in a species, but do not investigate the degree to which varying buoyancy rates impact competition between phytoplankton. Buoyancy is seen as an advantage in competition because buoyant species have better access to radiance-rich surface waters and nutrient-rich bottom waters (Ibelings et al. 1991; Paerl et al. 2001). Buoyant species dominate competition under stratified conditions (Huisman et al. 2004; Joehnk et al. 
2008; Carey et al. 2012), and can quickly reestablish presence at the surface after high wind stress events (Moreno-Ostos et al. 2009). The advantage of buoyancy regulation is often discussed in the context of competition for light between buoyant and sinking species (Huisman and Sommeijer 2002; Huisman et al. 2004; Joehnk et al. 2008; Paerl and Huisman 2008; Bengfort and Malchow 2016). The main findings of these studies indicate that vertical mixing can influence the outcome of competition between buoyancy-regulating species and sinking species, but it doesn't evaluate the degree to which buoyancy was an influential mechanism in the outcome of competition between two buoyant species. This thesis is unique in that varying buoyancy rates could influence the outcome of competition between two buoyant species of cyanobacteria was the focus of the investigation.

A theoretical competition model was used to explore if the buoyancy regulation mechanism impacts phytoplankton community assemblage under different weather scenarios. The model is not a predictive tool for detecting bloom development and does not forecast changes in weather. It is hypothesized the buoyancy rates for APFA in UKL are higher than published literature values for the species (Wood and Gartner 2010; Tammy Wood personal communication). Observations of high APFA concentrations in the Klamath River above expected temperature maxima suggest regional ecotypes of APFA exist with differential sensitivities to temperature (Paerl and Otten 2016). I investigated if regional ecotypes are also sensitive to buoyancy rate. My work aimed to parameterize the vertical velocity of APFA in UKL for two reasons: 1) Direct 
measurement of raft movement allows for comparison to published literature values, and 2) to use the calculated buoyancy rate in the competition model. I was unable to verify the buoyancy rate of MSAE because I was not able to locate and measure enough MSAE colonies to calculate the population buoyancy rate. The model allows for parameter sensitivity analysis and for identifying depths at which dangerous accumulations of cyanobacteria could occur. This information could be useful to lake managers as they consider regional impacts of climate change and contemplate risk assessment and mitigation plans for impaired lakes. The model's parameters are based on literature values but is not calibrated or validated with algal concentration data, and thus is a purely theoretical tool that could be used to design studies to monitor algal densities. MSAE growth is expected to outpace APFA growth under high temperatures and when the water column is fully mixed, due to its superior high temperature optima and in spite of slower vertical velocity.

\section{Methods}

Study site

UKL is a large $\left(232 \mathrm{~km}^{2}\right)$, shallow (average depth of $2.8 \mathrm{~m}$ ) lake located in southcentral Oregon (Lindenberg et al. 2009). This natural lake is in a sizeable watershed $\left(9,415 \mathrm{~km}^{2}\right)$, and a dam down river controls the height of the lake. Agency Lake is located north of UKL and is connected to UKL via a shallow channel, and adds about 38 $\mathrm{km}^{2}$ of surface area to the UKL total surface area (Johnson 1985). The lakes are 
connected by a channel and more recently through The Nature Conservancy project where the levees were removed and lake water could move across the property. Both lakes are hypereutrophic and have annual blooms of APFA. The prevailing winds at UKL are westerly over the northern part of the of the lake and northwesterly over the southern two-thirds of the lake (Lindenberg et al. 2009).

APFA samples were collected from three locations, including Moore Park, Howard Bay and Lake Ewuana (Figure 3-1). Moore Park is a municipal park in Klamath Falls and is located on the southern end of UKL. The park has boat access ramps and is a popular birding area. Howard Bay is located on the western end of UKL and is sheltered from local wind patterns. Lake Ewauna is a reservoir that is linked to UKL via the Link River, and is located at the headwaters of Klamath River. The three locations the samples were taken from were selected in order to gather specimens from locations with widely different characteristics and properties. A more accurate lake average buoyancy rate would be calculated by sampling APFA from many locations within the lake.

\section{Data collection}

A meteorological station and data loggers were deployed in October 2015, August 2016 and September 2016. This work focuses on the most recent and complete set of data, which was collected in September 2016. Data were collected from September 1-23, and was collected at ten-minute intervals. Please see Chapter 3 for 
details on variables, data processing, and modeled day selection. Four days were selected for hydrodynamic modeling based on the average day's temperature and wind conditions, and were categorized as: hot and windy, hot and calm, cool and windy, and cool and calm. The temperature and effective diffusion of heat was calculated in order to model the water column turbulence and thermal structure. Each modeled day was repeated for 5 days for input into the competition model.

\section{Sampling method and processing}

APFA rafts were collected from UKL between August 21 and 22, 2015. Sampling locations included: Moore Park, Howard Bay and Lake Ewuana. Lake water was collected at each site in brown-colored, 125-mI Nalgene HDPE bottles, and put directly into the dark for 30 minutes to 5 hours before APFA raft movement was video recorded. Samples were collected between 8 am to $5 \mathrm{pm}$. Thirty-three samples were derived from the collected APFA rafts. Samples were placed in a flat-sided cuvette and APFA raft movement was video recorded for approximately 10 minutes. The camera was placed approximately $10 \mathrm{~cm}$ from the cuvette such that the cuvette took up the full frame and no light was directed on the cuvette.

All buoyancy rates were calculated using Logger $\operatorname{Pro}^{\circledR} 3$ software. This software allows users to track movement in a video, which can be used to calculate movement rate (distance travelled over time it took to travel that distance). Videos were loaded into the software, and the cuvettes were subdivided into ten sections (Figure 3-2). One 
APFA raft was randomly selected from each section for tracking at a random minute in the video. The aim of this randomization in both space and time was to decrease the selector's bias of choosing the easiest, biggest or fastest raft for tracking. This ensured a random selection of rafts were chosen for rate calculation. Absolute distance travelled, regardless of direction, was tracked. Ten individual APFA rafts were selected for buoyancy measurement, and averaged to obtain one representative buoyancy rate per sample. The direct observation measurement and cuvette method is similar to the work pioneered by Reynolds (1972 and 1973), but has been simplified by the use of cameras and tracking software. Arick Rouhe and John Rueter in the Rueter Lab at Portland State developed the direct observation measurement and cuvette method (personal communication).

\section{Competition model}

The phytoplankton competition model is a one-dimensional model developed by Huisman and colleagues (Huisman et al. 1999; Huisman et al. 2004). The competition model was executed in the same platform as the one-dimensional hydrodynamic model (STELLA $^{\mathrm{TM}}$ version 10.0.6). The model assumes nutrients are not limiting, and thus do not play a role over the several-day scale. Light availability, water temperature, mixing, and buoyancy rates govern the model's population dynamics. Light and temperature data were measured in the field, the hydrodynamic model predicted the mixing parameters, the buoyance rate for MSAE was from the literature, and the buoyancy rate was from 
my measurements described above. The model simulates the cell concentration of two species of cyanobacteria (APFA and MSAE) in a vertical water column in seven layers at the following depths (cm): $0,10,20,30,40,50,60,70,80$, and sediment ( 90$)$. The population in each layer is dynamically simulated from specific loss and growth rates, and exchanges from the next layer via mixing and buoyancy (Figure 3-3). The population dynamics are explained by a series of reaction-advection-diffusion equations from Huisman et al. (2004). Let $N_{i}(z, t)$ be the density of species $i$ at depth $z$ and time $t$. Let I be the light intensity (in PAR range), and T be the temperature $\left({ }^{\circ} \mathrm{C}\right.$ ) at depth $z$ and time $t:$

$$
\begin{aligned}
\frac{\partial N_{i}}{\partial t}= & \mu_{i}(I, T) N_{i}-m_{i}(T) N_{i}+\frac{\partial}{\partial z}\left(v_{i}(T) N_{i}\right)+\frac{\partial}{\partial z}\left(D_{z} \frac{\partial N_{i}}{\partial z}\right) \quad i=1, \ldots \ldots, n . \\
& \text { where }
\end{aligned}
$$
$\mu_{i}(I, T)$ is the specific growth rate of species $i$ and is also a function of light $(I)$ and temperature $(T)$.

$m_{i}(T)$ is the specific loss rate and is a function of temperature. The loss rate includes cell natural mortality, grazing, and virus deaths.

$v_{i}(T)$ is the vertical velocity (i.e. buoyancy rate) depends on the viscosity of water, and thus, is it also a function of temperature.

$D_{z}$ is the turbulent diffusivity, and this is space and time dependent. What follows next is an explanation of each term and how it was calculated in the competition model. 


\section{$\underline{\text { Specific growth rate }}$}

The specific growth rate of both species is a function of light and temperature. It is an increasing saturation function light intensity:

$$
\begin{aligned}
& \mu_{i}(I, T)=\frac{\mu_{\max , i}(T) I}{\mu_{\max , i}(T) / \alpha_{i}+I} \\
& \text { where } \\
& \mu_{\max , i}(T)=\text { maximum specific growth rate of species } i \\
& \alpha_{i}=\text { initial slope of growth under light-limited conditions, and is determined by } \\
& \text { temperature independent processes }
\end{aligned}
$$

It should be noted that $\mu_{\max , i}$ is assumed to vary with temperature, while $\alpha_{i}$ is independent of temperature.

Since growth is not linear with temperature, it can be described by a temperature optimum curve (modified from Joehnk et al. 2008).

$$
\begin{aligned}
& \mu_{\text {max }, i}(T)=\mu_{\text {max }, i}\left(T_{o p t, i}\right)\left[1+b_{i}\left(\left(R_{1 i}^{T-T_{o p t, i}}-1\right)-\frac{\ln \left(R_{1 i}\right)}{\ln \left(R_{2 i}\right)}\left(R_{2 i}^{T-T_{o p t, i}}-1\right)\right)\right] \\
& \text { where } \\
& \mu_{\text {max }, i}\left(T_{o p t, i}\right)=\text { maximum specific growth rate at optimum temperature for } \\
& \text { species } i \\
& R_{1 i}, R_{2 i}, b_{i}=\text { are variables used to form the optimum curve for species } i
\end{aligned}
$$


The optimum curve for MSAE used values from Joehnk et al. (2008). The optimum curve for APFA was visually fitted using growth curves from Reynolds (1989).

Since light conditions change with depth, time, and is impacted by turbidity and phytoplankton densities, I can be described by:

$I(z, t)=I_{\text {in }}(t)(1-r) \exp \left(-\int_{0}^{z}\left[\sum_{i=1}^{n} k_{i} N_{i}(t)\right]-K_{b g} z\right)$

where

$I(z, t)=$ light intensity at depth $z$ and time $t$

$I_{\text {in }}(t)=$ incident light intensity $(\mathrm{PAR})$ at the water's surface

$r=$ reflection coefficient

$k_{i}=$ specific light attenuation coefficient of species $i$

$K_{b g}=$ background attenuation coefficient

\section{Specific loss rate}

The specific loss rate increases exponentially with temperature, and has been mathematically expressed as (Robarts and Zohary 1987):

$m_{i}(T)=m_{i}(20) Q_{i}^{(T-20) / 10}$

where

$m_{i}(20)=$ specific loss rate at $20^{\circ} \mathrm{C}$

$Q_{i}=$ describes the change in specific loss rate with a temperature change of $10^{\circ} \mathrm{C}$ 
$\underline{\text { Vertical flux }}$

The vertical flux term incorporates two processes that drive the exchange of water and cyanobacteria cells between two adjoining layers of water: vertical velocity and turbulent diffusion. The vertical velocity of phytoplankton is inversely proportional to the viscosity of water, which varies with temperature (Hutter and Joehnk 2004;

Reynolds 2006). The model assumes a uniform distribution of cells in each layer at the beginning of the simulations, and was adopted from Huisman and colleague's work (2002).

$v_{i}(T)=\frac{\eta(20)}{\eta(T)} v_{i}+\left(C_{2}-C_{1}\right) E_{z}$

where

$v_{i}(T)=$ vertical flux of species $i$ at temperature $T$

$\eta(T)=$ dynamic viscosity of water at temperature $T$

$\eta(20)=$ viscosity of water at $20^{\circ} \mathrm{C}$

$v_{i}=$ buoyancy rate of species $i$

$C_{2}$ and $C_{1}=$ concentration of cells in layers 2 and 1 , respectively

$E_{z}=$ effective diffusion at depth $z$

The effective diffusion rates were calculated from the weather scenarios generated in the 1D hydrodynamic model (see Chapter 3). Each weather scenario was 
allowed to run for five days to see how that temperature and wind regime influenced cyanobacteria growth.

\section{Data analysis}

Sample buoyancy rates were averaged to obtain an overall APFA buoyancy rate estimate, and the standard deviation was calculated to obtain the variance of buoyancy between the samples. Rate differences between locations were tested to investigate if there were statistically significant differences between the sample locations. Boxplots and normal QQ plots were used to visually inspect the normality of the data. The assumption of normality was tested using a Shapiro-Wilk test. Since the assumptions of normality and equal variance were violated, a Kruskal-Wallis test was used to investigate if the median rates of all locations were equal.

There were two main questions that required statistical analysis from the outputs of the competition model: 1) do the weather scenarios impact the concentration of APFA and MSAE differently, and 2) are the concentrations of APFA and MASE significantly different from each other within each layer. A repeated measures ANOVA was conducted for both questions because repeated measures ANOVA allows for the investigation of how the mean concentration of cyanobacteria changes over time with weather scenario. Since layer is a source of variability (cyanobacteria are not equally distributed throughout the water column), layer was treated as a treatment-bysubjects design. This allows the investigator to test if cyanobacteria concentrations are a 
function of weather scenario or species, given the layer. The concentration of APFA and MSAE was measured every four hours ( 6 times per day) across the 5 simulated days for each layer in order to capture daily variability in cyanobacteria water column position. For the first question, the repeated measures ANOVA investigated if cyanobacteria concentration is a function of weather scenario, given the layer. The concentration of APFA and MSAE was investigated separately. A Tukey test was conducted when weather scenarios were found to be statistically significant. A 90\% family-wise confidence level graph was made for every weather scenario combination. For the second question, the repeated measures ANOVA investigated if cyanobacteria concentration was a function of species, given the layer and weather scenario. The ANOVA and Tukey HSD test used $\alpha=0.05$ to signify statistical significance, but results that were close to 0.05 were also discussed.

\section{Buoyancy rate sensitivity}

A sensitivity analysis was conducted on the buoyancy parameter for both cyanobacteria species in every weather scenario. The species that "won" had its buoyancy parameter decreased while the other specie's buoyancy parameter stayed static. In a separate analysis, the losing species had its buoyancy increased while the other species' buoyancy parameter was held the same. APFA's buoyancy rate parameter was decreased from $0.89 \mathrm{~m} \mathrm{~h}^{-1}$ to $0.60 \mathrm{~m} \mathrm{~h}^{-1}, 0.50 \mathrm{~m} \mathrm{~h}^{-1}$ and $0.40 \mathrm{~m} \mathrm{~h}^{-1}$. The resulting growth pattern for each species was compared to the original simulation results in order 
to elucidate how buoyancy regulation impacts competition. MSAE's buoyancy rate was held static for comparison. In another buoyancy sensitivity analysis, MSAE's buoyancy rates were increased from $0.50 \mathrm{~m} \mathrm{~h}^{-1}$ to $0.70 \mathrm{~m} \mathrm{~h}^{-1}, 0.80 \mathrm{~m} \mathrm{~h}^{-1}$ and $0.90 \mathrm{~m} \mathrm{~h}^{-1}$ while APFA's buoyancy rate was held. Within each weather scenario, a repeated measure ANOVA was used to test if cyanobacteria accumulations were a function of buoyancy scenario (given the layer). This test was used in order to elucidate if buoyancy inferred competitive advantage under differing mixing regimes (i.e. weather scenarios). A Tukey HSD test was conducted when weather scenarios were found to be statistically significant $(\alpha=0.05)$.

\section{Model implementation}

The competition model was executed in STELLA ${ }^{\mathrm{TM}}$. The simulation ran for 120 hours at an eight-minute time step. Each layer was treated as a box $1 \mathrm{~m}$ by $1 \mathrm{~m}$ and $10 \mathrm{~cm}$ thick, and had 1,000 cells at the beginning of the simulation. The water temperature and effective diffusion coefficient outputs from the one-dimensional hydrodynamic model were used as inputs in the competition model to simulate different mixing regimes. The result of the APFA buoyancy rate calculations was used as a species parameter.

For a complete list of variables, model code and diagram, see Appendix B. Model outputs are available at http://www.cyanolab.research.pdx.edu/. 


\section{Results}

APFA buoyancy rates in UKL closely matched literature

The overall calculated buoyancy rate for APFA was $0.89 \mathrm{~m} \mathrm{~h}^{-1}\left(+/-0.34 \mathrm{~m} \mathrm{~h}^{-1}\right)$.

The average buoyancy rates for the three sampling locations ranged from $0.79 \mathrm{~m} \mathrm{~h}^{-1}$ to $1.12 \mathrm{~m} \mathrm{~h}^{-1}$. The buoyancy rates of the thirty-three subsamples were not drawn from a normal distribution (Shapiro-Wilk normality test, $\mathrm{W}=0.81, \mathrm{p}=0.001$ ). The variances were not equal ( $F$ test, $F=0, d f=32, p$-value $<0.05$ ). This is caused by a single outlier rate from Lake Ewuana (Figure 3-4). When this outlier is removed, the data become normally distributed. However, since there is no compelling reason to remove this point, the outlier was not removed. The median buoyancy rates for all three locations were not significantly different from each other (Kruskal-Wallis test, $\chi^{2}=2.85, D F=2, p$-value $=0.24)$.

Four weather scenarios and competition

MSAE cell accumulations between weather scenarios were significantly different from each other (repeated measures ANOVA, DFN=3, DFD=9, $F=2.9, p=0.03$ ), while APFA concentrations were not significantly different between the weather scenarios (repeated measures ANOVA, $\mathrm{F}=1.8, \mathrm{p}>0.05$ ). The MSAE accumulation patterns between hot calm and cool calm conditions were nearly significantly different from each other (TukeyHSD test, $p=0.07$ ). The MSAE accumulation patterns between hot windy and cool 
calm were also nearly significantly different from each other (TukeyHSD test, $p=0.08$;

Figure 3-5).

APFA and MSAE accumulations were significantly different from each between layers (repeated measures ANOVA, $F=33,916.3$ and 10,070.6, respectively, and $p<0.05$ for both). The F score was high in this test because of the high concentration of cyanobacteria cells in the layers in comparison to the model's residuals. Nevertheless, clear patterns of accumulations developed. Both species developed accumulations at the surface and cells were absent at the bottom of the water column at the end of the 5-day simulation. For APFA, the 0 and $10 \mathrm{~cm}$ layers were significantly different than all other layers and from each other (TukeyHSD test, $p<0.05$ ). For MSAE, the 0,10 and $20 \mathrm{~cm}$ layers were significantly different than all other layers and from each other (TukeyHSD test, $p<0.05)$.

The concentrations of APFA and MSAE were significantly different from each other in every weather scenario modeled (repeated measures ANOVA, see Table 3-1). Total water column cell accumulation was higher for APFA than MSAE in every weather scenario (Table 3-2). Total APFA accumulation outnumbered MSAE by between $15 \%$ (in both hot weather scenarios) to $9 \%$ (cool calm scenario). While APFA outnumbered MSAE in total and surface accumulations, MSAE had between $25-28 \%$ higher accumulations at near surface layers $(10 \mathrm{~cm})$ in every weather scenario competition. Due to its overall higher volume of cells, APFA was considered the fittest species in all competition scenarios. 
APFA buoyancy sensitivity analysis

The column APFA cell accumulation decreased as buoyancy rates decreased in every weather scenario, however this increase was not significant in any weather scenario (repeated measures ANOVA, $\mathrm{p}>0.05$ ). The general water column distribution was the same under all scenarios: the majority of cells occupied the surface layer, and no cells occupied the bottom half of the water column, which was around 40 to $50 \mathrm{~cm}$ (Table 3-3). Surface accumulations of APFA decreased with decreasing buoyancy as cells accumulated at near surface layers $(10 \mathrm{~cm})$ instead (total water column cell concentrations were mostly unchanged; see Table 3-3).

MSAE cell accumulation was unaffected by decreasing APFA buoyancy rates ( Table 3-4), and there was no statistical difference between the decreasing APFA buoyancy rates and MSAE accumulations (repeated measures ANOVA, $F=0, p=1$ ). Total APFA cell accumulations outpaced MSAE in every weather scenario and under every buoyancy rate.

\section{MSAE buoyancy sensitivity analysis}

The column MSAE cell accumulation increased slightly as buoyancy rates increased in every weather scenario, however this increase was not significant in any weather scenario (repeated measures ANOVA, $p>0.05$ ). The general water column distribution was the same under all scenarios: the majority of cells occupied the surface 
layer, and no cells occupied the bottom half of the water column, which was around 40 to $50 \mathrm{~cm}($

Table 3-5). While surface accumulations of MSAE increased with increasing buoyancy, near surface layers $(10 \mathrm{~cm})$ saw a decrease in cell accumulation. The hot day scenarios saw a slightly increase in the total water column cell concentration for MSAE, while cool days only saw a slight redistribution of cell location.

APFA cell accumulation was unaffected by increasing MSAE buoyancy rates ( Table 3-6), and there was no statistical difference between the increasing MSAE buoyancy rates and APFA accumulations (repeated measures ANOVA, $F=0, p=1$ ). Total APFA cell accumulations outpaced MSAE in every weather scenario and under every buoyancy rate.

Other parameter sensitivity analysis

Since changing buoyancy didn't impact the outcome of the competition, the MSAE's light attenuation coefficient and optimum temperature growth curve were changed to match APFA species parameters in order to test if the accumulations of APFA and MSAE were significantly different from each other within each weather scenario. The altered light attenuation coefficient had no impact on the competition overall. The species' cell accumulations were exactly the same as in the original simulation. 
Using the same optimum temperature growth curve for MSAE that was used for APFA did yield different cell accumulations (Table 3-7). Cell accumulations for APFA and MSAE were investigated within each weather scenario to see if APFA and MSAE had different cell concentrations within each layer. Within the layers, APFA and MSAE concentrations were not significantly different from each other in the cool calm, cool windy, or hot calm weather scenarios, but were significantly different in the hot windy scenario (repeated measures ANOVA, see Table 3-8). When a buoyancy sensitivity analysis was conducted on the model with equal growth curves for the hot windy scenario, MSAE layer accumulations were still not a function of buoyancy rate (repeated measures ANOVA, $F=0, p=1)$.

\section{Discussion}

APFA buoyancy rate in UKL

The purpose of investigating the buoyancy rate of APFA in UKL was to see if the ecotype in UKL was significantly different from the published literature rates. There was a high degree of agreement between the calculated APFA buoyancy rate in UKL $(0.89 \mathrm{~m}$ $\mathrm{hr}^{-1}+/-0.34 \mathrm{~m} \mathrm{hr}^{-1}$ ) with the rate published by Walsby $\left(1995 ; 0.9+/-0.5 \mathrm{~m} \mathrm{hr}^{-1}\right)$. Walsby (1995) calculated APFA buoyancy from the time it took rafts to float between gradation marks on a measuring cylinder. However, the calculated buoyancy rate was not recorded in situ, and should not be interpreted as the in-lake buoyancy rate of APFA in UKL. APFA raft movement was recorded in a lab setting, and many conditions 
(temperature, light source) did not replicate in-lake conditions. The results indicate the APFA buoyancy rate in UKL could be similar to published literature rates. While the results of this study could be interpreted as a physiological response of APFA under lab conditions, it does not represent the fastest velocity possible since water column stability and turbulence were not factors in the lab experiment. Wood and Gartner (2010) found that when cycles of vertical velocity were present, they were out of phase with the expected vertical movement of APFA rafts based on the theory of light-driven movement. This suggests that water stability (thermal gradient) and turbulence were more important in explaining APFA's movements in UKL than light. Thus, temperature and mixing of the water column could have a significant impact on the vertical velocity of APFA within UKL. Since the vertical transport of phytoplankton is driven by both the sinking/buoyancy of the cell and by turbulent mixing of the cells through the water column (Huisman et al. 2004), any model that attempts to simulate the movement of APFA through water will have to account for the raft's buoyancy and turbulent mixing.

\section{Competition model}

Overall, MSAE accumulation patterns differed between the weather scenarios, while APFA did not. However, a pairwise comparison between the weather scenarios for MSAE accumulation did not yield significant differences. This is because the Tukey test controls for Type I error, and requires a larger difference for significance than ANOVA Ftests. Using the near significance weather scenario comparisons, the results indicate that MSAE might be influenced by thermal and turbulent mixing regimes, while APFA 
growth is less sensitive to the modeled mixing and thermal regimes. On calm days, the temperature difference alone was enough to significantly impact MSAE cell accumulations. MSAE growth is more limited in water cooler than $15^{\circ} \mathrm{C}$ than APFA (Robarts and Zohary 1987). The average surface temperature on the calm days fell on either side of this temperature; cool calm scenario was $11.1^{\circ} \mathrm{C}$, and on the hot calm scenario it was $17.6^{\circ} \mathrm{C}$. However, the cool calm scenario accumulated more MSAE cells than the hot windy scenario, indicating that the turbulence on the windy day was more of a barrier to accumulation than lower temperatures. The temperatures on the hot windy scenario was also much less than the optimal growth temperature for MSAE: on average, the hot windy day had a temperature of less than $18^{\circ} \mathrm{C}$, while MSAE's optimal temperature for growth is much higher $\left(28^{\circ} \mathrm{C}\right.$; Reynolds 2006).

APFA accumulation outpaced MSAE accumulation at the surface layers, while MSAE accumulated more cells at near surface layers $(10-30 \mathrm{~cm})$. Both APFA and MSAE were absent from the bottom layers. This pattern was expected given positive and differing buoyancies for the two species.

Within each weather scenario more APFA accumulated in the total water column and at the surface than MSAE. This indicates that APFA is the dominant competitor in UKL under a variety of thermal and mixing regimes. APFA exhibited the same accumulation patterns on both hot weather scenarios, which indicates APFA was able to accumulate at the surface regardless of the increased turbulence on the windy day. MSAE accumulation was higher than APFA at the near surface layer $(10 \mathrm{~cm})$, which 
suggests there was enough light to sustain growth. APFA was not able to establish itself and shade out competitors.

The results from the buoyancy sensitivity analysis show that altering buoyancy alone is not sufficient to change the outcome of competition. The light attenuation coefficient sensitivity analysis also yielded no change in the outcome of competition, which indicates APFA's lower critical intensity was not a factor in the outcome of the competition. However, the species optimum temperature growth curve was an important factor in determining the outcome of competition. When MSAE and APFA's growth curve was set to the same parameters, APFA accumulation was insignificantly higher than MSAE accumulation in all weather scenarios except for hot windy. However, the buoyancy rate sensitivity analysis on the model with equal growth curve did not find buoyancy rate to be a significant factor in MSAE concentration between the layers in the hot windy scenario. This indicates that if species have very similar growth rates and temperature sensitivities, a change in buoyancy rate might not be enough to influence the outcome of competition.

There are limitations and uncertainty associated with this modeling approach. The model is a simplistic one-dimensional representation of a complex process. As such, there are many natural phenomena that are not accounted for, such as: photoinhibition, nutrient dynamics, lateral water movement, and varying buoyancy rates due to vesicle formation and ballast changes. The model is also not calibrated with algal 
biovolume samples. Nevertheless, there are benefits of this simple theoretical modeling for lake managers.

The greatest uncertainty in forecasting and mitigating the impacts of climate change will be in understanding how species level interactions will change (Winder and Schindler 2004). The complex interactions between APFA and MSAE are confounded by regional response to climate change in the highly-impacted system of UKL, and it is unclear if lake restoration might result in a shift in species composition (Nadia Gillett, personal communication). The insights gained from the results of this simple competition model can assist lake managers as they assess mitigation plans and adapt to climate change.

The dynamics between APFA and MSAE can be driven by temperature in some lakes (Wu et al. 2015) or nitrogen dynamics in others (Lehman et al. 2009), but there is not a clear pattern of succession established in UKL. Modeling competition and potential succession between species can be used to gain insights and consider mitigation plans based on regional needs. The competition model focused on population dynamics and how species compete for light through buoyancy. It showed that mixing regimes impact MSAE population dynamics, and MSAE's buoyancy rate was not able to overcome the turbulent mixing patterns modeled from UKL data to outcompete APFA. In this shallow, enriched, and well-mixed lake, APFA dominates the system (Eldridge et al. 2014) and the ecotype in UKL might be accustomed to much higher temperatures than other APFA ecotypes (Paerl and Otten 2016). UKL also mixes on an almost daily 
basis, so it is likely that buoyant cyanobacteria's vertical migration is controlled by physical turbulence and thermal gradients (Wood and Gartner 2010). On turbulent days, MSAE accumulated less than on calm days, so it is possible that mixing can be used to suppress MSAE without impacting APFA. If mixing regimes are significantly altered by regional responses to climate change, mangers might consider reestablishing current mixing regimes if MSAE blooms become a regular occurrence.

\section{Conclusion}

The buoyancy rate of APFA in UKL is similar to published literature values.

However, water column stability and turbulence could significantly alter the vertical velocity of APFA under various weather conditions. The hypothesized outcome of MSAE dominance under conditions of high water temperature did not occur. APFA was the better competitor under high temperatures and high turbulence. The proposition that increasing buoyancy rates would shift the outcome of competition did not occur either, as buoyancy was not found to be a function of algal concentration. The species optimum temperature growth curve was found to be the most important in determining the outcome of competition between APFA and MSAE. In these competition scenarios, MSAE had a slightly higher cell concentration that APFA on the cool calm days, however the difference was not significant. 


\section{Tables and Figures Chapter 3}

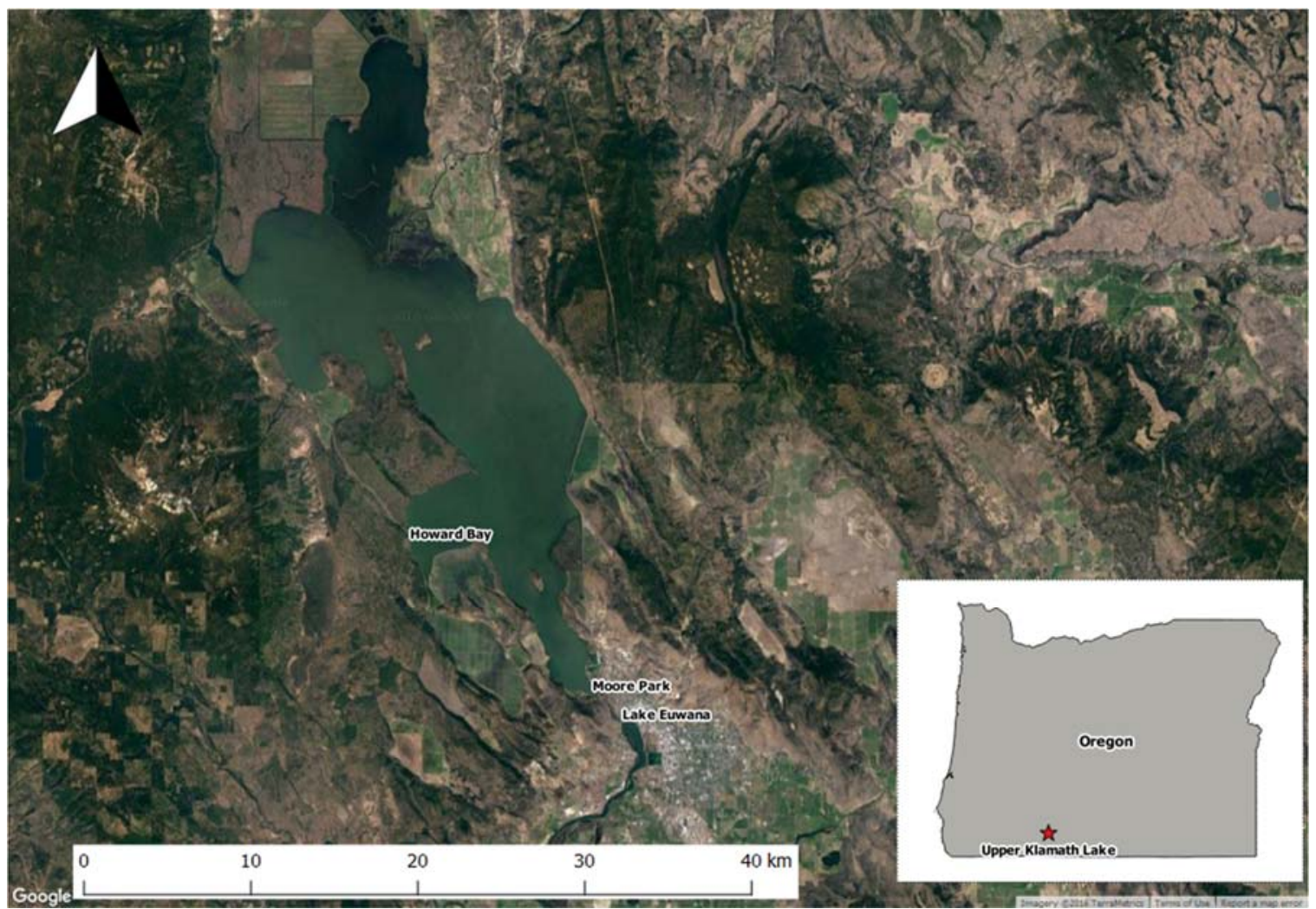

Figure 3-1 Map of Upper Klamath Lake APFA collection sites. 


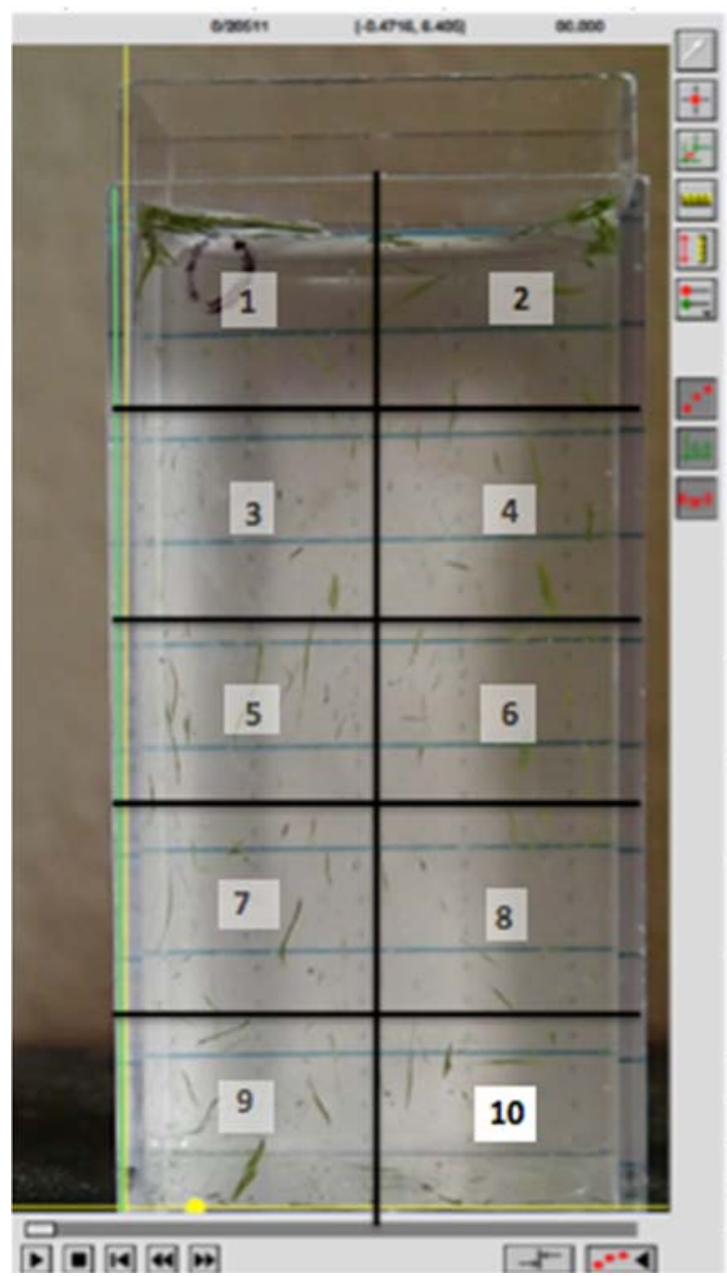

Figure 3-2 This is the Logger Pro ${ }^{\circledR}$ tracking software interface. An APFA raft video has been loaded into the software. The subdivisions used in raft selection are marked (1-10).

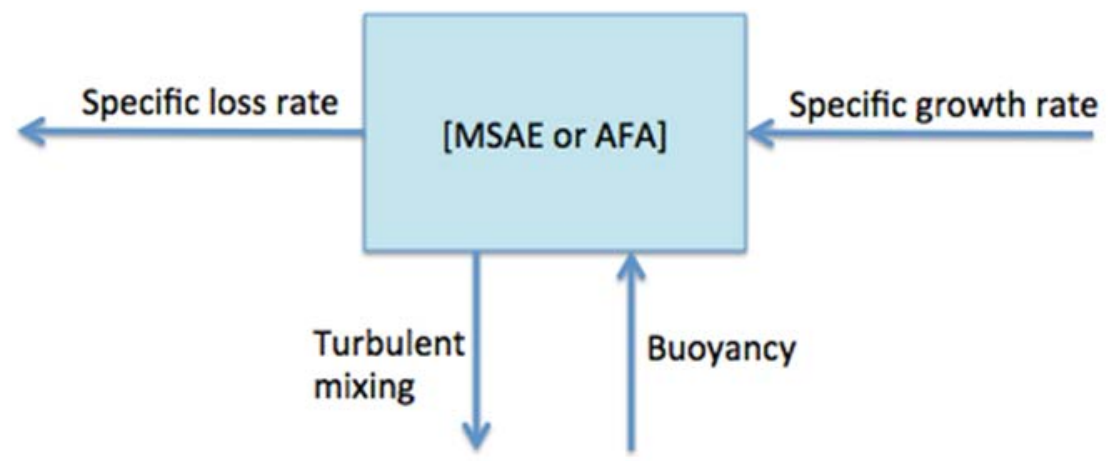

Figure 3-3 schematic diagram of the competition model. 


\section{Boxplot of Buoyancy Rates by Sample Location}

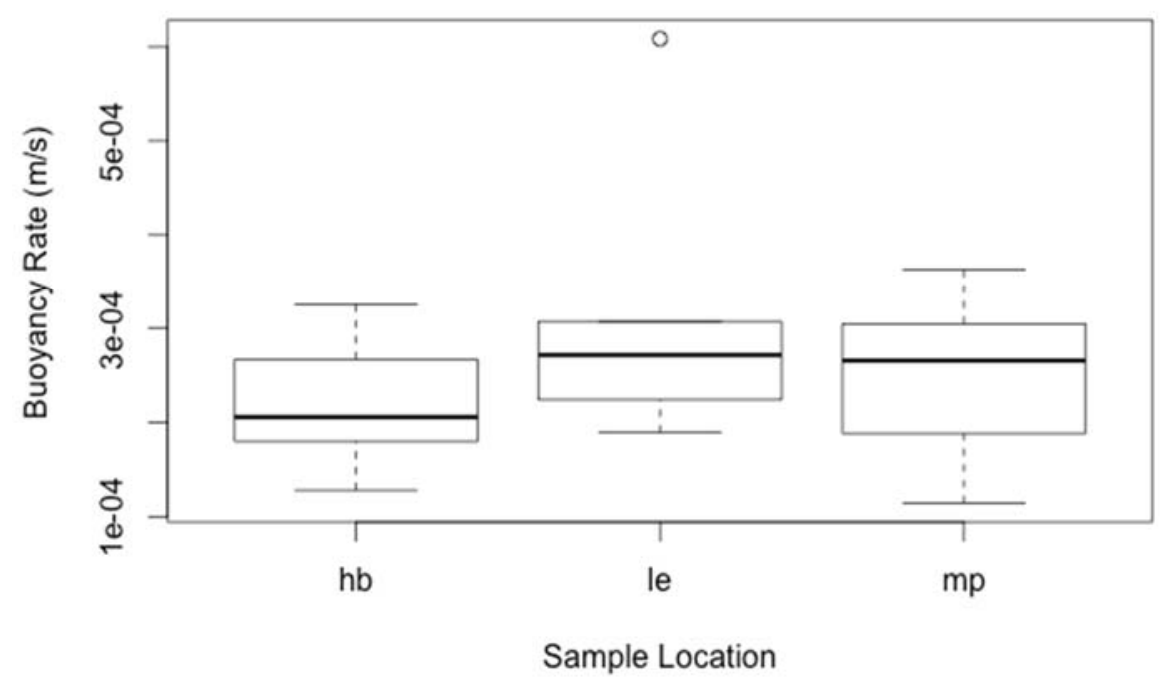

Figure 3-4 Boxplot of buoyancy rates by location ( $\mathrm{hb}=$ Howard Bay, le = Lake Ewuana, and $\mathrm{mp}=\mathrm{Moore}$ Park). A single outlier buoyancy rate can be seen in the 'le' location boxplot.

$90 \%$ family-wise confidence level

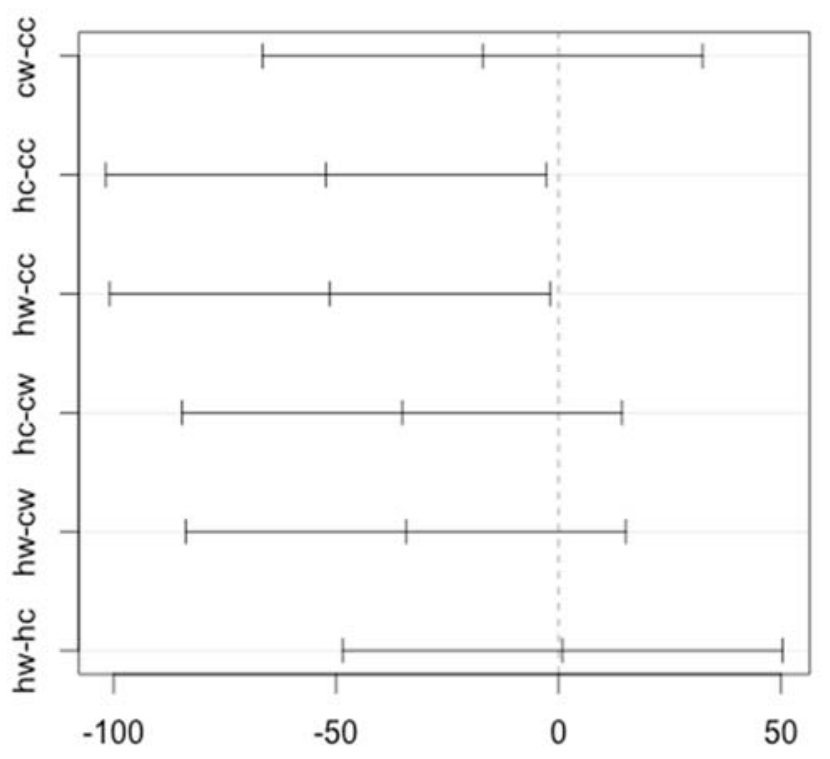

Differences in mean levels of scenario.msae

Figure 3-5 A 90\% confidence level graph for concentrations of MSAE under various weather scenarios ( $C C=$ cool calm, $\mathrm{CW}=\mathrm{cool}$ windy, $\mathrm{HC}=$ hot calm, and $\mathrm{HW}=$ hot windy). Confidence intervals were 
constructed using TukeyHSD test. Two confidence intervals were significant (HC-CC, $p=0.07 ; \mathrm{HW}-\mathrm{CC}$, $\mathrm{p}=\mathbf{0 . 0 8 )}$

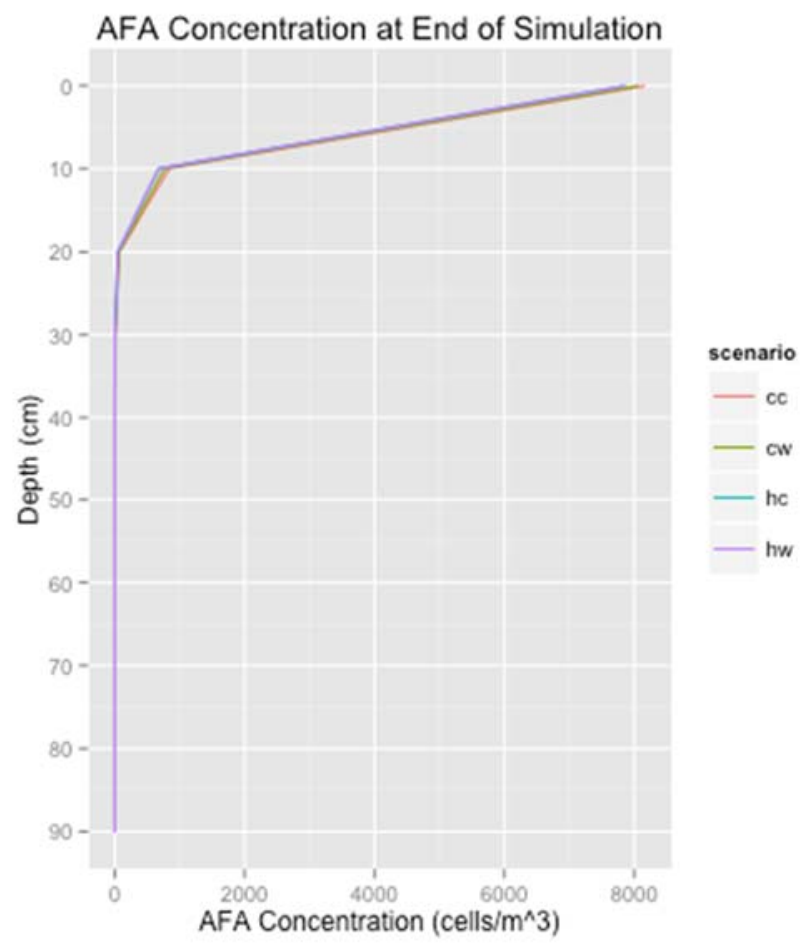

Figure 3-6 Concentration of APFA cells with depth for each weather scenario at the end of simulation ( $C C=$ cool calm, $\mathrm{CW}=$ cool windy, $\mathrm{HC}=$ hot calm, and $\mathrm{HW}=$ hot windy). 


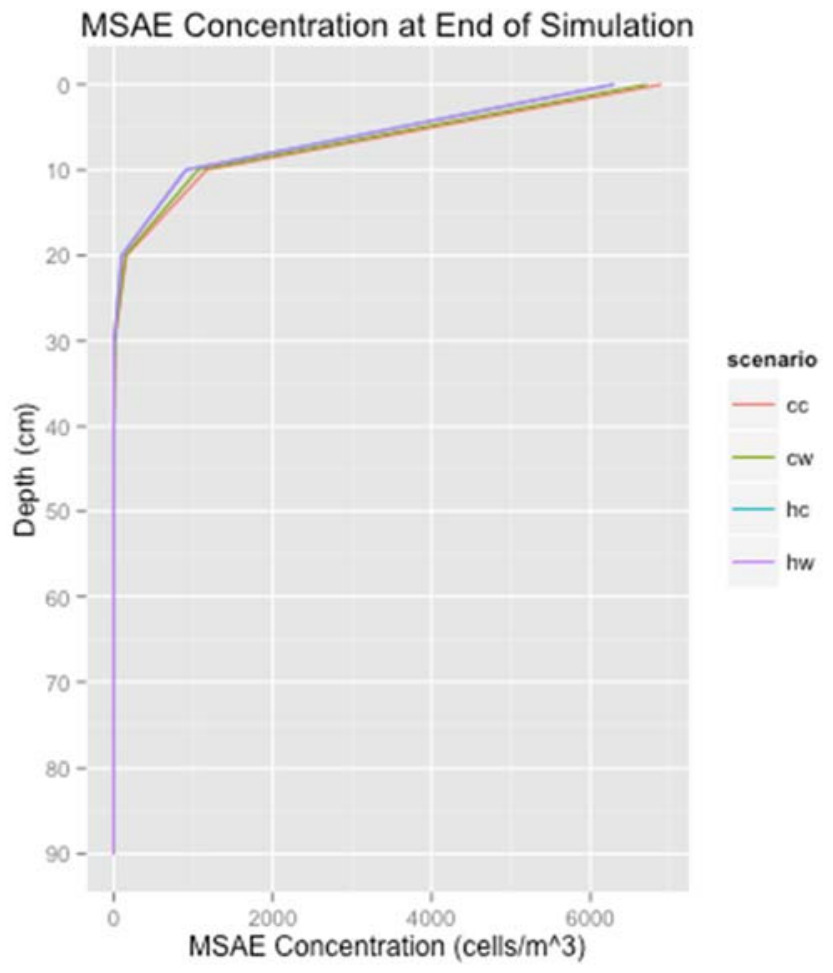

Figure 3-7 Concentration of MSAE cells with depth for each weather scenario at the end of simulation ( $\mathrm{CC}=$ cool calm, $\mathrm{CW}=$ cool windy, $\mathrm{HC}=$ hot calm, and $\mathrm{HW}=$ hot windy).

Table 3-1 Repeated measures ANOVA table comparing the concentration of APFA and MSAE cells between different weather scenarios.

\begin{tabular}{lcc}
\hline Weather Scenario & F-ratio & P-value \\
\hline Cool calm & 4.6 & $3.20 \mathrm{E}-02$ \\
Cool windy & 8.9 & $3.00 \mathrm{E}-03$ \\
Hot calm & 8.5 & $3.60 \mathrm{E}-03$ \\
Hot windy & 11.9 & $6.10 \mathrm{E}-04$ \\
\hline
\end{tabular}


Table 3-2 Total cell accumulations for each species at the end of the 5-day simulations. Totals assume a $1 \mathrm{~m}^{3}$ volume water column.

\begin{tabular}{rcccccccc}
\hline & \multicolumn{2}{c}{ Cool Calm } & \multicolumn{2}{c}{ Cool Windy } & \multicolumn{2}{c}{ Hot Calm } & \multicolumn{2}{c}{ Hot Windy } \\
\hline $\begin{array}{l}\text { Depth } \\
\text { (cm) }\end{array}$ & APFA & MSAE & APFA & MSAE & APFA & MSAE & APFA & MSAE \\
(cells) & (cells) & (cells) & (cells) & (cells) & (cells) & (cells) & (cells) \\
$\mathbf{0}$ & 8,165 & 6,894 & 8,065 & 6,713 & 7,863 & 6,290 & 7,867 & 6,304 \\
$\mathbf{1 0}$ & 837 & 1,167 & 767 & 1,060 & 679 & 906 & 681 & 910 \\
$\mathbf{2 0}$ & 68 & 160 & 60 & 142 & 43 & 98 & 44 & 100 \\
$\mathbf{3 0}$ & 3 & 11 & 3 & 12 & 1 & 4 & 1 & 4 \\
$\mathbf{4 0}$ & 0 & 0 & 0 & 1 & - & - & - & 0 \\
$\mathbf{5 0}$ & - & 0 & - & 0 & - & - & - & - \\
$\mathbf{6 0}$ & - & - & - & - & - & - & - & - \\
$\mathbf{7 0}$ & - & - & - & - & - & - & - & - \\
$\mathbf{8 0}$ & - & - & - & - & - & - & - & - \\
$\mathbf{9 0}$ & - & - & - & - & - & - & - & - \\
\hline
\end{tabular}




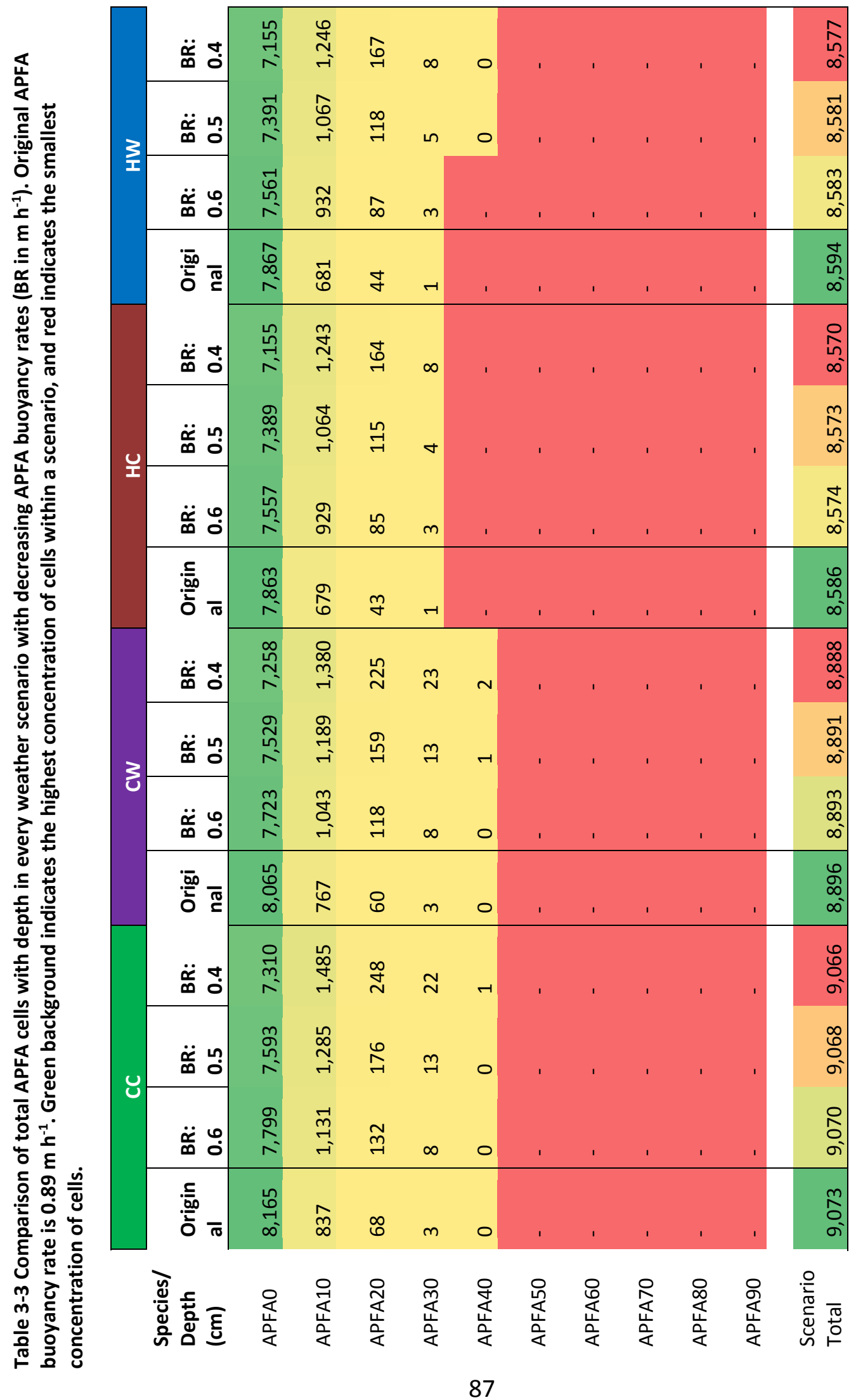




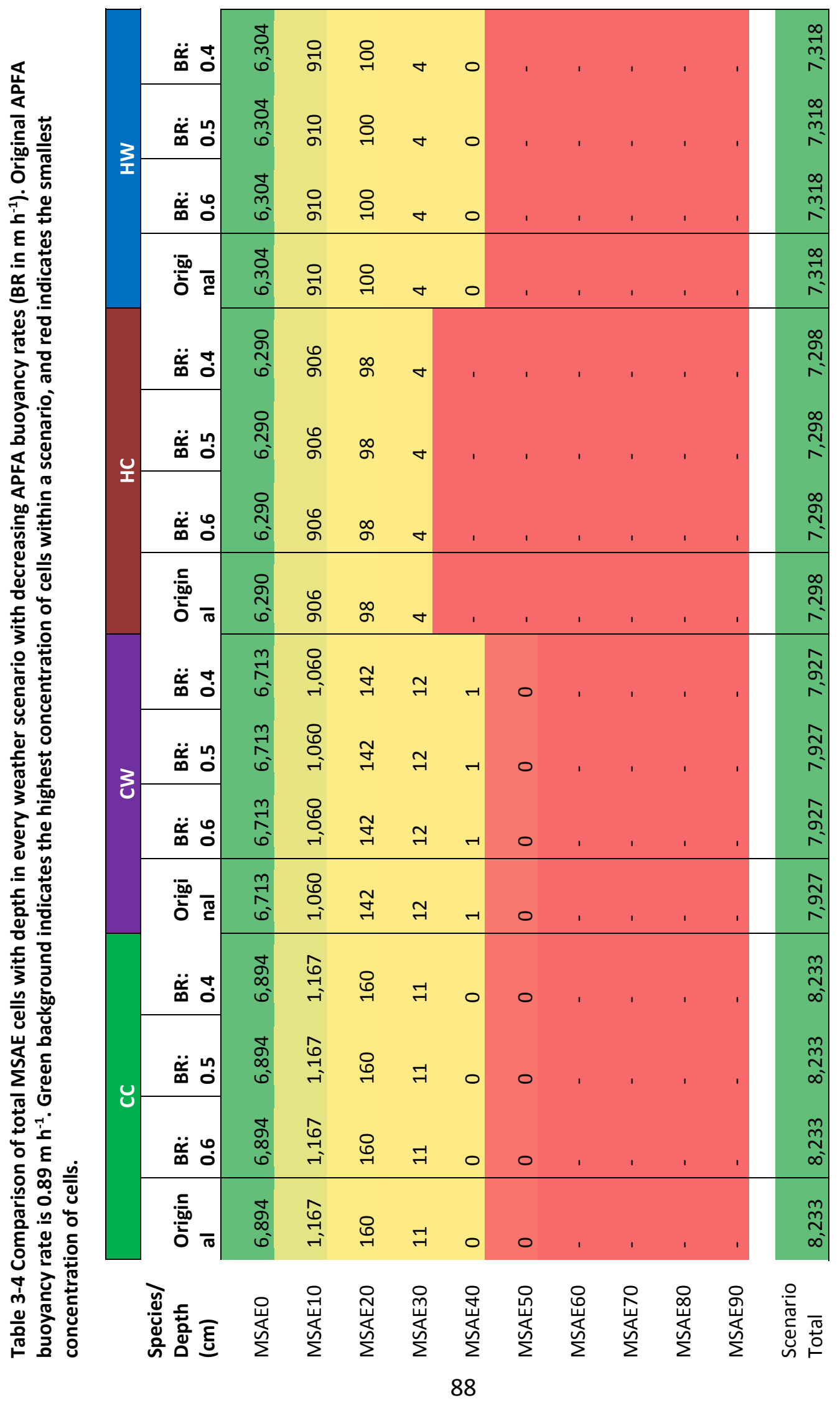




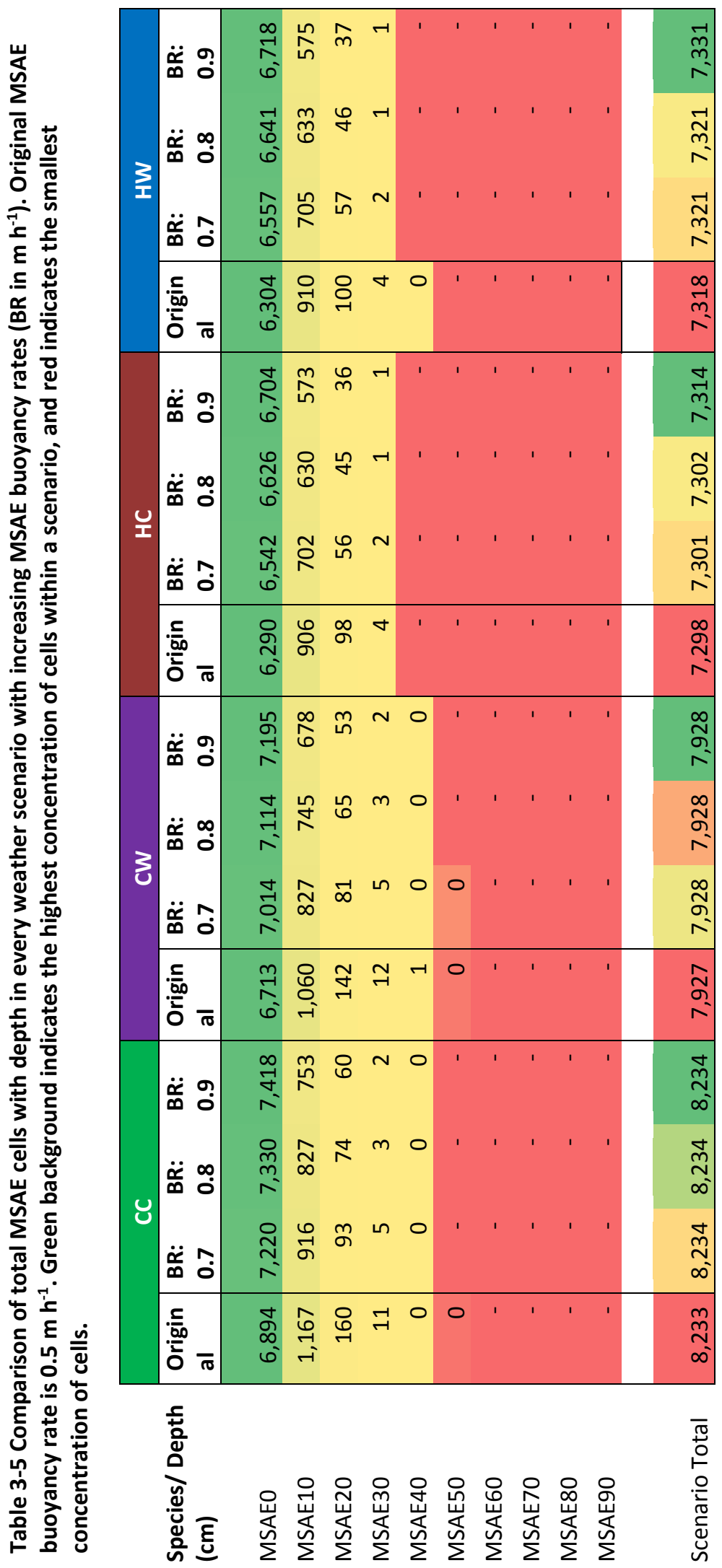




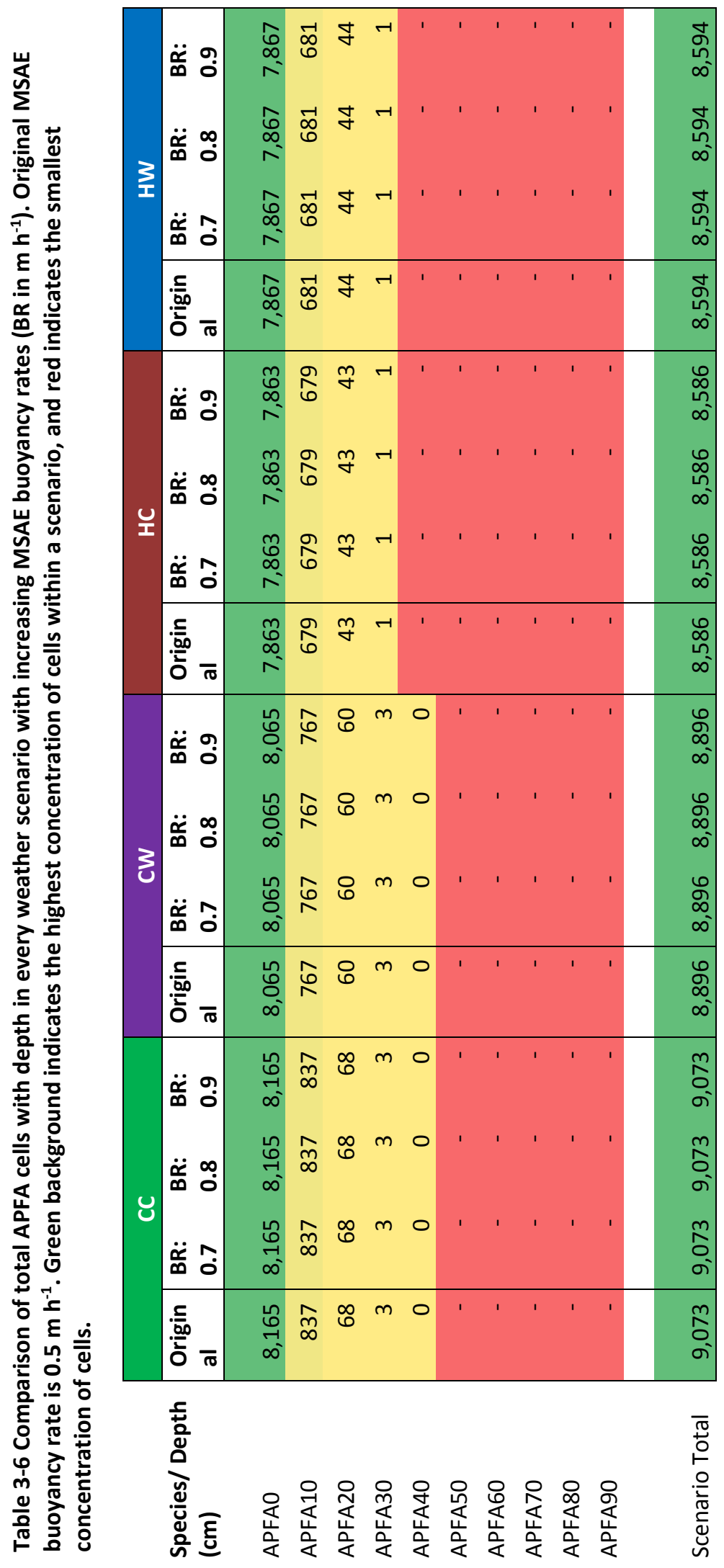


Table 3-7 Comparison of algal cell counts among different weather scenarios when MSAE parameters were changed to equal APFA's parameter, and the competition model was ran for a 5-day simulation.

\begin{tabular}{lllllllll}
\hline $\begin{array}{l}\text { MSAE } \\
\text { parameter } \\
\text { changed }\end{array}$ & Cool Calm & \multicolumn{2}{c}{ Cool Windy } & Hot Calm & \multicolumn{2}{l}{ Hot Windy } \\
\hline & $\begin{array}{l}\text { APFA } \\
\text { (cells) }\end{array}$ & $\begin{array}{l}\text { MSAE } \\
\text { (cells) }\end{array}$ & $\begin{array}{l}\text { APFA } \\
\text { (cells) }\end{array}$ & $\begin{array}{l}\text { MSAE } \\
\text { (cells) }\end{array}$ & $\begin{array}{l}\text { APFA } \\
\text { (cells) }\end{array}$ & $\begin{array}{l}\text { MSAE } \\
\text { (cells) }\end{array}$ & $\begin{array}{l}\text { APFA } \\
\text { (cells) }\end{array}$ & MSAE \\
(cells)
\end{tabular}

Table 3-8 Repeated measures ANOVA table comparing the concentration of APFA and MSAE cells between different weather scenarios when the optimum temperature growth curve for APFA was used for both species.

\begin{tabular}{lcc}
\hline Weather Scenario & F-ratio & P-value \\
\hline Cool calm & 0.005 & 0.95 \\
Cool windy & 0.4 & 0.53 \\
Hot calm & 2.3 & 0.13 \\
Hot windy & 3.7 & 0.05 \\
\hline
\end{tabular}




\section{Chapter 4. Conclusions and potential future work}

It is generally believed that climate change will promote and increase the frequency and intensity of cyanobacterial blooms due to their unique physiological adaptions (Paerl and Huisman 2008; Adrian et al. 2009; Carey et al. 2012; O'Neil et al. 2012). Thus, climate change will add more challenges to preventing and controlling blooms. To improve and devise new management methods for bloom control, it is critical to understand how cyanobacterial physiological adaptions interact with and is impacted by lake morphology, watershed geology, climate, and a lake's physical and chemical properties. It is also critical to better understand the physiological adaptions of lake specific ecotypes that may differ in light and temperature ranges (Paerl and Otten 2016) since competitive advantage is only exploited at the upper and lower end of a cyanobacteria's range tolerance. This thesis investigated buoyancy rates of Aphanizomenon flos-aquae (APFA) in Upper Klamath Lake (UKL), Oregon and contributed to a better understanding of buoyancy's role in cyanobacteria competition under varying mixing regimes.

\section{Aphanizomenon flos-aquae buoyancy in Upper Klamath Lake}

The buoyancy rate of APFA was calculated from in-lake specimens in Chapter 3. The investigation focused on determining if the vertical movement of APFA in UKL was significantly different from the published literature values. APFA movement through water was directly measured, in a lab setting, and the buoyancy rate of $0.89 \mathrm{~m} \mathrm{~h}^{-1}(+/-$ 
$0.34 \mathrm{~m} \mathrm{~h}^{-1}$ ) was calculated. A high degree of agreement was found between the buoyancy rate calculated and the published literature rate. The calculated buoyancy rate was not recorded in situ, and should not be interpreted as the in-lake buoyancy rate of APFA in UKL. However, the calculated buoyancy rate is an indicator of the physiological adaptions of APFA in UKL. APFA raft movement was recorded in a lab setting, and while some conditions replicated lake conditions (temperature, controlled light source), others did not replicate in-lake conditions (wind patterns, relative humidity). In situ APFA buoyancy rates in UKL have not been recorded (although Wood and Gartner (2010) recorded suspended particle movement, the particles were not verified as APFA colonies). More work is needed to confirm the range of APFA buoyancy rates in UKL.

\section{Modeling cyanobacteria competition under different mixing regimes}

Buoyancy regulation confers ecological advantages to cyanobacteria over sinking phytoplankton, however the role of buoyancy on competition between buoyant cyanobacteria is not well understood and depends on the species involved and the physical turbulence and thermal density gradients of the water column. The objective of this study was to model how weather patterns and algal buoyancy regulation influence the competition and growth of two bloom-forming buoyant cyanobacteria species (APFA and toxin-forming Microcystis aeruginosa (MSAE)) in UKL, Oregon. This was accomplished by modifying and combining a coupled one-dimensional hydrodynamic 
with an algal competition model, using lake specific physiological parameters following the example of Huisman et al. (2004). The hydrodynamic model is driven by meteorological variables, and is a system of four partial differential equations, which describe the mechanics of momentum, heat transfer, turbulent kinetic energy, and turbulent dissipation rate (Joehnk et al. 2008). The competition model tracked APFA and MSAE growth with depth over 5 days, and a sensitivity analysis was conducted on the buoyancy parameter.

In Chapter 2, weather data was collected, and turbulent mixing patterns were modeled for days with contrasting weather patterns. In Chapter 3, the turbulent mixing regimes modeled in Chapter 2 were applied it to short term competition for light for periods when both APFA and MSAE were in the water column. The hypothesized outcome of MSAE dominance under conditions of high water temperature did not occur. APFA was the better competitor under high temperatures and high turbulence. The hypothesis that increasing buoyancy rates would shift the outcome of competition did not occur either, as buoyancy was not found to be a function of algal concentration. APFA's optimum temperature growth curve was found to be the most important factor in determining the outcome of competition between APFA and MSAE. When MSAE's growth curve was set to equal APFA's growth curve, APFA ceased to be the fitter competitor in every weather scenario except for hot windy conditions. Since windy conditions negatively impacted MSAE concentrations, lakes managers could investigate localized mixing to suppress MSAE accumulations, if they become a reoccurring problem 
in UKL. While buoyancy might not play a large role in competition in UKL because the shallow lake regularly mixes and does not develop a thermocline, future work is needed in order to understand what governs the interaction between competing and coexisting buoyant cyanobacteria species.

\section{Management implications}

The goal of hydrologic withdrawal and aeration is to both weaken thermal stratification and deepen the mixing layer in order to suppress cyanobacteria blooms (Lehman et al. 2009). Inducing physical turbulence can be a fast acting technique that can be deployed quickly in response to a threat of a bloom. While nutrient limitation and control is often the ultimate long-term goal for reducing cyanobacteria blooms (Paerl et al. 2001; Paerl et al. 2001; Paerl and Otten 2016), alternative short-term management strategies should be surveyed and studied in order to address potential increasing cyanobacteria blooms under climate change (Arick Rouhe, personal communication). The competition model supports exploring the competition of buoyancy cyanobacteria under various mixing regimes. Results from the competition model indicates that high turbulence and lower temperatures in UKL can negatively impact MSAE accumulation, which agrees with previous findings from other lakes (Bonnet and Poulin 2002; Joehnk et al. 2008; Wu et al. 2015). While more study is needed to determine the key mechanisms of competition, coexistence, and the role of nutrients in the succession between APFA and MSAE, results from this study indicate 
that adapting short-term management techniques that mimic turbulence gradients that negatively impact MSAE accumulations could be viable if MSAE blooms become a persistent problem in late summer.

\section{Potential future work}

Future work is needed in order to understand how buoyancy is regulated in UKL. Previous studies have shown that the vertical distribution of MSAE depends on carbohydrate ballast dynamics and colony size (Wallace et al. 2000). To understand how buoyancy influences the competition between APFA and MSAE, we need to understand how key parameters of buoyancy differ between the two species present in UKL. Parameters include: the strength of gas vesicles, the speed of carbohydrate ballast accumulation, and the response time for physiological adjustment to an increase in light. Once the groundwork for buoyancy regulation comparison has been laid, an investigation of why APFA is so abundant in UKL can be conducted. Understanding the reason why APFA currently dominates UKL could help inform management strategies if UKL experiences a shift to more MSAE blooms due to climate change.

An in-depth observation experiment similar to work conducted by lbelings et al. (1991) would be beneficial in UKL. Their study consisted of a couple 24-hour observational periods, where measurements of carbohydrate, protein, turgor pressure, relative gas vacuole volume (RGV), buoyancy, and vertical distribution of phytoplankton species was taken every two hours throughout the water column. The depth of the 
mixed layer was determined by the lake's temperature profile and wind patterns. From this information, diurnal changes in carbohydrate, ballast content, RGV, and buoyancy can be tracked and compared to the vertical distribution of the species. Understanding relationship and patterns between the vertical distribution of species and diurnal changes in buoyancy is the first step to determining how buoyancy impacts the competition between APFA and MSAE.

Lastly, the one-dimensional hydrodynamic model could be used with a more thorough sensitivity analysis to look for weather patterns that create turbulence gradients that might result in a competitive difference between APFA and MSAE accumulations. Temperature and turbulence gradients can be simulated using hypothetical weather patterns that represent possible weather conditions under climate change scenarios. Water column analysis for MSAE and APFA would be a challenging and labor-intensive task that would be necessary to test the model predictions.

\section{Conclusion}

The impacts of climate change and human induced enrichment has the potential to change existing patterns of species interactions in lentic systems. Understanding how key physiological adaptions operate is the first step to assessing the scope of this impact and devising adaptable smart management strategies. Therefore, more research on the physiological determinants of competition/coexistence is necessary to understand mechanisms that influence competition for resources in lentic systems. 


\section{References}

Adrian R, Reilly CMO, Zagarese H, et al (2009) Lakes as sentinels of climate change. Limnol Oceanogr 54:2283-2297. doi: 10.4319/lo.2009.54.6_part_2.2283

Anderson TR (2005) Plankton functional type modelling: Running before we can walk? J Plankton Res 27:1073-1081. doi: 10.1093/plankt/fbi076

Bailey-Watts A, Wise E, Kirika A (1987) An experiment in phytoplankton ecology and applied fishery management: effects of artificial aeration on troublesome algal blooms in a small eutrophic loch. Aquac Res 18:259-275. doi: 10.1111/j.13652109.1987.tb00146.x

Barr BR, Koopman ME, Williams CD, et al (2010) Preparing for Climate Change in the Klamath Basin. National Center for Conservation Science and Policy, Corvallis, Oregon

Bengfort M, Malchow $\mathrm{H}$ (2016) Vertical mixing and hysteresis in the competition of buoyant and non-buoyant plankton prey species in a shallow lake. Ecol Modell 323:51-60. doi: 10.1016/j.ecolmodel.2015.12.009

Bonnet MP, Poulin M (2002) Numerical modelling of the planktonic succession in a nutrient-rich reservoir: Environmental and physiological factors leading to Microcystis aeruginosa dominance. Ecol Modell 156:93-112. doi: 10.1016/S03043800(02)00132-1

Booker M, Walsby A (1981) Bloom formation and stratification by a planktonic bluegreen alga in an experimental water column. Br Phycol J 16:411-421. doi: 10.1080/00071618100650471

Brookes JD, Ganf G (2001) Variations in the buoyancy response of Microcystis aeruginosa to nitrogen, phosphorus and light. J Plankton Res 23:1399-1411.

Carey C, Ibelings B, Hoffmann E, et al (2012) Eco-physiological adaptations that favour freshwater cyanobacteria in a changing climate. Water Res 46:1394-407. doi: 10.1016/j.watres.2011.12.016

Carmichael WW, Jones C, Mahmood N, et al (1985) Algal toxins and water-based diseases. Crititcal Rev Environ Control 15:275-313. 
Chen C (1970) Concepts and utilities of ecological models. J Sanit Eng Div 96:1085-1097.

Chung SW, Imberger J, Hipsey MR, Lee HS (2014) The influence of physical and physiological processes on the spatial heterogeneity of a Microcystis bloom in a stratified reservoir. Ecol Modell 289:133-149. doi:

10.1016/j.ecolmodel.2014.07.010

Codd G (1995) Cyanobacterial toxins: occurrence, properties and biological significance. Water Sci Technol 32:149-156.

Dingman S (2002) Physical Hydrology, 2nd edn. Waveland Press, Inc., Long Grove, II

Dodson S (2005) Introduction to Limnology, 1st edn. McGraw-Hill, Boston, MA

Edinger JE, Duttweiler DW, Geyer JC (1968) The Response of Water Temperatures to Meteorological Condition. Water Resour Res 4:1137-1143.

Eilers JM, Kann J, Cornett J, et al (2004) Paleolimnological evidence of change in a shallow, hypereutrophic lake: Upper Klamath Lake, Oregon, USA. Hydrobiologia 520:7-18. doi: 10.1023/B:HYDR.0000027718.95901.ae

Eldridge SLC, Wherry SA, Wood T (2014) Statistical Analysis of the Water-Quality Monitoring Program, Upper Klamath Lake, Oregon , and Optimization of the Program for 2013 and Beyond. Reston, Virginia

Eldridge SL, Wood T, Echols KR, Topping BR (2013) Microcystins, nutrient dynamics, and other environmental factors during blooms of non-microcystin-producing Aphanizomenon flos-aquae in Upper Klamath Lake, Oregon, 2009. Lake Reserv Manag 29:68-81. doi: 10.1080/10402381.2013.775199

Fogg G (1969) The Physiology of an Algal Nuisance. Proc R Soc London Ser B, Biol Sci 173:175-189.

Foy RH, Gibson CE, Smith RV (1976) The influence of daylength, light intensity and temperature on the growth rates of planktonic blue-green algae. Br Phycol J 11:151-163. doi: 10.1080/00071617600650181

Fritz JJ, Meredith DD, Middleton AC (1980) Non-steady state bulk temperature determination for stabilization ponds. Water Res 14:413-420. doi: 10.1016/00431354(80)90205-5 
Ganf G, Oliver R, Walsby A (1989) Optical properties of Gas-vacuolate cells and colonies of Microcystis in relation to light Attenuation in a Turbid, Stratified Reservoir (Mount Bold Reservoir, South Australia). Aust J Mar Freshw Res 40:595-611.

Gillett N (2015) Long-term phytoplankton dynamics in Upper Klamath Lake with considerations of trophic structure and climate change.

Henderson-Sellers B (1984) Engineering Limnology. Pitman Advanced Publishing Program, Boston, MA

Huisman J, Jonker RR, Zonneveld C, Weissing FJ (1999) Competition for light between phytoplankton species: Experimental tests of mechanistic theory. Ecology 80:211222. doi: 10.1890/0012-9658(1999)080[0211:CFLBPS]2.0.CO;2

Huisman J, Sharples J, Stroom JM, et al (2004) Changes in Turbulent Mixing Shift Competition for Light between Phytoplankton Species. Ecology 85:2960-2970. doi: 10.1890/03-0763

Huisman J, Sommeijer B (2002) Population dynamics of sinking phytoplankton in lightlimited environments: Simulation techniques and critical parameters. J Sea Res 48:83-96. doi: 10.1016/S1385-1101(02)00137-5

Humphries SE, Lyne VD (1988) Cyanophyte blooms: The role of cell buoyancy. Limnol Oceanogr 33:79-91. doi: 10.4319/lo.1988.33.1.0079

Hurley KA (1977) Vertical heat transport mechanisms in lakes and reservoirs. Massachusetts Institute of Technology

Ibelings B, Mur L (1991) Microprofiles of photosynthesis and oxygen concentration in Microcystis sp. scums. FEMS Microbiol Ecol 9:195-203. doi: 10.1111/j.15746941.1991.tb01753.x

Ibelings B, Mur L (1992) Microprofiles of photosynthesis and oxygen concentration in Microcystis sp. scums. FEMS Microbiol Ecol 9:195-203. doi: 10.1111/j.15746941.1991.tb01753.x

Ibelings B, Mur L, Walsby A (1991) Diurnal changes in buoyancy and vertical distribution in populations of Microcystis in tow shallow lakes. J Plankton Res 13:419-436.

Jacobson L, Hallmann M (1982) Polyphosphate metabolism in the blue-green alga Microcystis aeruginosa. J Plankton Res 4:481-488. 
Joehnk K, Huisman J, Sharples J, et al (2008) Summer heatwaves promote blooms of harmful cyanobacteria. Glob Chang Biol 14:495-512. doi: 10.1111/j.1365-

2486.2007.01510.x

Joehnk K, Hutter K (2004) Continuum Methods of Physical Modeling - Continuum Mechanics, Dimensional Analysis, Turbulence. Springer, Berlin, Germany

Joehnk K, Umlauf L (2001) Modelling the metalimnetic oxygen minimum in a medium sized alpine lake. Ecol Modell 136:67-80. doi: 10.1016/S0304-3800(00)00381-1

Johnson D (1985) Atlas of Oregon Lakes. Oregon State University Press, Corvallis, Oregon

Kahn J (1998) Ecology and water quality dynamics of a shallow hypereutrophic lake dominated by cyanobacteria (Aphanizomenon flos-aquae). University of North Carolina at Chapel Hill

Kestin J, Sokolov M, Wakeham WA (1978) Viscosity of liquid water in the range of $-8 \mathrm{C}$ to 150C. Tel-Aviv, Israel

Klausmeier C, Litchman E (2001) Algal games: The vertical distribution of phytoplankton in poorly mixed water columns. Limnol Oceanogr 46:1998-2007. doi: 10.4319/lo.2001.46.8.1998

Kromkamp J, Walsby A (1990) A computer model of buoyancy and vertical migration in cyanobacteria. J Plankton Res 12:161-183.

Lampert W (1981) Inhibitory and Toxic Effects of Blue-green Algae on Daphnia. Int Rev der gesamten Hydrobiol und Hydrogr 66:285-298.

Lehman EM, McDonald KE, Lehman JT (2009) Whole lake selective withdrawal experiment to control harmful cyanobacteria in an urban impoundment. Water Res 43:1187-1198. doi: 10.1016/j.watres.2008.12.007

Lewis W (1983) Interception of atmospheric fixed nitrogen as an adaptive advantage of scum formation in blue-green algae. J Phycol 19:534-536.

Lindenberg M, Hoilman G, Wood T (2009) Water quality conditions in Upper Klamath and Agency Lakes, Oregon, 2006.

Livingstone D (2003) Impact of secular climate change on the thermal structure of a large temperate central european lake. Dübendorf, Switzerland 
Losordo TM (1988) The characterization and modeling of thermal and oxygen stratification in aquaculture ponds. University of California, Davis

Losordo TM, Piedrahita RH (1991) Modelling temperature variation and thermal stratification in shallow aquaculture ponds. Ecol Modell 54:189-226.

Mccauley E, Murdoch WW (1987) Cyclic and Stable Populations: Plankton as Paradigm. Am Nat 129:97-121.

McDonald KE, Lehman JT (2013) Dynamics of Aphanizomenon and Microcystis (cyanobacteria) during experimental manipulation of an urban impoundment. Lake Reserv Manag 29:103-115. doi: 10.1080/10402381.2013.800172

Mehnert G, Leunert F, Cires S, et al (2010) Competitiveness of invasive and native cyanobacteria from temperate freshwaters under various light and temperature conditions. J Plankton Res 32:1009-1021. doi: 10.1093/plankt/fbq033

Moore SK, Trainer VL, Mantua NJ, et al (2008) Impacts of climate variability and future climate change on harmful algal blooms and human health. Environ Heal 7:S4.

Moreno-Ostos E, Cruz-Pizarro L, Basanta A, George DG (2009) The influence of windinduced mixing on the vertical distribution of buoyant and sinking phytoplankton species. Aquat Ecol 43:271-284. doi: 10.1007/s10452-008-9167-x

O'Neil JM, Davis TW, Burford M a., Gobler CJ (2012) The rise of harmful cyanobacteria blooms: The potential roles of eutrophication and climate change. Harmful Algae 14:313-334. doi: 10.1016/j.hal.2011.10.027

Orlob G (1981) Models for Water Quality Management. In: Biswas A (ed) Models for stratified impoundments. McGraw-Hill, New York, pp 273-313

Paerl H, Fulton RS, Moisander PH, Dyble J (2001) Harmful freshwater algal blooms, With an emphasis on cyanobacteria. Sci World J 1:76-113. doi: 10.1100/tsw.2001.16

Paerl H, Hall NS, Calandrino ES (2011) Controlling harmful cyanobacterial blooms in a world experiencing anthropogenic and climatic-induced change. Sci Total Environ 409:1739-1745. doi: 10.1016/j.scitotenv.2011.02.001

Paerl H, Huisman J (2008) Climate. Blooms like it hot. Science 320:57-8. doi: $10.1126 /$ science. 1155398 
Paerl H, Huisman J (2009) Climate change: a catalyst for global expansion of harmful cyanobacterial blooms. Environ Microbiol Rep 1:27-37. doi: 10.1111/j.17582229.2008.00004.x

Paerl H, Otten TG (2016) Duelling "CyanoHABs": Unravelling the environmental drivers controlling dominance and succession among diazotrophic and non-N2-fixing harmful cyanobacteria. Environ Microbiol 18:316-324. doi: 10.1111/14622920.13035

Paerl H, Otten TG (2013) Harmful Cyanobacterial Blooms: Causes, Consequences, and Controls. Microb Ecol 65:995-1010. doi: 10.1007/s00248-012-0159-y

Paerl H, Ustach J (1982) Blue-green algal scums: An explanation for their occurrence during freshwater blooms. Limnol Oceanogr 27:212-217. doi:

10.4319/lo.1982.27.2.0212

Pham S V, Leavitt PR, Mcgowan S, Peres-neto P (2008) Spatial variability of climate and land-use effects on lakes of the northern Great Plains. Limnol Oceanogr 53:728742.

Pironneau M (1994) Analysis of the K-Epsilon Turbulence Model. Wiley \& Sons, Chichester

Reynolds C (1997) Vegetation Process in the Pelagic: A Model for Ecosystem Theory. Ecology Institute, Oldendorf

Reynolds C (1973) Growth and Buoyancy of Microcystis aeruginosa Kutz. emend. Elenkin in a Shallow Eutrophic Lake. Proc R Soc B Biol Sci 184:29-50. doi:

10.1098/rspb.1973.0029

Reynolds C (1972) Growth, gas vacuolation and buoyancy in a natural population of a planktonic blue-green alga. Freshw Biol 2:87-106. doi: 10.1111/j.1365-

2427.1972.tb00364.x

Reynolds C (2006) Ecology of Phytoplankton. Cambridge University Press, Cambridge

Reynolds C (1987) Cyanobacterial Water-Blooms. Adv Bot Res 13:67-143. doi: 10.1016/S0065-2296(08)60341-9

Reynolds C, Oliver RL, Walsby A (1987) Cyanobacterial dominance: The role of buoyancy regulation in dynamic lake environments. New Zeal J Mar Freshw Res 21:379-90. doi: 10.1080/00288330.1987.9516234 
Reynolds C, Walsby A (1975) Water-blooms. Biol Rev 50:437-481.

Rigosi A, Carey C, Ibelings B, Brookes J (2014) The interaction between climate warming and eutrophication to promote cyanobacteria is dependent on trophic state and varies among taxa. Limnol Oceanogr 59:99-114. doi: 10.4319/lo.2014.59.01.0099

Robarts RD, Zohary T (1987) Temperature effects on photosynthetic capacity, respiration, and growth rates of bloom-forming cyanobacteria. New Zeal J Mar Freshw Res 21:391-399. doi: 10.1080/00288330.1987.9516235

Robson B, Hamilton D (2004) Three-dimensional modelling of a Microcystis bloom event in the Swan River estuary, Western Australia. Ecol Modell 174:203-222. doi: 10.1016/j.ecolmodel.2004.01.006

Rodi W (1993) Turbulence Models and their Application in Hydraulics - a State of the Art Review, 3rd edn. Balkema, Rotterdam

Schindler DW (1990) Experimental Perturbations of Whole Lakes as Tests of Hypotheses concerning Ecosystem Structure and Function. Oikos 57:25-41.

Sciences S, Design J\& T, Atkins, et al (2013) Water Quality Improvement Techniques for the Upper Klamath Basin: A Technical Workshop and Project Conceptual Design. Oakland, CA

Shimoda Y, Arhonditsis GB (2016) Phytoplankton functional type modelling: Running before we can walk? A critical evaluation of the current state of knowledge. Ecol Modell 320:29-43. doi: 10.1016/j.ecolmodel.2015.08.029

Smith VH (1983) Low Nitrogen to Phosphorus Ratios Favor Dominance by Blue-Green Algae in Lake Phytoplankton. Science 221:669-671. doi: 10.1126/science.221.4611.669

Steele J (1974) The Structure of Marine Ecosystems. Harvard University Press, Cambridge

Sundaram T, Rehm R (1973) The seasonal thermal structure of deep temperate lakes. Tellus 25:157-167.

Takamura N (1987) Uptake of $13 \mathrm{C}$ and $15 \mathrm{~N}$ (ammonium, nitrate and urea) by Microcystis in Lake Kasumigaura. J Plankton Res 9:151-165. 
Uehlinger von $U$ (1981) Experimental studies on the autecology of Aphanizomenon flosaquae. Hydrobiologia 60:260-288.

Van Nes EH, Scheffer M (2005) A strategy to improve the contribution of complex simulation models to ecological theory. Ecol Modell 185:153-164. doi:

10.1016/j.ecolmodel.2004.12.001

Walker WW (2001) Development of a Phosphorus TMDL for Upper Klamath Lake, Oregon. Bend, Oregon

Wallace BB, Bailey MC, Hamilton D (2000) Simulation of vertical position of buoyancy regulating Microcystis aeruginosa in a shallow eutrophic lake. Aquat Sci 62:320333. doi: 10.1007/PL00001338

Walsby A (1994) Gas vesicles. Microbiol Rev 58:94-144. doi: 10.1146/annurev.pp.26.060175.002235

Walsby A, Hayes PK, Boje R (1995) The gas vesicles, buoyancy and vertical distribution of cyanobacteria in the Baltic Sea. Eur J Phycol 30:87-94. doi: $10.1080 / 09670269500650851$

Water Resources Engineers (1968) Prediction of thermal energy distribution in streams and reservoirs. State of California

Wetzel R (1983) Limnology. Saunders, Philadelphia, PA

Winder M, Hunter DA (2008) Temporal organization of phytoplankton communities linked to physical forcing. Oecologia 156:179-192. doi: 10.1007/s00442-008-0964-7

Winder M, Schindler D (2004) Climate Change Uncouples Trophic Interactions in an Aquatic Ecosystem. Ecology 85:2100-2106.

Wood T, Fuhrer G, Morace J (1996) Relation Between Selected Water-Quality Variables and Lake Level in Upper Klamath and Agency Lakes, Oregon. Portland, Oregon

Wood T, Gartner J (2010) Use of acoustic backscatter and vertical velocity to estimate concentration and dynamics of suspended solids in Upper Klamath Lake, southcentral Oregon: Implications for Aphanizomenon flos-aquae.

Wroblewski J, Sarmiento J, Flier G (1988) n ocean basin scale model of plankton dynamics in the North Atlantic. I. Solutions for the climatological oceanographic conditions in May. Global Biogeochem Cycles 2:199-218. 
Wu X, Kong F (2009) Effects of light and wind speed on the vertical distribution of Microcystis aeruginosa colonies of different sizes during a summer bloom. Int Rev Hydrobiol 94:258-266. doi: 10.1002/iroh.200811141

Wu Y, Li L, Zheng L, et al (2015) Patterns of succession between bloom-forming cyanobacteria Aphanizomenon flos-aquae and Microcystis and related environmental factors in large, shallow Dianchi Lake, China. Hydrobiologia. doi: $10.1007 / \mathrm{s} 10750-015-2392-0$

Yamamoto Y (2009) Environmental factors that determine the occurrence and seasonal dynamics of Aphanizomenon flos-aquae. J Limnol 68:122-132. 


\section{Appendix A. Hydrodynamic model}

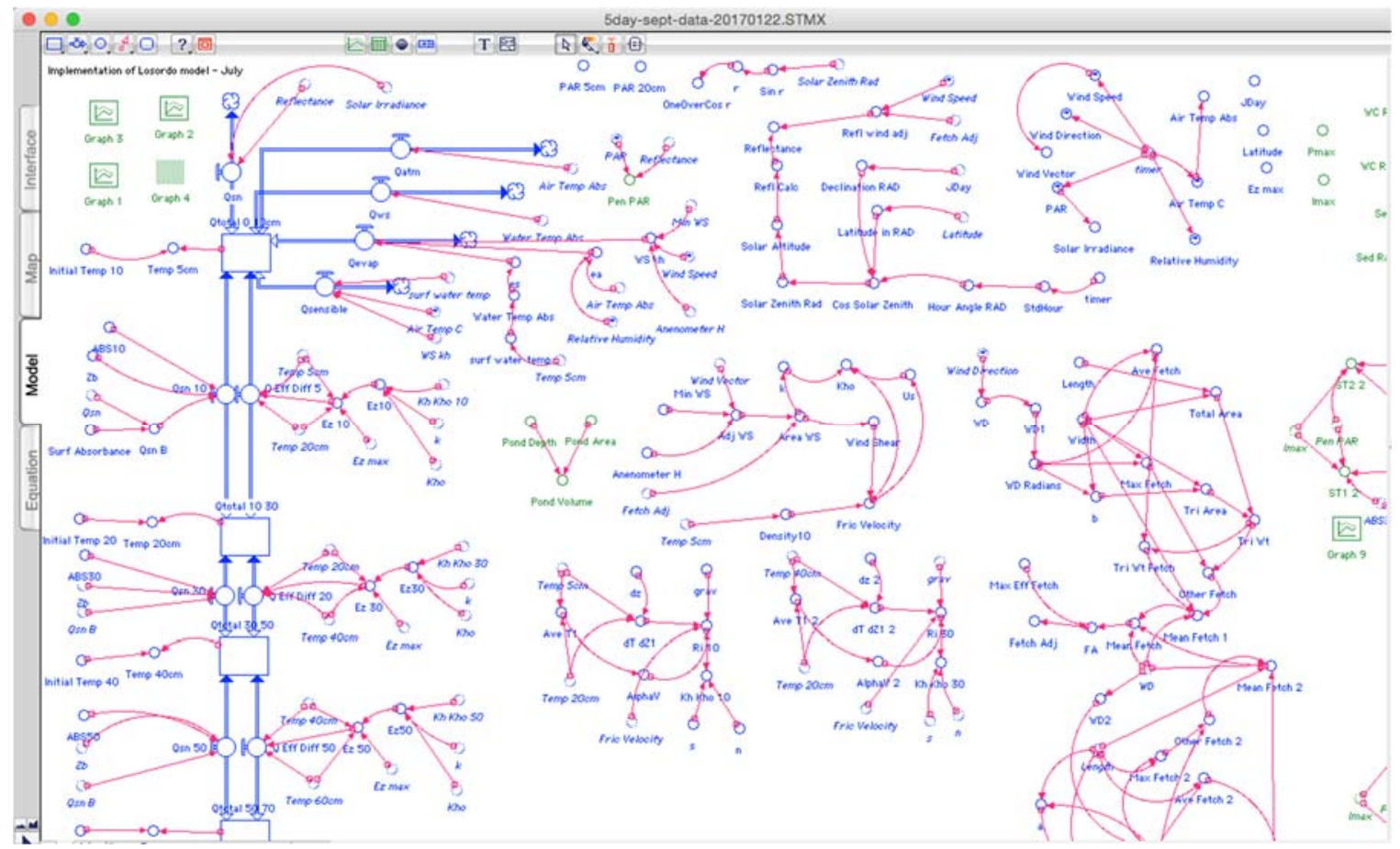

Appendix Figure A-1 Model diagram for the one-dimensional hydrodynamic model, implemented in STELLA ${ }^{\text {TM }}$. 


\section{Model code}

conc_0_10 $(\mathrm{t})=$ conc_0_10 $(\mathrm{t}-\mathrm{dt})+\left(-\mathrm{DZ} \_10\right) * \mathrm{dt}$

INIT conc_0_10 $=30$

OUTFLOWS:

DZ_10 $=$ Ez_10* (conc_0_10-conc_10_30)/(.2-.05)*1/.1

conc_10_30 $(\mathrm{t})=$ conc_10_30 $(\mathrm{t}-\mathrm{dt})+\left(\mathrm{DZ} \_10-\mathrm{Dz} \_30\right) * \mathrm{dt}$

INIT conc_10_30 $=30$

INFLOWS:

DZ_10 $=$ Ez_10* $($ conc_0_10-conc_10_30)/(.2-.05)*1/.1

OUTFLOWS:

Dz_30 $=$ Ez_30*(conc_10_30-conc_30_50)/(.4-.2)*1/.2

conc_30_50 $(\mathrm{t})=$ conc_30_50 $(\mathrm{t}-\mathrm{dt})+\left(\mathrm{Dz} \_30-\mathrm{Dz} \_50\right) * \mathrm{dt}$

INIT conc_30_50 $=30$

INFLOWS:

Dz_30 $=$ Ez_30* (conc_10_30-conc_30_50)/(.4-.2)*1/.2

OUTFLOWS:

Dz_50 $=$ Ez_50*(conc_30_50-conc_50_70)/(.6-.4)*1/.2

conc_50_70 $(\mathrm{t})=$ conc_50_70 $(\mathrm{t}-\mathrm{dt})+\left(\mathrm{Dz} \_50-\mathrm{Dz} \_70\right) * \mathrm{dt}$

INIT conc_50_70 $=30$

INFLOWS:

Dz_50 = Ez_50* (conc_30_50-conc_50_70)/(.6-.4)*1/.2

OUTFLOWS:

$\mathrm{Dz}$ 70 $=$ Ez_70*(conc_50_70-conc_70_90)/(.8-.6)*1/.2

conc_70_90 $(\mathrm{t})=$ conc_70_90 $(\mathrm{t}-\mathrm{dt})+\left(\mathrm{Dz}\right.$-70 $\left.-\mathrm{Dz} \_90\right) * \mathrm{dt}$

INIT conc_70_90 $=30$

INFLOWS:

$\mathrm{Dz}$-70 $=\mathrm{Ez}$-70 $*($ conc_50_70-conc_70_90)/(.8-.6)*1/.2

OUTFLOWS:

Dz_90 $=$ Ez_90 $*($ conc_70_90-conc_90_110)/(1-.8)*1/.2

conc_90_110 $(\mathrm{t})=$ conc_90_110 $(\mathrm{t}-\mathrm{dt})+\left(\mathrm{Dz} \_90\right) * \mathrm{dt}$

INIT conc_90_110 $=30$

INFLOWS:

Dz_90 $=$ Ez_90*(conc_70_90-conc_90_110)/(1-.8)*1/.2

Qtotal_0_10cm $(\mathrm{t})=$ Qtotal_0_10cm $(\mathrm{t}$ - dt $)+($ Qsn + Qatm + Qws + Qevap + Qsensible - Qsn_10 -

Q_Eff_Diff_5)*dt

INIT Qtotal_0_10 $10 \mathrm{~cm}=0$

INFLOWS:

Qsn $=($ Solar_Irradiance $* 3600) *(1-$ Reflectance $)$

Qatm $=\left(2.042 * 10^{\wedge}(-7)\right) *\left(0.398 * 10^{\wedge}(-5) *\right.$ Air_Temp_Abs^(2.148) $) *$ Air_Temp_Abs^(4)

Qws $=-\left(\left(\right.\right.$ Water_Temp_Abs^4)*0.97* $\left.\left(2.042^{*} 10^{\wedge}(-7)\right) * 1.0\right)$

Qevap $=-(5.0593 *$ WS_kh*(es-ea) $)$

Qsensible $=-(1.5701 *$ WS_kh*(surf_water_temp-Air_Temp_C $))$

OUTFLOWS:

Qsn_10 = Qsn_B*(EXP(-ABS10*(10-Zb)))

Q_Eff_Diff_5 $=\left(4.1816 * 0.001 * 10000 *\right.$ Ez_10* $\left(\left(T e m p \_5 \mathrm{~cm}-\right.\right.$ Temp_20cm $\left.\left.) / 10\right)\right)$

Qtotal_10_30 $(\mathrm{t})=$ Qtotal_10_30 $(\mathrm{t}-\mathrm{dt})+\left(\mathrm{Qsn} \_10+\right.$ Q_Eff_Diff_5 - Qsn_30 - Q_Eff_Diff_20 $) * \mathrm{dt}$ INIT Qtotal_10_30 = 0

INFLOWS:

Qsn_10 = Qsn_B*(EXP(-ABS10*(10-Zb)))

Q_Eff_Diff_5 $=\left(4.1816 * 0.001 * 10000 * E z \_10 *\left(\left(T e m p \_5 \mathrm{~cm}-T e m p \_20 \mathrm{~cm}\right) / 10\right)\right)$ 
OUTFLOWS:

Qsn_30 = Qsn_B*EXP(-ABS30*(30-Zb))

Q_Eff_Diff_20 $=\left(4.1816 * 001 * 10000 * E z \_30 *\left(\left(T e m p \_20 \mathrm{~cm}-T e m p \_40 \mathrm{~cm}\right) / 20\right)\right)$

Qtotal_30_50(t) $=$ Qtotal_30_50(t - dt) + (Qsn_30 + Q_Eff_Diff_20 - Qsn_50 - Q_Eff_Diff_50) * dt INIT Qtotal_30_50=0

INFLOWS:

Qsn_30 = Qsn_B*EXP(-ABS30*(30-Zb))

Q_Eff_Diff_20 $=\left(4.1816 * .001 * 10000 * E z \_30 *\left(\left(T e m p \_20 \mathrm{~cm}-T e m p \_40 \mathrm{~cm}\right) / 20\right)\right)$ OUTFLOWS:

Qsn_50 = Qsn_B*EXP(-ABS50*(50-Zb))

Q_Eff_Diff_50 $=\left(4.1816 * .001 * 10000 * E z \_50 *\left(\left(T e m p \_40 \mathrm{~cm}-T e m p \_60 \mathrm{~cm}\right) / 20\right)\right)$

Qtotal_50_70(t) $=$ Qtotal_50_70 $(\mathrm{t}-\mathrm{dt})+($ Qsn_50 + Q_Eff_Diff_50 - Qsn_70 - Q_Eff_Diff_70) * dt INIT Qtotal_50_70=0

INFLOWS:

Qsn_50 = Qsn_B*EXP(-ABS50*(50-Zb))

Q_Eff_Diff_50 $=\left(4.1816 * 001 * 10000 * E z \_50 *\left(\left(T e m p \_40 \mathrm{~cm}-T e m p \_60 \mathrm{~cm}\right) / 20\right)\right)$

OUTFLOWS:

Qsn_70 = Qsn_B*EXP(-ABS70*(70-Zb))

Q_Eff_Diff_70 $=\left(4.1816 * 001 * 10000 * E z \_70 *\left(\left(T e m p \_60 \mathrm{~cm}-T e m p \_80 \mathrm{~cm}\right) / 20\right)\right)$

Qtotal_70_90(t) $=$ Qtotal_70_90 $(\mathrm{t}-\mathrm{dt})+($ Qsn_70 + Q_Eff_Diff_70 - Qsn_90 - Q_Eff_Diff_90) * dt INIT Qtotal_70_90 = 0

INFLOWS:

Qsn_70 = Qsn_B*EXP(-ABS70*(70-Zb))

Q_Eff_Diff_70 $=\left(4.1816 * .001 * 10000 * E z \_70 *\left(\left(T e m p \_60 \mathrm{~cm}-T e m p \_80 \mathrm{~cm}\right) / 20\right)\right)$

OUTFLOWS:

Qsn_90 = Qsn_B*EXP(-ABS90*(90-Zb))

Q_Eff_Diff_90 $=\left(4.1816 * .001 * 10000 * E z \_90 *\left(\left(T e m p \_80 \mathrm{~cm}-T e m p \_100 \mathrm{~cm}\right) / 20\right)\right)$

Qtotal_90_110(t) $=$ Qtotal_90_110(t - dt) + (Qsn_90 + Q_Eff_Diff_90 - Qsn_Bottom - Cond_S $)$ dt INIT Qtotal_90_110=0

INFLOWS:

Qsn_90 = Qsn_B*EXP(-ABS90* $(90-Z b))$

Q_Eff_Diff_90 $=\left(4.1816 * 001 * 10000 * E z \_90 *\left(\left(T e m p \_80 \mathrm{~cm}-T e m p \_100 \mathrm{~cm}\right) / 20\right)\right)$ OUTFLOWS:

Qsn_Bottom = Qsn_B*EXP(-ABS100*(110-Zb))

Cond_S $=\mathrm{Ks} *\left(\left(T e m p \_100 \mathrm{~cm}-\right.\right.$ Temp_Sediment $\left.) / 0.20\right) * 3.6 * 1$

$\mathrm{Q}_{-} \operatorname{Earth}(\mathrm{t})=\mathrm{Q}_{-} \operatorname{Earth}(\mathrm{t}-\mathrm{dt})+($ Conductivity_E$) * d t$

INIT Q_Earth $=0$

INFLOWS:

Conductivity_E $=\mathrm{Ke} *\left(\left(T e m p \_S e d i m e n t-T e m p \_E a r t h\right) / 5\right) * 3.6 * 1$

Q_Sediment $(\mathrm{t})=$ Q_Sediment $(\mathrm{t}-\mathrm{dt})+(\mathrm{Q}$ sn_Bottom + Cond_S - Conductivity_E $) * d t$

INIT Q_Sediment $=0$

INFLOWS:

Qsn_Bottom = Qsn_B*EXP(-ABS100*(110-Zb))

Cond_S $=\mathrm{Ks} *\left(\left(T e m p \_100 \mathrm{~cm}-\right.\right.$ Temp_Sediment $\left.) / 0.20\right) * 3.6 * 1$

OUTFLOWS:

Conductivity_E $=K \mathrm{Ke}^{*}(($ Temp_Sediment-Temp_Earth $) / 5) * 3.6 * 1$

$\mathrm{a}=\mathrm{TAN}\left((\mathrm{PI} * 5)-\mathrm{WD} \_ \text {Radians_2 }\right)^{*}$ Length

ABSO $=0.64$

$\mathrm{ABS} 10=0.34$

$\mathrm{ABS} 100=0.001$ 


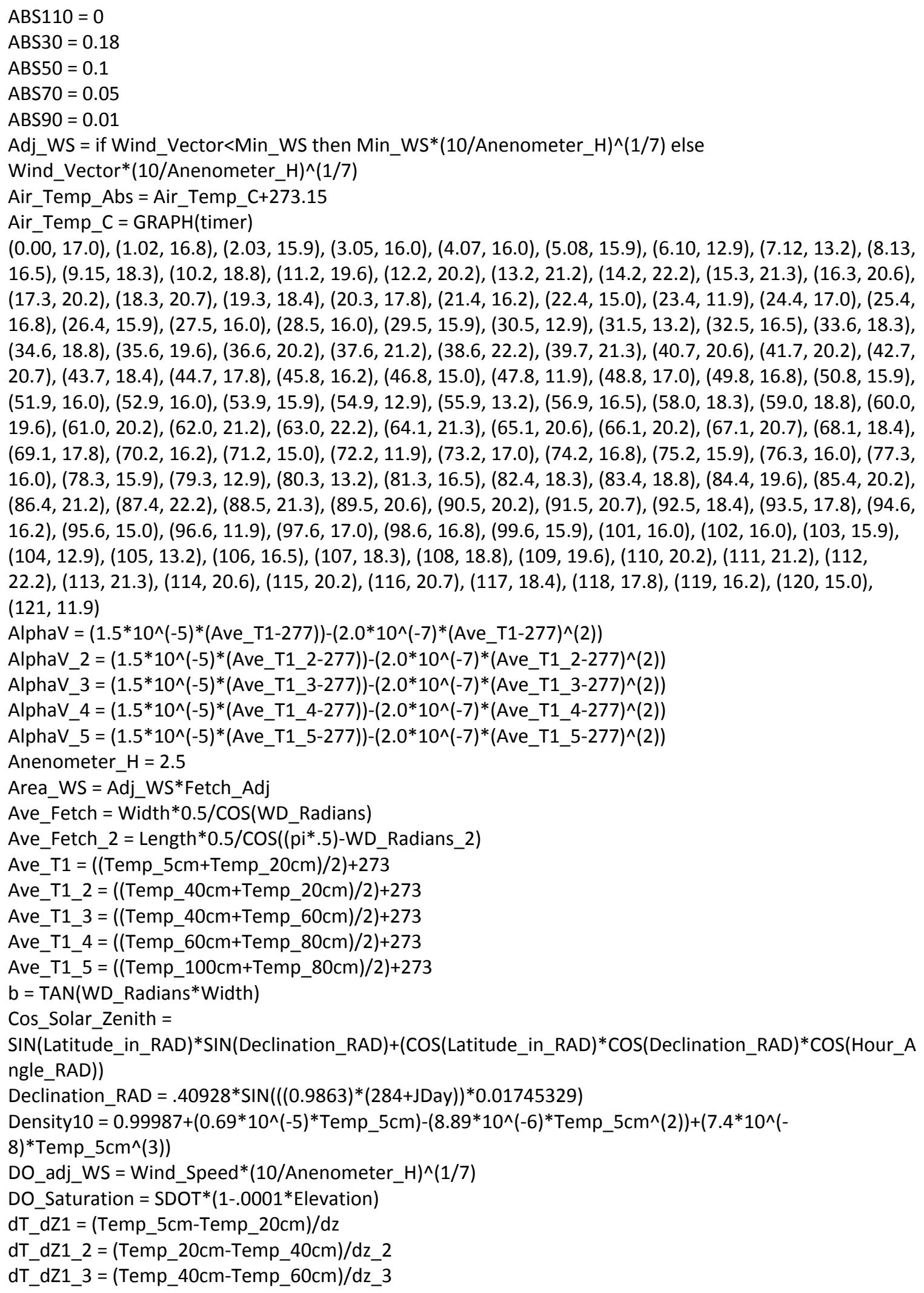




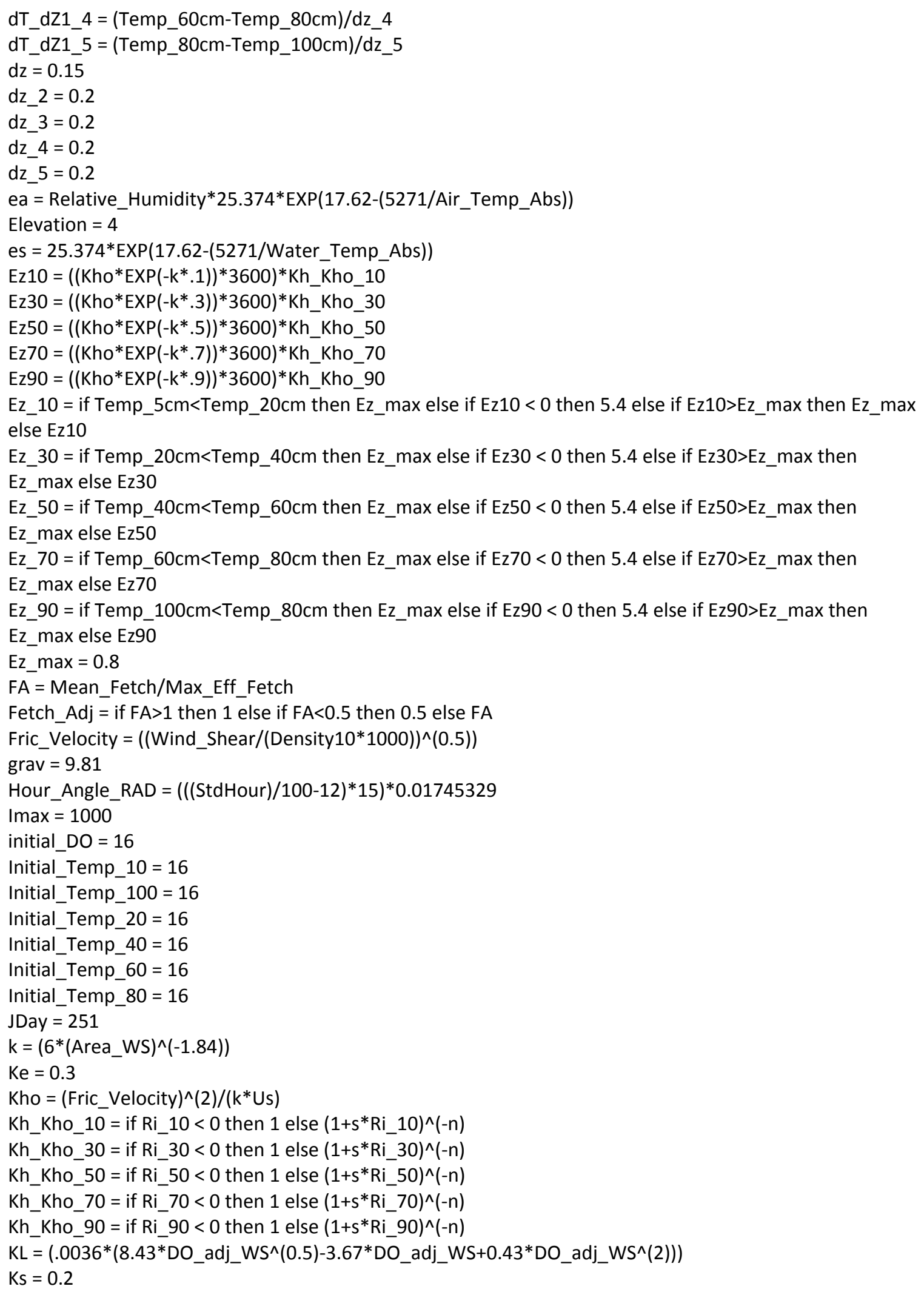




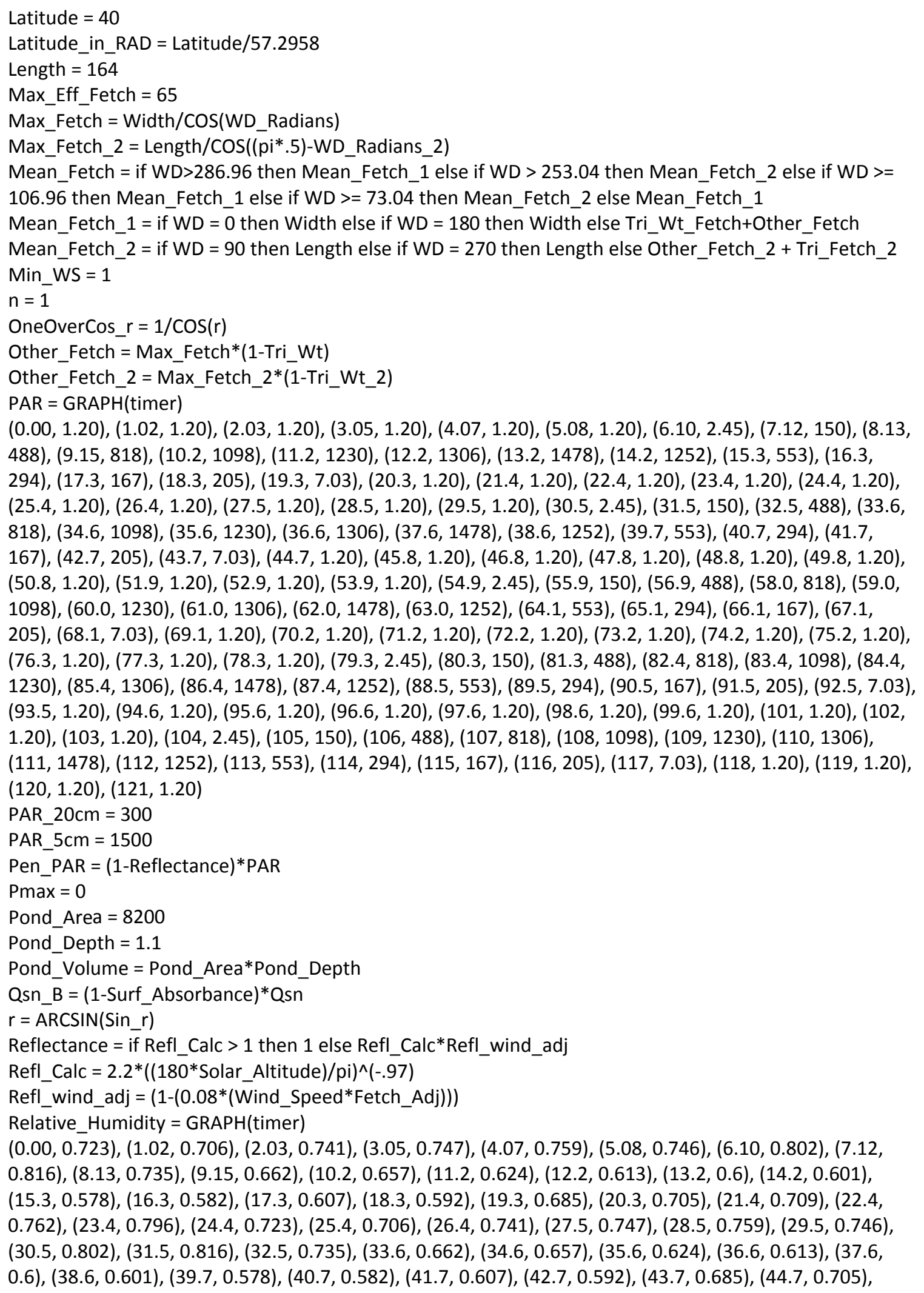


(45.8, 0.709), (46.8, 0.762), (47.8, 0.796), (48.8, 0.723), (49.8, 0.706), (50.8, 0.741), (51.9, 0.747), (52.9, $0.759),(53.9,0.746),(54.9,0.802),(55.9,0.816),(56.9,0.735),(58.0,0.662),(59.0,0.657),(60.0,0.624)$, $(61.0,0.613),(62.0,0.6),(63.0,0.601),(64.1,0.578),(65.1,0.582),(66.1,0.607),(67.1,0.592),(68.1$, 0.685), (69.1, 0.705), (70.2, 0.709), (71.2, 0.762), (72.2, 0.796), (73.2, 0.723), (74.2, 0.706), (75.2, 0.741), (76.3, 0.747), (77.3, 0.759), (78.3, 0.746), (79.3, 0.802), (80.3, 0.816), (81.3, 0.735), (82.4, 0.662), (83.4, 0.657), (84.4, 0.624), (85.4, 0.613), (86.4, 0.6), (87.4, 0.601), (88.5, 0.578), (89.5, 0.582), (90.5, 0.607), (91.5, 0.592), (92.5, 0.685), (93.5, 0.705), (94.6, 0.709), (95.6, 0.762), (96.6, 0.796), (97.6, 0.723), (98.6, $0.706),(99.6,0.741),(101,0.747),(102,0.759),(103,0.746),(104,0.802),(105,0.816),(106,0.735),(107$, $0.662),(108,0.657),(109,0.624),(110,0.613),(111,0.6),(112,0.601),(113,0.578),(114,0.582),(115$, $0.607),(116,0.592),(117,0.685),(118,0.705),(119,0.709),(120,0.762),(121,0.796)$

Ri_10 $=\left((\text { AlphaV*grav*(.10)^2)/Fric_Velocity^(2) })^{*} \mathrm{dT}_{-} \mathrm{dZ1}\right.$

Ri_30 $=\left(\left(\text { AlphaV_2 }{ }^{*} \operatorname{grav}^{*}(.10)^{\wedge} 2\right) / \text { Fric_Velocity^}(2)\right)^{*}$ dT_dZ1_2

Ri_50 $=\left(\left(\right.\right.$ AlphaV_3* $\left.\operatorname{grav}^{*}(.10)^{\wedge} 2\right) /$ Fric_Velocity^(2) $) * \mathrm{dT}_{-} \mathrm{dZ1}$ _3

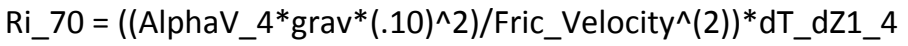

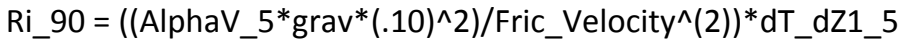

$\mathrm{s}=0.1$

SDOT $=14.652-0.41022 * T e m p \_5 \mathrm{~cm}+0.007991 * T e m p \_5 \mathrm{~cm}^{\wedge}(2)-.0000778 * T e m p \_5 \mathrm{~cm}^{\wedge}(3)$

Sed_Rate $=12$

Sed_Rate_Tconst $=23.5$

Sin_r $=$ Sin(Solar_Zenith_Rad) $/ 1.33$

Solar_Altitude $=(1.570796-$ Solar_Zenith_Rad $)$

Solar_Irradiance $=\mathrm{PAR}^{*} 4^{*} 10^{\wedge}(-4)$

Solar_Zenith_Rad $=(\mathrm{pi} / 180) * A R C C O S\left(C O{ }_{-} \_S o l a r \_Z e n i t h\right)$

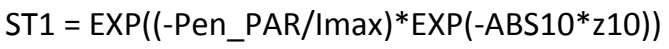

ST1_2 $=\operatorname{EXP}\left(\left(-P e n \_P A R / I m a x\right) * \operatorname{EXP}(-A B S 30 * z 30)\right)$

ST1_3 $=\operatorname{EXP}\left(\left(-P e n \_P A R / I m a x\right) * \operatorname{EXP}(-A B S 50 * z 50)\right)$

ST1_4 $=\operatorname{EXP}\left(\left(-P e n \_P A R / I m a x\right) * \operatorname{EXP}(-A B S 70 * z 70)\right)$

ST1_5 = EXP $\left(\left(-P e n \_P A R / I m a x\right) * \operatorname{EXP}(-A B S 90 * z 90)\right)$

ST1_6 = EXP((-Pen_PAR/Imax $) * \operatorname{EXP}(-A B S 110 * z 110))$

$\mathrm{ST} 2=\operatorname{EXP}\left(\left(-\mathrm{Pen} \_\mathrm{PAR} / \mathrm{Imax}\right) * \operatorname{EXP}(-\mathrm{ABSO} * \mathrm{zO})\right)$

ST2_2 = EXP((-Pen_PAR/Imax $\left.) * \operatorname{EXP}\left(-A B S 10 * z 10 \_2\right)\right)$

ST2_3 = EXP( $\left.\left(-P e n \_P A R / I m a x\right) * \operatorname{EXP}\left(-A B S 30 * z 30 \_2\right)\right)$

ST2_4 $=\operatorname{EXP}\left(\left(-P e n \_P A R / I m a x\right) * \operatorname{EXP}\left(-A B S 50 * z 50 \_2\right)\right)$

ST2_5 = EXP((-Pen_PAR/Imax $\left.) * \operatorname{EXP}\left(-A B S 70 * z 70 \_2\right)\right)$

ST2_6 = EXP((-Pen_PAR/Imax $\left.) * \operatorname{EXP}\left(-A B S 90 * z 90 \_2\right)\right)$

StdHour $=$ timer

Surf_Absorbance $=0.05$

surf_water_temp $=$ Temp_5 $5 \mathrm{~cm}$

Temp_100cm = Initial_Temp_100+(Qtotal_90_110/836.32)

Temp_20cm = Initial_Temp_20+Qtotal_10_30/836.32

Temp_40cm = Initial_Temp_40+Qtotal_30_50/836.32

Temp_5cm = Initial_Temp_10+Qtotal_0_10cm/418.16

Temp_60cm = Initial_Temp_60+Qtotal_50_70/836.32

Temp_80 cm $=$ Initial_Temp_80+Qtotal_70_90/836.32

Temp_Earth $=10$

Temp_Sediment $=$ Initial_Temp_100+ $\left(Q_{\_}\right.$Sediment $\left./(.2 * 1760)\right)$

timer $=$ TIME

Total_Area $=$ Length*Width

Tri_Area $=((\mathrm{b} *$ Width $) / 2) * 2$

Tri_ARea_2 $=(a *$ Length $/ 2) * 2$ 
Tri_Fetch_2 = Tri_Wt_2*Ave_Fetch_2

Tri_Wt $=$ Total_Area*Tri_Area

Tri_Wt_2 = Tri_ARea_2*Total_Area

Tri_Wt_Fetch $=$ Ave_Fetch $*$ Tri_Wt

Us $=30 *$ Fric_Velocity

Water_Temp_Abs $=$ surf_water_temp +273.15

WC_Rate_Tconst $=24.5$

WC_Resp_Rate $=0.39$

$W D=$ Wind_Direction

$W D 1=$ if $W D>286.96$ then $360-W D$ else if WD >180 then WD-180 else if WD>106.96 then 180-WD else WD

$W D 2=$ if $W D>270$ then $360-W D$ else if $W D>253.04$ then WD-180 else if WD>90 then 180-WD else WD

WD_Radians $=$ WD1 $*(p i / 180)$

WD_Radians_2 $=$ WD2* $*$ pi/180)

Width $=50$

Wind_Direction $=$ GRAPH $($ timer $)$

(0.00, 259), (1.01, 200), (2.02, 199), (3.03, 271), (4.03, 276), (5.04, 171), (6.05, 139), (7.06, 145), (8.07, 111), (9.08, 213), (10.1, 175), (11.1, 215), (12.1, 258), (13.1, 265), (14.1, 261), (15.1, 303), (16.1, 304), $(17.1,292),(18.2,308),(19.2,121),(20.2,290),(21.2,183),(22.2,110),(23.2,113),(24.2,259),(25.2$, 200), (26.2, 199), (27.2, 271), (28.2, 276), (29.2, 171), (30.3, 139), (31.3, 145), (32.3, 111), (33.3, 213), $(34.3,175),(35.3,215),(36.3,258),(37.3,265),(38.3,261),(39.3,303),(40.3,304),(41.3,292),(42.4$, 308), (43.4, 121), (44.4, 290), (45.4, 183), (46.4, 110), (47.4, 113), (48.4, 259), (49.4, 200), (50.4, 199), $(51.4,271),(52.4,276),(53.4,171),(54.5,139),(55.5,145),(56.5,111),(57.5,213),(58.5,175),(59.5$, 215), (60.5, 258), (61.5, 265), (62.5, 261), (63.5, 303), (64.5, 304), (65.5, 292), (66.6, 308), (67.6, 121), $(68.6,290),(69.6,183),(70.6,110),(71.6,113),(72.6,259),(73.6,200),(74.6,199),(75.6,271),(76.6$, 276), (77.6, 171), (78.7, 139), (79.7, 145), (80.7, 111), (81.7, 213), (82.7, 175), (83.7, 215), (84.7, 258), (85.7, 265), (86.7, 261), (87.7, 303), (88.7, 304), (89.7, 292), (90.8, 308), (91.8, 121), (92.8, 290), (93.8, $183),(94.8,110),(95.8,113),(96.8,259),(97.8,200),(98.8,199),(99.8,271),(101,276),(102,171),(103$, 139), (104, 145), (105, 111), (106, 213), (107, 175), (108, 215), (109, 258), (110, 265), (111, 261), (112, 303), (113, 304), (114, 292), (115, 308), (116, 121), (117, 290), (118, 183), (119, 110), (120, 113)

Wind_Shear $=1.1988 * 1.3^{*} 10^{\wedge}(-3)^{*}(\text { Area_WS })^{\wedge} 2$

Wind_Speed $=$ GRAPH $($ timer $)$

$(0.00,3.61),(1.02,4.11),(2.03,2.23),(3.05,3.36),(4.07,3.27),(5.08,1.85),(6.10,0.798),(7.12,0.292)$, (8.13, 0.335), (9.15, 1.09), (10.2, 2.90), (11.2, 4.41), (12.2, 6.13), (13.2, 4.49), (14.2, 3.86), (15.3, 6.67), $(16.3,6.34),(17.3,5.00),(18.3,2.90),(19.3,3.44),(20.3,3.06),(21.4,1.76),(22.4,0.798),(23.4,1.05)$, $(24.4,3.61),(25.4,4.11),(26.4,2.23),(27.5,3.36),(28.5,3.27),(29.5,1.85),(30.5,0.798),(31.5,0.292)$, $(32.5,0.335),(33.6,1.09),(34.6,2.90),(35.6,4.41),(36.6,6.13),(37.6,4.49),(38.6,3.86),(39.7,6.67)$, $(40.7,6.34),(41.7,5.00),(42.7,2.90),(43.7,3.44),(44.7,3.06),(45.8,1.76),(46.8,0.798),(47.8,1.05)$, $(48.8,3.61),(49.8,4.11),(50.8,2.23),(51.9,3.36),(52.9,3.27),(53.9,1.85),(54.9,0.798),(55.9,0.292)$, $(56.9,0.335),(58.0,1.09),(59.0,2.90),(60.0,4.41),(61.0,6.13),(62.0,4.49),(63.0,3.86),(64.1,6.67)$, $(65.1,6.34),(66.1,5.00),(67.1,2.90),(68.1,3.44),(69.1,3.06),(70.2,1.76),(71.2,0.798),(72.2,1.05)$, (73.2, 3.61), (74.2, 4.11), (75.2, 2.23), (76.3, 3.36), (77.3, 3.27), (78.3, 1.85), (79.3, 0.798), (80.3, 0.292), (81.3, 0.335), (82.4, 1.09), (83.4, 2.90), (84.4, 4.41), (85.4, 6.13), (86.4, 4.49), (87.4, 3.86), (88.5, 6.67), $(89.5,6.34),(90.5,5.00),(91.5,2.90),(92.5,3.44),(93.5,3.06),(94.6,1.76),(95.6,0.798),(96.6,1.05)$, (97.6, 3.61), (98.6, 4.11), (99.6, 2.23), (101, 3.36), (102, 3.27), (103, 1.85), (104, 0.798), (105, 0.292), (106, $0.335),(107,1.09),(108,2.90),(109,4.41),(110,6.13),(111,4.49),(112,3.86),(113,6.67),(114,6.34)$, $(115,5.00),(116,2.90),(117,3.44),(118,3.06),(119,1.76),(120,0.798),(121,1.05)$

Wind_Vector $=$ Wind_Speed

WS_kh $=$ if Wind_Speed<Min_WS then Min_WS*3.6 else (Wind_Speed *3.6)*(2/Anenometer_H $)^{\wedge}(1 / 7)$ $\mathrm{zO}=0$ 


$$
\begin{aligned}
& z 10=10 \\
& z 10 \_2=10 \\
& z 110=110 \\
& z 30=30 \\
& z 30 \_2=30 \\
& z 50=50 \\
& z 50 \_2=50 \\
& z 70=70 \\
& z 70 \_2=70 \\
& z 90=90 \\
& z 90 \_2=90 \\
& z b=0
\end{aligned}
$$




\section{Appendix B. Competition model}

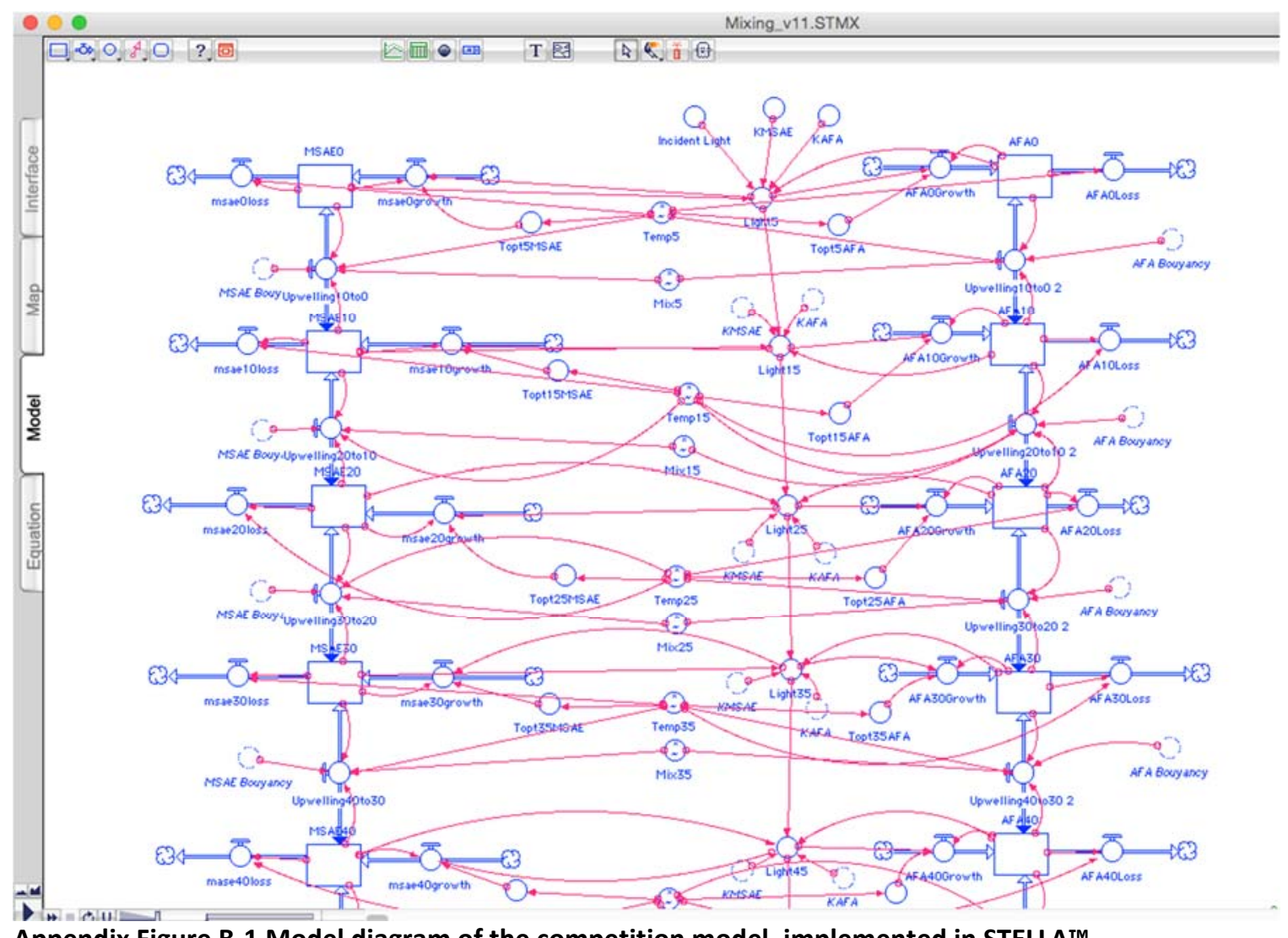

Appendix Figure B-1 Model diagram of the competition model, implemented in STELLA ${ }^{\mathrm{TM}}$. 
Variable tables

Appendix Table B-1 Species specific parameters used in the competition model simulations.

\begin{tabular}{|c|c|c|c|c|c|c|}
\hline $\begin{array}{l}\text { Para } \\
\text { meter }\end{array}$ & Description & MSAE & Source & APFA & Source & Units \\
\hline$\mu_{\max }$ & $\begin{array}{l}\text { Max spec growth rate } \\
\text { at optimum } \\
\text { temperature }\end{array}$ & 0.8 & Reynolds 1997 & 1.2 & Uehlinger 1981 & day $^{-1}$ \\
\hline$\alpha$ & $\begin{array}{l}\text { Initial slope of light- } \\
\text { dependent growth }\end{array}$ & 0.01 & $\begin{array}{l}\text { model } \\
\text { calibration }\end{array}$ & 0.011 & Mehnert 2010 & $\begin{array}{l}\text { day }^{-1} \text { (umol } \\
\left.m^{-2} s^{-1}\right)^{-1}\end{array}$ \\
\hline$T_{\text {opt }}$ & Optimum temperature & 28.2 & Reynolds 1997 & 24 & $\begin{array}{l}\text { Paerl \& Otten } \\
\text { 2016; Mehnert } \\
2010\end{array}$ & ${ }^{\circ} \mathrm{C}$ \\
\hline b & $\begin{array}{l}\text { Coefficient in optimum } \\
\text { curve }\end{array}$ & 5.77 & Reynolds 1997 & 4 & calibration & - \\
\hline $\mathbf{R}_{\mathbf{1}}$ & $\begin{array}{l}\text { Coefficient in optimum } \\
\text { curve }\end{array}$ & 1.3 & Reynolds 1997 & 1.3 & calibration & - \\
\hline $\mathbf{R}_{\mathbf{2}}$ & $\begin{array}{l}\text { Coefficient in optimum } \\
\text { curve }\end{array}$ & 1.37 & Reynolds 1997 & 1.32 & calibration & - \\
\hline$N(0)$ & $\begin{array}{l}\text { Initial population } \\
\text { density }\end{array}$ & $\begin{array}{c}10,00 \\
0\end{array}$ & & 1,000 & & cells $\mathrm{m}^{-3}$ \\
\hline $\mathbf{k}_{\mathbf{i}}$ & $\begin{array}{l}\text { Specific light } \\
\text { attenuation coefficient }\end{array}$ & 3.4 & Huisman 2004 & 304 & Husiman 1999 & $\mathrm{um}^{-2}$ cell $^{-1}$ \\
\hline $\mathbf{v}$ & Buoyancy rate & 0.5 & Huisman 2004 & 0.89 & Brunkalla 2017 & $\mathrm{~m} \mathrm{~h}^{-1}$ \\
\hline $\mathrm{m}(20)$ & $\begin{array}{l}\text { Specific loss rate at } 20 \\
{ }^{\circ} \mathrm{C}\end{array}$ & 0.08 & $\begin{array}{l}\text { Robson \& } \\
\text { Hamilton } 2004\end{array}$ & 0.06 & Walker 2001 & day $^{-1}$ \\
\hline $\mathbf{Q}$ & $\begin{array}{l}\text { Temperature } \\
\text { dependence of specific } \\
\text { loss rate }\end{array}$ & 2.16 & Joehnk 2008 & 1.52 & Foy 1976 & - \\
\hline
\end{tabular}

Appendix Table B-2 Environmental parameters used in the competition model simulations.

\begin{tabular}{|c|c|c|c|c|}
\hline Parameter & Description & Value & Source & Units \\
\hline$I_{\text {in }}$ & Incident light intensity & $\begin{array}{l}\text { est from PAR } \\
\text { sin curve }\end{array}$ & calculated & umol m $\mathrm{m}^{-2} \mathrm{~s}^{-1}$ \\
\hline $\mathbf{r}$ & Reflection coefficient & 0.06 & calibrated & - \\
\hline $\mathbf{N}_{\mathrm{i}}$ & Population of species i & 1,000 & & cells $\mathrm{m}^{-3}$ \\
\hline$K_{b g}$ & $\begin{array}{l}\text { Background attenuation } \\
\text { coefficient }\end{array}$ & 0.7 & calibrated & $\mathrm{m}^{-1}$ \\
\hline$\eta$ & Dynamic viscosity & $\eta(T)$ & $\begin{array}{l}\text { Hutter \& Joehnk } \\
2004\end{array}$ & $\mathrm{~kg} \mathrm{~m}^{-1} \mathrm{~s}^{-1}$ \\
\hline$E_{z}$ & Effective diffusion at depth $z$ & $E_{z}(T)$ & modeled & $m_{2} h^{-1}$ \\
\hline
\end{tabular}

\section{Model code}

APFAO $(t)=$ APFAO $(t-d t)+($ APFA0Growth + Upwelling10to0_2 - APFAOLoss $) * d t$ INIT APFAO = 1000

INFLOWS: 
APFA0Growth $=($ APFA0 $*$ Topt5APFA $*$ Light5 $/($ Topt5APFA/.01+Light5) $) / 24$

Upwelling10to0_2 $=1.002 /(-0.461 * \ln ($ Temp5) +2.3719$) *($ APFA_Buoyancy/.1)*APFA10+(APFA10-

APFA0)*Mix5

OUTFLOWS:

APFAOLoss $=\left(\right.$ APFA0 $* .06 * 1.52^{\wedge}(($ Temp5-20) $/ 10)) / 24$

APFA10 $(t)=$ APFA10 $(t-d t)+($ APFA10Growth + Upwelling20to10_2 - Upwelling10to0_2 - APFA10Loss $) * d t$ INIT APFA10 $=1000$

INFLOWS:

APFA10Growth $=$ APFA10*Topt15APFA $*$ Light15/(Topt15APFA $/ .01+$ Light15) $/ 24$

Upwelling20to10_2 $=1.002 /(-0.461 * \ln ($ Temp15) +2.3719$) *($ APFA_Buoyancy/.1)*APFA20+(APFA20-

APFA10)*Mix15

OUTFLOWS:

Upwelling10to0_2 $=1.002 /(-0.461 * \ln ($ Temp5) +2.3719$) *($ APFA_Buoyancy/.1)*APFA10+(APFA10-

APFA0)*Mix5

APFA10Loss $=\left(\right.$ APFA10* $.06 * 1.52^{\wedge}(($ Temp $\left.15-20) / 10)\right) / 24$

APFA20 $(t)=$ APFA20 $(t-d t)+($ APFA20Growth + Upwelling30to20_2 - Upwelling20to10_2 - APFA20Loss) *

dt

INIT APFA20 $=1000$

INFLOWS:

APFA20Growth $=$ APFA20*Topt25APFA*Light25/(Topt25APFA/.01+Light25)/24

Upwelling30to20_2 $=1.002 /(-0.461 * \ln ($ Temp25) +2.3719$) *($ APFA_Buoyancy/.1)*APFA30+(APFA30-

APFA20)*Mix25

OUTFLOWS:

Upwelling20to10_2 $=1.002 /(-0.461 * \ln ($ Temp15) +2.3719$) *($ APFA_Buoyancy/.1)*APFA20+(APFA20-

APFA10)*Mix15

APFA20Loss $=($ APFA20*.06*1.52^((Temp25-20)/10) $) / 24$

APFA30 $(t)=$ APFA30 $(t-d t)+($ APFA30Growth + Upwelling40to30_2 - Upwelling30to20_2 - APFA30Loss $)$ *

dt

INIT APFA30 $=1000$

INFLOWS:

APFA30Growth $=$ APFA30*Topt35APFA*Light35/(Topt35APFA/.01+Light35) $/ 24$

Upwelling40to30_2 $=1.002 /(-0.461 * \ln ($ Temp35) +2.3719$) *($ APFA_Buoyancy/.1)*APFA40+(APFA40-

APFA30*Mix35

OUTFLOWS:

Upwelling30to20_2 $=1.002 /(-0.461 * \ln ($ Temp25) +2.3719$) *($ APFA_Buoyancy/.1)*APFA30+(APFA30-

APFA20)*Mix25

APFA30Loss $=($ APFA30*.06*1.52^((Temp35-20)/10) $) / 24$

APFA40 $(t)=$ APFA40 $(t-d t)+($ APFA40Growth + upwelling50to40_2 - Upwelling40to30_2 - APFA40Loss $)$ * $\mathrm{dt}$

INIT APFA40 $=1000$

INFLOWS:

APFA40Growth = APFA40*Topt45APFA $*$ Light45/(Topt45APFA/.01+Light45)/24

upwelling50to40_2 $=1.002 /(-0.461 * \ln ($ Temp45) +2.3719)*(APFA_Buoyancy/.1)*APFA50+(APFA50-

APFA40)*Mix45

OUTFLOWS:

Upwelling40to30_2 = 1.002/(-0.461*In(Temp35)+2.3719)*(APFA_Buoyancy/.1)*APFA40+(APFA40-

APFA30)*Mix35

APFA40Loss $=\left(\right.$ APFA40* $.06 * 1.52^{\wedge}(($ Temp $\left.45-20) / 10)\right) / 24$

APFA50 $(t)=$ APFA50 $(t-d t)+($ APFA50Growth + Upwelling60to50_2 - APFA50Loss - upwelling50to40_2) * $\mathrm{dt}$ 


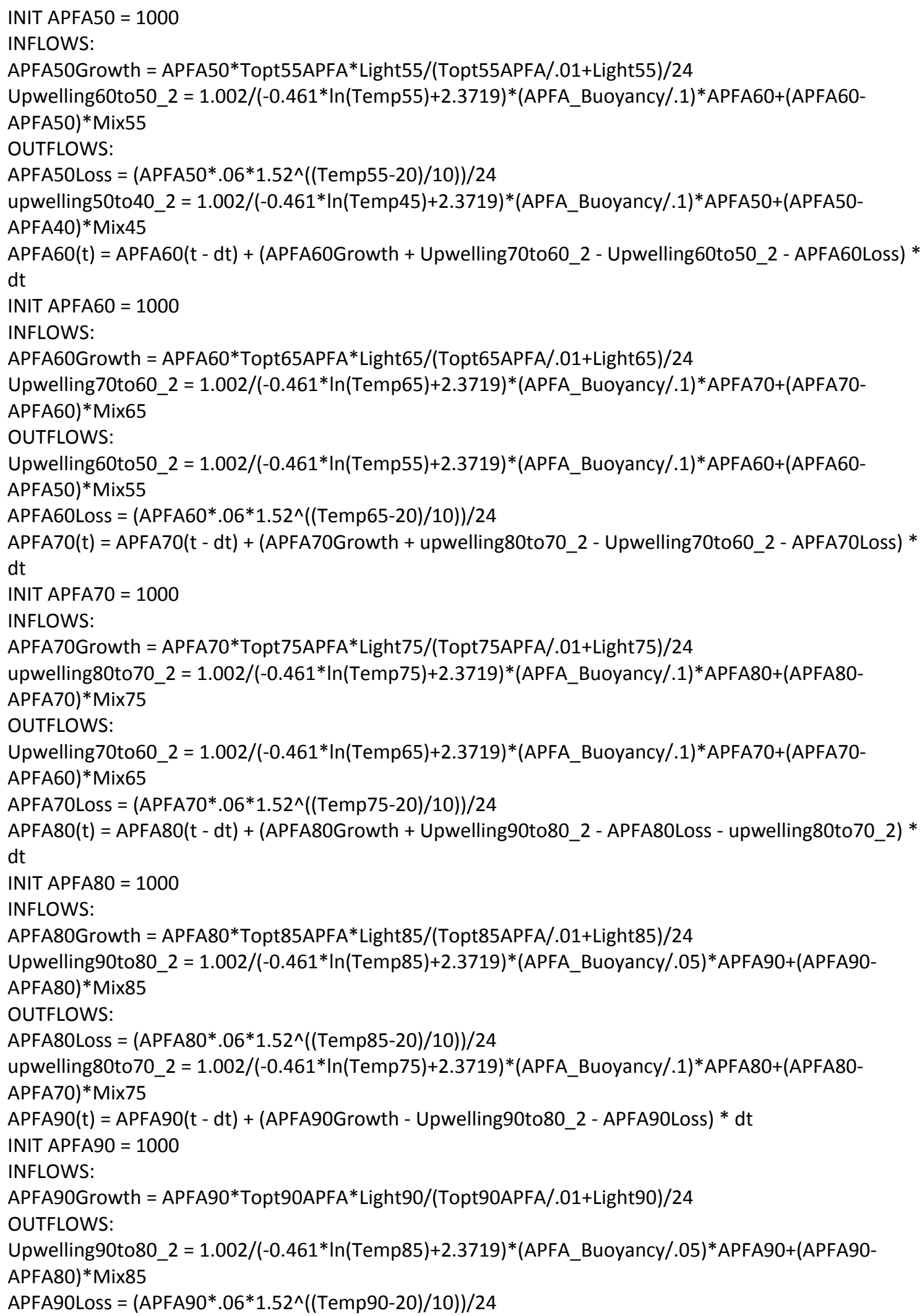




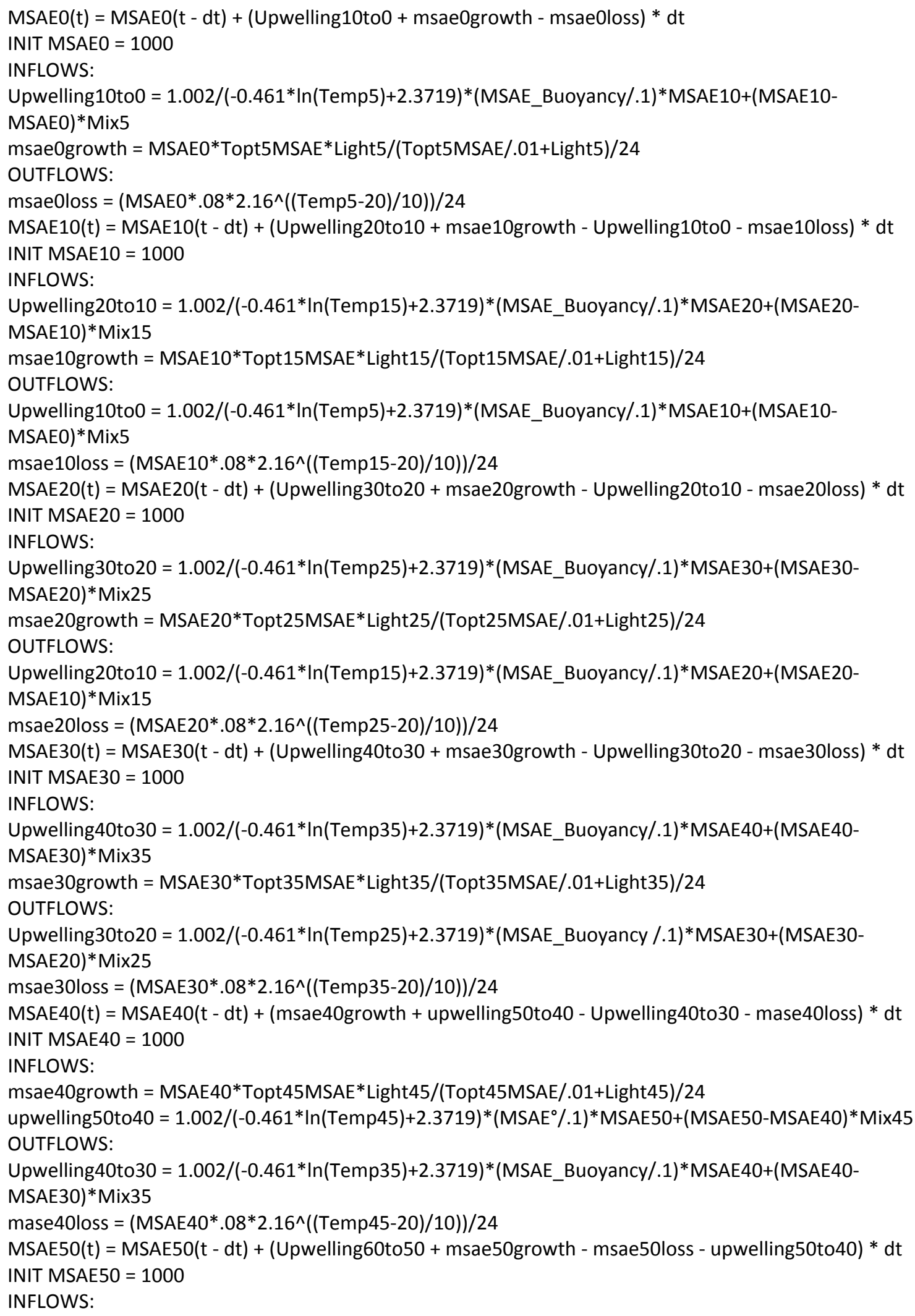




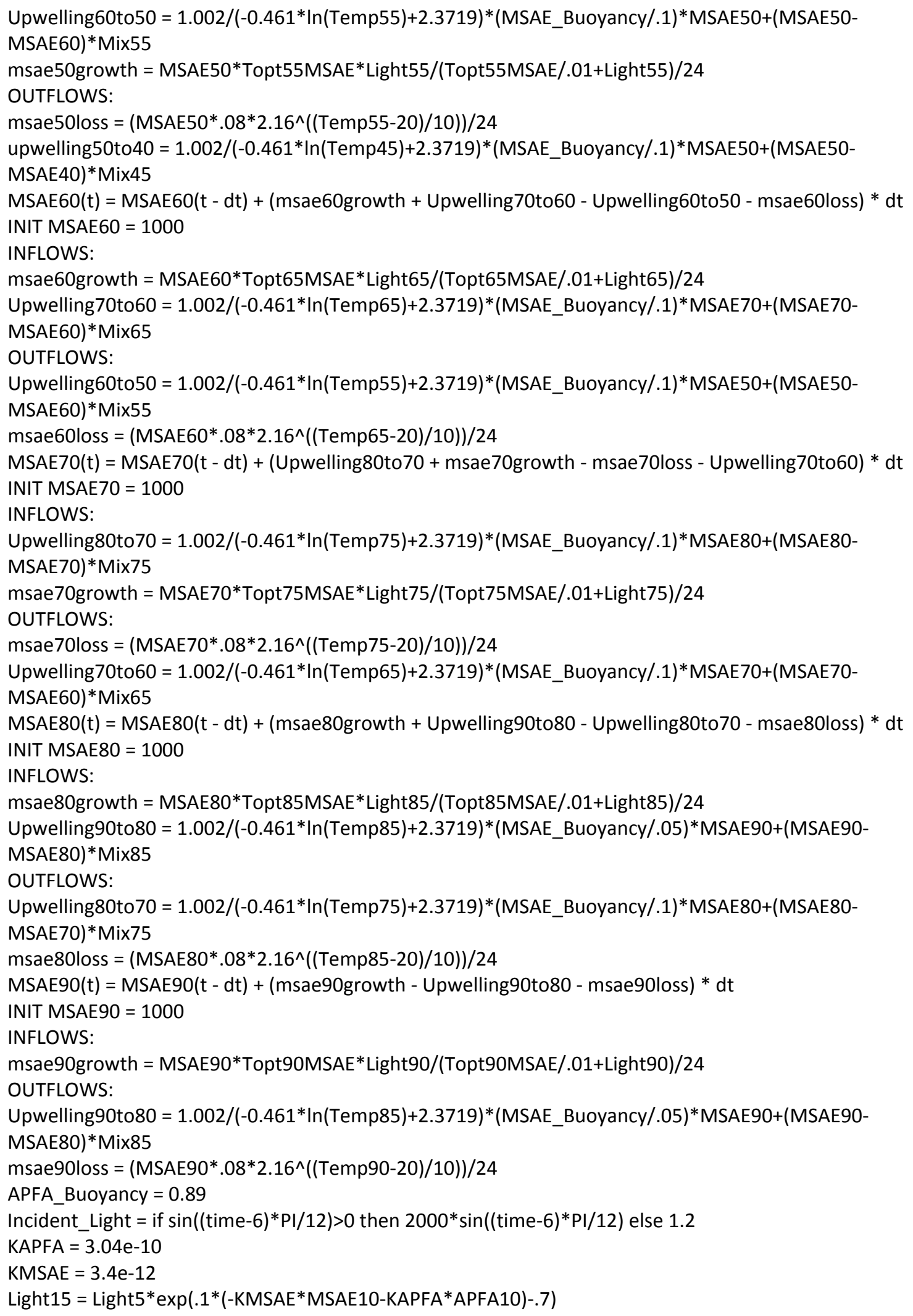


Light25 = Light15*exp(.1*(-KMSAE*MSAE20-KAPFA*APFA20)-.7)

Light35 = Light25*exp(.1*(-KMSAE*MSAE30-KAPFA*APFA30)-.7)

Light45 = Light35*exp(.1*(-KMSAE*MSAE40-KAPFA*APFA40)-.7)

Light5 $=$ Incident_Light*exp(.05*(-KMSAE*MSAEO-KAPFA*APFA0)-.7)

Light55 $=$ Light45*exp(.1*(-KMSAE*MSAE50-KAPFA*APFA50)-.7)

Light65 = Light55*exp(.1*(-KMSAE*MSAE60-KAPFA*APFA60)-.7)

Light75 = Light65* $\exp (.1 *(-K M S A E *$ MSAE70-KAPFA*APFA70)-.7)

Light85 $=$ Light75*exp $(.1 *(-K M S A E * M S A E 80-K A P F A * A P F A 80)-.7)$

Light90 $=$ Light85*exp(.05*(-KMSAE*MSAE90-KAPFA*APFA90)-.7)

Mix15 = GRAPH $($ TIME $)$

$(0.00,0.207),(1.01,0.207),(2.02,0.368),(3.03,0.306),(4.03,0.528),(5.04,0.551),(6.05,0.351),(7.06$, $0.204),(8.07,0.238),(9.08,0.399),(10.1,0.648),(11.1,0.601),(12.1,0.602),(13.1,0.622),(14.1,0.611)$, (15.1, 0.144), (16.1, 0.00637), (17.1, 0.274), (18.2, 0.6), (19.2, 0.668), (20.2, 0.611), (21.2, 0.6), (22.2, 0.6), $(23.2,0.6),(24.2,0.207),(25.2,0.207),(26.2,0.368),(27.2,0.306),(28.2,0.528),(29.2,0.551),(30.3$, $0.351),(31.3,0.204),(32.3,0.238),(33.3,0.399),(34.3,0.648),(35.3,0.601),(36.3,0.602),(37.3,0.622)$, $(38.3,0.611),(39.3,0.144),(40.3,0.00637),(41.3,0.274),(42.4,0.6),(43.4,0.668),(44.4,0.611),(45.4$, $0.6),(46.4,0.6),(47.4,0.6),(48.4,0.207),(49.4,0.207),(50.4,0.368),(51.4,0.306),(52.4,0.528),(53.4$, $0.551),(54.5,0.351),(55.5,0.204),(56.5,0.238),(57.5,0.399),(58.5,0.648),(59.5,0.601),(60.5,0.602)$, (61.5, 0.622), (62.5, 0.611), (63.5, 0.144), (64.5, 0.00637), (65.5, 0.274), (66.6, 0.6), (67.6, 0.668), (68.6, 0.611), (69.6, 0.6), (70.6, 0.6), (71.6, 0.6), (72.6, 0.207), (73.6, 0.207), (74.6, 0.368), (75.6, 0.306), (76.6, $0.528),(77.6,0.551),(78.7,0.351),(79.7,0.204),(80.7,0.238),(81.7,0.399),(82.7,0.648),(83.7,0.601)$, $(84.7,0.602),(85.7,0.622),(86.7,0.611),(87.7,0.144),(88.7,0.00637),(89.7,0.274),(90.8,0.6),(91.8$, 0.668), $(92.8,0.611),(93.8,0.6),(94.8,0.6),(95.8,0.6),(96.8,0.207),(97.8,0.207),(98.8,0.368),(99.8$, $0.306),(101,0.528),(102,0.551),(103,0.351),(104,0.204),(105,0.238),(106,0.399),(107,0.648),(108$, $0.601),(109,0.602),(110,0.622),(111,0.611),(112,0.144),(113,0.00637),(114,0.274),(115,0.6),(116$, $0.668),(117,0.611),(118,0.6),(119,0.6),(120,0.6)$

Mix25 = GRAPH $($ TIME $)$

(0.00, 0.602), (1.01, 0.603), (2.02, 0.656), (3.03, 0.635), (4.03, 0.709), (5.04, 0.717), (6.05, 0.65), (7.06, $0.601),(8.07,0.613),(9.08,0.666),(10.1,0.345),(11.1,0.202),(12.1,0.207),(13.1,0.265),(14.1,0.232)$, $(15.1,0.052),(16.1,0.00213),(17.1,0.0914),(18.2,0.2),(19.2,0.404),(20.2,0.233),(21.2,0.2),(22.2,0.2)$, $(23.2,0.2),(24.2,0.602),(25.2,0.603),(26.2,0.656),(27.2,0.635),(28.2,0.709),(29.2,0.717),(30.3,0.65)$, $(31.3,0.601),(32.3,0.613),(33.3,0.666),(34.3,0.345),(35.3,0.202),(36.3,0.207),(37.3,0.265),(38.3$, $0.232),(39.3,0.052),(40.3,0.00213),(41.3,0.0914),(42.4,0.2),(43.4,0.404),(44.4,0.233),(45.4,0.2)$, $(46.4,0.2),(47.4,0.2),(48.4,0.602),(49.4,0.603),(50.4,0.656),(51.4,0.635),(52.4,0.709),(53.4,0.717)$, $(54.5,0.65),(55.5,0.601),(56.5,0.613),(57.5,0.666),(58.5,0.345),(59.5,0.202),(60.5,0.207),(61.5$, $0.265),(62.5,0.232),(63.5,0.052),(64.5,0.00213),(65.5,0.0914),(66.6,0.2),(67.6,0.404),(68.6,0.233)$, $(69.6,0.2),(70.6,0.2),(71.6,0.2),(72.6,0.602),(73.6,0.603),(74.6,0.656),(75.6,0.635),(76.6,0.709)$, (77.6, 0.717), (78.7, 0.65), (79.7, 0.601), (80.7, 0.613), (81.7, 0.666), (82.7, 0.345), (83.7, 0.202), (84.7, $0.207),(85.7,0.265),(86.7,0.232),(87.7,0.052),(88.7,0.00213),(89.7,0.0914),(90.8,0.2),(91.8,0.404)$, $(92.8,0.233),(93.8,0.2),(94.8,0.2),(95.8,0.2),(96.8,0.602),(97.8,0.603),(98.8,0.656),(99.8,0.635)$, (101, 0.709), (102, 0.717), (103, 0.65), (104, 0.601), (105, 0.613), (106, 0.666), (107, 0.345), (108, 0.202), (109, 0.207), (110, 0.265), (111, 0.232), (112, 0.052), (113, 0.00213), (114, 0.0914), (115, 0.2), (116, 0.404), $(117,0.233),(118,0.2),(119,0.2),(120,0.2)$

Mix35 = GRAPH(TIME)

$(0.00,0.6),(1.01,0.6),(2.02,0.636),(3.03,0.622),(4.03,0.695),(5.04,0.698),(6.05,0.633),(7.06,0.6)$, $(8.07,0.606),(9.08,0.603),(10.1,0.15),(11.1,0.00169),(12.1,0.00844),(13.1,0.084),(14.1,0.0419)$, $(15.1,0.006),(16.1,0.00),(17.1,0.00),(18.2,0.00),(19.2,0.276),(20.2,0.045),(21.2,0.00),(22.2,0.00)$, $(23.2,0.00),(24.2,0.6),(25.2,0.6),(26.2,0.636),(27.2,0.622),(28.2,0.695),(29.2,0.698),(30.3,0.633)$, $(31.3,0.6),(32.3,0.606),(33.3,0.603),(34.3,0.15),(35.3,0.00169),(36.3,0.00844),(37.3,0.084),(38.3$, 0.0419), $(39.3,0.006),(40.3,0.00),(41.3,0.00),(42.4,0.00),(43.4,0.276),(44.4,0.045),(45.4,0.00),(46.4$, 
$0.00),(47.4,0.00),(48.4,0.6),(49.4,0.6),(50.4,0.636),(51.4,0.622),(52.4,0.695),(53.4,0.698),(54.5$, $0.633),(55.5,0.6),(56.5,0.606),(57.5,0.603),(58.5,0.15),(59.5,0.00169),(60.5,0.00844),(61.5,0.084)$, $(62.5,0.0419),(63.5,0.006),(64.5,0.00),(65.5,0.00),(66.6,0.00),(67.6,0.276),(68.6,0.045),(69.6,0.00)$, $(70.6,0.00),(71.6,0.00),(72.6,0.6),(73.6,0.6),(74.6,0.636),(75.6,0.622),(76.6,0.695),(77.6,0.698)$, $(78.7,0.633),(79.7,0.6),(80.7,0.606),(81.7,0.603),(82.7,0.15),(83.7,0.00169),(84.7,0.00844),(85.7$, $0.084),(86.7,0.0419),(87.7,0.006),(88.7,0.00),(89.7,0.00),(90.8,0.00),(91.8,0.276),(92.8,0.045)$, $(93.8,0.00),(94.8,0.00),(95.8,0.00),(96.8,0.6),(97.8,0.6),(98.8,0.636),(99.8,0.622),(101,0.695),(102$, $0.698),(103,0.633),(104,0.6),(105,0.606),(106,0.603),(107,0.15),(108,0.00169),(109,0.00844),(110$, $0.084),(111,0.0419),(112,0.006),(113,0.00),(114,0.00),(115,0.00),(116,0.276),(117,0.045),(118$, $0.00),(119,0.00),(120,0.00)$

Mix45 = GRAPH(TIME)

$(0.00,0.2),(1.01,0.2),(2.02,0.309),(3.03,0.267),(4.03,0.486),(5.04,0.495),(6.05,0.299),(7.06,0.201)$, (8.07, 0.217), (9.08, 0.21), (10.1, 0.0632), (11.1, 0.000562), (12.1, 0.00731), (13.1, 0.0775), (14.1, 0.0406), $(15.1,0.006),(16.1,0.00),(17.1,0.00),(18.2,0.00),(19.2,0.284),(20.2,0.046),(21.2,0.00),(22.2,0.00)$, $(23.2,0.00),(24.2,0.2),(25.2,0.2),(26.2,0.309),(27.2,0.267),(28.2,0.486),(29.2,0.495),(30.3,0.299)$, $(31.3,0.201),(32.3,0.217),(33.3,0.21),(34.3,0.0632),(35.3,0.000562),(36.3,0.00731),(37.3,0.0775)$, $(38.3,0.0406),(39.3,0.006),(40.3,0.00),(41.3,0.00),(42.4,0.00),(43.4,0.284),(44.4,0.046),(45.4,0.00)$, $(46.4,0.00),(47.4,0.00),(48.4,0.2),(49.4,0.2),(50.4,0.309),(51.4,0.267),(52.4,0.486),(53.4,0.495)$, $(54.5,0.299),(55.5,0.201),(56.5,0.217),(57.5,0.21),(58.5,0.0632),(59.5,0.000562),(60.5,0.00731)$, $(61.5,0.0775),(62.5,0.0406),(63.5,0.006),(64.5,0.00),(65.5,0.00),(66.6,0.00),(67.6,0.284),(68.6$, 0.046), (69.6, 0.00), (70.6, 0.00), (71.6, 0.00), (72.6, 0.2), (73.6, 0.2), (74.6, 0.309), (75.6, 0.267), (76.6, $0.486),(77.6,0.495),(78.7,0.299),(79.7,0.201),(80.7,0.217),(81.7,0.21),(82.7,0.0632),(83.7$, $0.000562),(84.7,0.00731),(85.7,0.0775),(86.7,0.0406),(87.7,0.006),(88.7,0.00),(89.7,0.00),(90.8$, $0.00),(91.8,0.284),(92.8,0.046),(93.8,0.00),(94.8,0.00),(95.8,0.00),(96.8,0.2),(97.8,0.2),(98.8$, $0.309),(99.8,0.267),(101,0.486),(102,0.495),(103,0.299),(104,0.201),(105,0.217),(106,0.21),(107$, $0.0632),(108,0.000562),(109,0.00731),(110,0.0775),(111,0.0406),(112,0.006),(113,0.00),(114$, $0.00),(115,0.00),(116,0.284),(117,0.046),(118,0.00),(119,0.00),(120,0.00)$

Mix5 = GRAPH(TIME) (0.00, 0.00927), (1.01, 0.01), (2.02, 0.225), (3.03, 0.142), (4.03, 0.438), (5.04, 0.468), (6.05, 0.202), (7.06, $0.005),(8.07,0.0508),(9.08,0.265),(10.1,0.8),(11.1,0.8),(12.1,0.8),(13.1,0.8),(14.1,0.8),(15.1,0.19)$, (16.1, 0.0085), (17.1, 0.365), (18.2, 0.8), (19.2, 0.8), (20.2, 0.8), (21.2, 0.8), (22.2, 0.8), (23.2, 0.8), (24.2, $0.00927),(25.2,0.01),(26.2,0.225),(27.2,0.142),(28.2,0.438),(29.2,0.468),(30.3,0.202),(31.3,0.005)$, $(32.3,0.0508),(33.3,0.265),(34.3,0.8),(35.3,0.8),(36.3,0.8),(37.3,0.8),(38.3,0.8),(39.3,0.19),(40.3$, $0.0085),(41.3,0.365),(42.4,0.8),(43.4,0.8),(44.4,0.8),(45.4,0.8),(46.4,0.8),(47.4,0.8),(48.4,0.00927)$, $(49.4,0.01),(50.4,0.225),(51.4,0.142),(52.4,0.438),(53.4,0.468),(54.5,0.202),(55.5,0.005),(56.5$, $0.0508),(57.5,0.265),(58.5,0.8),(59.5,0.8),(60.5,0.8),(61.5,0.8),(62.5,0.8),(63.5,0.19),(64.5,0.0085)$, $(65.5,0.365),(66.6,0.8),(67.6,0.8),(68.6,0.8),(69.6,0.8),(70.6,0.8),(71.6,0.8),(72.6,0.00927),(73.6$, $0.01),(74.6,0.225),(75.6,0.142),(76.6,0.438),(77.6,0.468),(78.7,0.202),(79.7,0.005),(80.7,0.0508)$, $(81.7,0.265),(82.7,0.8),(83.7,0.8),(84.7,0.8),(85.7,0.8),(86.7,0.8),(87.7,0.19),(88.7,0.0085),(89.7$, $0.365),(90.8,0.8),(91.8,0.8),(92.8,0.8),(93.8,0.8),(94.8,0.8),(95.8,0.8),(96.8,0.00927),(97.8,0.01)$, (98.8, 0.225), (99.8, 0.142), (101, 0.438), (102, 0.468), (103, 0.202), (104, 0.005), (105, 0.0508), (106, $0.265),(107,0.8),(108,0.8),(109,0.8),(110,0.8),(111,0.8),(112,0.19),(113,0.0085),(114,0.365),(115$, $0.8),(116,0.8),(117,0.8),(118,0.8),(119,0.8),(120,0.8)$

Mix55 = GRAPH (TIME)

$(0.00,0.00),(1.01,0.00),(2.02,0.141),(3.03,0.0863),(4.03,0.374),(5.04,0.386),(6.05,0.128),(7.06$, $0.001),(8.07,0.0219),(9.08,0.012),(10.1,0.0186),(11.1,0.00),(12.1,0.00506),(13.1,0.072),(14.1$, $0.0387),(15.1,0.00581),(16.1,0.00),(17.1,0.00),(18.2,0.00),(19.2,0.283),(20.2,0.0453),(21.2,0.00)$, $(22.2,0.00),(23.2,0.00),(24.2,0.00),(25.2,0.00),(26.2,0.141),(27.2,0.0863),(28.2,0.374),(29.2,0.386)$, $(30.3,0.128),(31.3,0.001),(32.3,0.0219),(33.3,0.012),(34.3,0.0186),(35.3,0.00),(36.3,0.00506),(37.3$, $0.072),(38.3,0.0387),(39.3,0.00581),(40.3,0.00),(41.3,0.00),(42.4,0.00),(43.4,0.283),(44.4,0.0453)$, 
$(45.4,0.00),(46.4,0.00),(47.4,0.00),(48.4,0.00),(49.4,0.00),(50.4,0.141),(51.4,0.0863),(52.4,0.374)$, $(53.4,0.386),(54.5,0.128),(55.5,0.001),(56.5,0.0219),(57.5,0.012),(58.5,0.0186),(59.5,0.00),(60.5$, $0.00506),(61.5,0.072),(62.5,0.0387),(63.5,0.00581),(64.5,0.00),(65.5,0.00),(66.6,0.00),(67.6,0.283)$, $(68.6,0.0453),(69.6,0.00),(70.6,0.00),(71.6,0.00),(72.6,0.00),(73.6,0.00),(74.6,0.141),(75.6,0.0863)$, (76.6, 0.374), (77.6, 0.386), (78.7, 0.128), (79.7, 0.001), (80.7, 0.0219), (81.7, 0.012), (82.7, 0.0186), (83.7, $0.00),(84.7,0.00506),(85.7,0.072),(86.7,0.0387),(87.7,0.00581),(88.7,0.00),(89.7,0.00),(90.8,0.00)$, $(91.8,0.283),(92.8,0.0453),(93.8,0.00),(94.8,0.00),(95.8,0.00),(96.8,0.00),(97.8,0.00),(98.8,0.141)$, (99.8, 0.0863), (101, 0.374), (102, 0.386), (103, 0.128), (104, 0.001), (105, 0.0219), (106, 0.012), (107, 0.0186), (108, 0.00), (109, 0.00506), (110, 0.072), (111, 0.0387), (112, 0.00581), (113, 0.00), (114, 0.00), $(115,0.00),(116,0.283),(117,0.0453),(118,0.00),(119,0.00),(120,0.00)$

Mix65 = GRAPH(TIME)

$(0.00,0.00),(1.01,0.00),(2.02,0.134),(3.03,0.0814),(4.03,0.36),(5.04,0.37),(6.05,0.121),(7.06,0.001)$, (8.07, 0.0201), (9.08, 0.0095), (10.1, 0.0162), (11.1, 0.00), (12.1, 0.00169), (13.1, 0.0675), (14.1, 0.0362), (15.1, 0.00544), (16.1, 0.00), (17.1, 0.00), (18.2, 0.00), (19.2, 0.274), (20.2, 0.0429), (21.2, 0.00), (22.2, $0.00),(23.2,0.00),(24.2,0.00),(25.2,0.00),(26.2,0.134),(27.2,0.0814),(28.2,0.36),(29.2,0.37),(30.3$, $0.121),(31.3,0.001),(32.3,0.0201),(33.3,0.0095),(34.3,0.0162),(35.3,0.00),(36.3,0.00169),(37.3$, $0.0675),(38.3,0.0362),(39.3,0.00544),(40.3,0.00),(41.3,0.00),(42.4,0.00),(43.4,0.274),(44.4,0.0429)$, $(45.4,0.00),(46.4,0.00),(47.4,0.00),(48.4,0.00),(49.4,0.00),(50.4,0.134),(51.4,0.0814),(52.4,0.36)$, $(53.4,0.37),(54.5,0.121),(55.5,0.001),(56.5,0.0201),(57.5,0.0095),(58.5,0.0162),(59.5,0.00),(60.5$, $0.00169),(61.5,0.0675),(62.5,0.0362),(63.5,0.00544),(64.5,0.00),(65.5,0.00),(66.6,0.00),(67.6$, 0.274), (68.6, 0.0429), (69.6, 0.00), (70.6, 0.00), (71.6, 0.00), (72.6, 0.00), (73.6, 0.00), (74.6, 0.134), (75.6, $0.0814),(76.6,0.36),(77.6,0.37),(78.7,0.121),(79.7,0.001),(80.7,0.0201),(81.7,0.0095),(82.7,0.0162)$, (83.7, 0.00), (84.7, 0.00169), (85.7, 0.0675), (86.7, 0.0362), (87.7, 0.00544), (88.7, 0.00), (89.7, 0.00), (90.8, $0.00),(91.8,0.274),(92.8,0.0429),(93.8,0.00),(94.8,0.00),(95.8,0.00),(96.8,0.00),(97.8,0.00),(98.8$, 0.134), (99.8, 0.0814), (101, 0.36), (102, 0.37), (103, 0.121), (104, 0.001), (105, 0.0201), (106, 0.0095), $(107,0.0162),(108,0.00),(109,0.00169),(110,0.0675),(111,0.0362),(112,0.00544),(113,0.00),(114$, $0.00),(115,0.00),(116,0.274),(117,0.0429),(118,0.00),(119,0.00),(120,0.00)$

Mix75 = GRAPH(TIME) (0.00, 0.00), (1.01, 0.00), (2.02, 0.124), (3.03, 0.0741), (4.03, 0.342), (5.04, 0.352), (6.05, 0.113), (7.06, $0.001),(8.07,0.189),(9.08,0.206),(10.1,0.211),(11.1,0.2),(12.1,0.2),(13.1,0.249),(14.1,0.226),(15.1$, $0.204),(16.1,0.2),(17.1,0.2),(18.2,0.2),(19.2,0.402),(20.2,0.231),(21.2,0.2),(22.2,0.2),(23.2,0.2)$, $(24.2,0.00),(25.2,0.00),(26.2,0.124),(27.2,0.0741),(28.2,0.342),(29.2,0.352),(30.3,0.113),(31.3$, $0.001),(32.3,0.189),(33.3,0.206),(34.3,0.211),(35.3,0.2),(36.3,0.2),(37.3,0.249),(38.3,0.226),(39.3$, $0.204),(40.3,0.2),(41.3,0.2),(42.4,0.2),(43.4,0.402),(44.4,0.231),(45.4,0.2),(46.4,0.2),(47.4,0.2)$, $(48.4,0.00),(49.4,0.00),(50.4,0.124),(51.4,0.0741),(52.4,0.342),(53.4,0.352),(54.5,0.113),(55.5$, $0.001),(56.5,0.189),(57.5,0.206),(58.5,0.211),(59.5,0.2),(60.5,0.2),(61.5,0.249),(62.5,0.226),(63.5$, $0.204),(64.5,0.2),(65.5,0.2),(66.6,0.2),(67.6,0.402),(68.6,0.231),(69.6,0.2),(70.6,0.2),(71.6,0.2)$, $(72.6,0.00),(73.6,0.00),(74.6,0.124),(75.6,0.0741),(76.6,0.342),(77.6,0.352),(78.7,0.113),(79.7$, $0.001),(80.7,0.189),(81.7,0.206),(82.7,0.211),(83.7,0.2),(84.7,0.2),(85.7,0.249),(86.7,0.226),(87.7$, $0.204),(88.7,0.2),(89.7,0.2),(90.8,0.2),(91.8,0.402),(92.8,0.231),(93.8,0.2),(94.8,0.2),(95.8,0.2)$, $(96.8,0.00),(97.8,0.00),(98.8,0.124),(99.8,0.0741),(101,0.342),(102,0.352),(103,0.113),(104,0.001)$, $(105,0.189),(106,0.206),(107,0.211),(108,0.2),(109,0.2),(110,0.249),(111,0.226),(112,0.204),(113$, $0.2),(114,0.2),(115,0.2),(116,0.402),(117,0.231),(118,0.2),(119,0.2),(120,0.2)$

Mix85 = GRAPH(TIME) $(0.00,0.00),(1.01,0.00),(2.02,0.111),(3.03,0.0642),(4.03,0.32),(5.04,0.331),(6.05,0.105),(7.06$, $0.001),(8.07,0.53),(9.08,0.602),(10.1,0.604),(11.1,0.6),(12.1,0.6),(13.1,0.616),(14.1,0.609),(15.1$, $0.601),(16.1,0.6),(17.1,0.6),(18.2,0.6),(19.2,0.667),(20.2,0.61),(21.2,0.6),(22.2,0.6),(23.2,0.6)$, $(24.2,0.00),(25.2,0.00),(26.2,0.111),(27.2,0.0642),(28.2,0.32),(29.2,0.331),(30.3,0.105),(31.3$, $0.001),(32.3,0.53),(33.3,0.602),(34.3,0.604),(35.3,0.6),(36.3,0.6),(37.3,0.616),(38.3,0.609),(39.3$, 0.601), (40.3, 0.6), $(41.3,0.6),(42.4,0.6),(43.4,0.667),(44.4,0.61),(45.4,0.6),(46.4,0.6),(47.4,0.6)$, 
$(48.4,0.00),(49.4,0.00),(50.4,0.111),(51.4,0.0642),(52.4,0.32),(53.4,0.331),(54.5,0.105),(55.5$, $0.001),(56.5,0.53),(57.5,0.602),(58.5,0.604),(59.5,0.6),(60.5,0.6),(61.5,0.616),(62.5,0.609),(63.5$, $0.601),(64.5,0.6),(65.5,0.6),(66.6,0.6),(67.6,0.667),(68.6,0.61),(69.6,0.6),(70.6,0.6),(71.6,0.6)$, $(72.6,0.00),(73.6,0.00),(74.6,0.111),(75.6,0.0642),(76.6,0.32),(77.6,0.331),(78.7,0.105),(79.7$, $0.001),(80.7,0.53),(81.7,0.602),(82.7,0.604),(83.7,0.6),(84.7,0.6),(85.7,0.616),(86.7,0.609),(87.7$, $0.601),(88.7,0.6),(89.7,0.6),(90.8,0.6),(91.8,0.667),(92.8,0.61),(93.8,0.6),(94.8,0.6),(95.8,0.6)$, $(96.8,0.00),(97.8,0.00),(98.8,0.111),(99.8,0.0642),(101,0.32),(102,0.331),(103,0.105),(104,0.001)$, $(105,0.53),(106,0.602),(107,0.604),(108,0.6),(109,0.6),(110,0.616),(111,0.609),(112,0.601),(113$, $0.6),(114,0.6),(115,0.6),(116,0.667),(117,0.61),(118,0.6),(119,0.6),(120,0.6)$

MSAE_Buoyancy $=0.5$

Temp15 = GRAPH(TIME)

(0.00, 27.4), (1.01, 27.4), (2.02, 27.4), (3.03, 27.4), (4.03, 27.4), (5.04, 27.4), (6.05, 27.4), (7.06, 27.4), (8.07, 27.5), (9.08, 27.6), (10.1, 27.8), (11.1, 28.1), (12.1, 28.5), (13.1, 28.9), (14.1, 29.2), (15.1, 29.5), (16.1, 29.7), (17.1, 29.7), (18.2, 29.4), (19.2, 29.0), (20.2, 29.0), (21.2, 29.0), (22.2, 29.0), (23.2, 29.0), (24.2, 27.4), (25.2, 27.4), (26.2, 27.4), (27.2, 27.4), (28.2, 27.4), (29.2, 27.4), (30.3, 27.4), (31.3, 27.4), (32.3, 27.5), (33.3, 27.6), $(34.3,27.8),(35.3,28.1),(36.3,28.5),(37.3,28.9),(38.3,29.2),(39.3,29.5),(40.3,29.7),(41.3,29.7),(42.4$, 29.4), (43.4, 29.0), (44.4, 29.0), (45.4, 29.0), (46.4, 29.0), (47.4, 29.0), (48.4, 27.4), (49.4, 27.4), (50.4, 27.4), (51.4, 27.4), (52.4, 27.4), (53.4, 27.4), (54.5, 27.4), (55.5, 27.4), (56.5, 27.5), (57.5, 27.6), (58.5, 27.8), (59.5, 28.1), (60.5, 28.5), (61.5, 28.9), (62.5, 29.2), (63.5, 29.5), (64.5, 29.7), (65.5, 29.7), (66.6, 29.4), (67.6, 29.0), (68.6, 29.0), (69.6, 29.0), (70.6, 29.0), (71.6, 29.0), (72.6, 27.4), (73.6, 27.4), (74.6, 27.4), (75.6, 27.4), (76.6, 27.4), (77.6, 27.4), (78.7, 27.4), (79.7, 27.4), (80.7, 27.5), (81.7, 27.6), (82.7, 27.8), (83.7, 28.1), (84.7, 28.5), (85.7, 28.9), (86.7, 29.2), (87.7, 29.5), (88.7, 29.7), (89.7, 29.7), (90.8, 29.4), (91.8, 29.0), (92.8, 29.0), (93.8, 29.0), (94.8, 29.0), (95.8, 29.0), (96.8, 27.4), (97.8, 27.4), (98.8, 27.4), (99.8, 27.4), (101, 27.4), (102, 27.4), $(103,27.4),(104,27.4),(105,27.5),(106,27.6),(107,27.8),(108,28.1),(109,28.5),(110,28.9),(111$, 29.2), (112, 29.5), (113, 29.7), (114, 29.7), (115, 29.4), (116, 29.0), (117, 29.0), (118, 29.0), (119, 29.0), $(120,29.0)$

Temp25 = GRAPH $($ TIME $)$

$(0.00,27.4),(1.01,27.4),(2.02,27.4),(3.03,27.4),(4.03,27.4),(5.04,27.4),(6.05,27.4),(7.06,27.4),(8.07$, 27.5), (9.08, 27.6), (10.1, 27.9), (11.1, 28.1), (12.1, 28.5), (13.1, 28.8), (14.1, 29.1), (15.1, 29.3), (16.1, 29.5), $(17.1,29.6),(18.2,29.6),(19.2,29.6),(20.2,29.6),(21.2,29.6),(22.2,29.6),(23.2,29.6),(24.2,27.4),(25.2$, 27.4), (26.2, 27.4), (27.2, 27.4), (28.2, 27.4), (29.2, 27.4), (30.3, 27.4), (31.3, 27.4), (32.3, 27.5), (33.3, 27.6), $(34.3,27.9),(35.3,28.1),(36.3,28.5),(37.3,28.8),(38.3,29.1),(39.3,29.3),(40.3,29.5),(41.3,29.6),(42.4$, 29.6), (43.4, 29.6), (44.4, 29.6), (45.4, 29.6), (46.4, 29.6), (47.4, 29.6), (48.4, 27.4), (49.4, 27.4), (50.4, 27.4), $(51.4,27.4),(52.4,27.4),(53.4,27.4),(54.5,27.4),(55.5,27.4),(56.5,27.5),(57.5,27.6),(58.5,27.9),(59.5$, 28.1), (60.5, 28.5), (61.5, 28.8), (62.5, 29.1), (63.5, 29.3), (64.5, 29.5), (65.5, 29.6), (66.6, 29.6), (67.6, 29.6), (68.6, 29.6), (69.6, 29.6), (70.6, 29.6), (71.6, 29.6), (72.6, 27.4), (73.6, 27.4), (74.6, 27.4), (75.6, 27.4), (76.6, 27.4), (77.6, 27.4), (78.7, 27.4), (79.7, 27.4), (80.7, 27.5), (81.7, 27.6), (82.7, 27.9), (83.7, 28.1), (84.7, 28.5), (85.7, 28.8), (86.7, 29.1), (87.7, 29.3), (88.7, 29.5), (89.7, 29.6), (90.8, 29.6), (91.8, 29.6), (92.8, 29.6), (93.8, 29.6), (94.8, 29.6), (95.8, 29.6), (96.8, 27.4), (97.8, 27.4), (98.8, 27.4), (99.8, 27.4), (101, 27.4), (102, 27.4), $(103,27.4),(104,27.4),(105,27.5),(106,27.6),(107,27.9),(108,28.1),(109,28.5),(110,28.8),(111$, 29.1), (112, 29.3), (113, 29.5), (114, 29.6), (115, 29.6), (116, 29.6), (117, 29.6), (118, 29.6), (119, 29.6), $(120,29.6)$

Temp35 $=$ GRAPH $($ TIME $)$

(0.00, 27.5), (1.01, 27.5), (2.02, 27.5), (3.03, 27.5), (4.03, 27.5), (5.04, 27.5), (6.05, 27.5), (7.06, 27.5), (8.07, 27.5), (9.08, 27.6), (10.1, 27.8), (11.1, 28.0), (12.1, 28.3), (13.1, 28.5), (14.1, 28.8), (15.1, 28.9), (16.1, 29.1), $(17.1,29.1),(18.2,29.2),(19.2,29.2),(20.2,29.2),(21.2,29.2),(22.2,29.2),(23.2,29.2),(24.2,27.5),(25.2$, 27.5), (26.2, 27.5), (27.2, 27.5), (28.2, 27.5), (29.2, 27.5), (30.3, 27.5), (31.3, 27.5), (32.3, 27.5), (33.3, 27.6), $(34.3,27.8),(35.3,28.0),(36.3,28.3),(37.3,28.5),(38.3,28.8),(39.3,28.9),(40.3,29.1),(41.3,29.1),(42.4$, 29.2), (43.4, 29.2), (44.4, 29.2), (45.4, 29.2), (46.4, 29.2), (47.4, 29.2), (48.4, 27.5), (49.4, 27.5), (50.4, 27.5), $(51.4,27.5),(52.4,27.5),(53.4,27.5),(54.5,27.5),(55.5,27.5),(56.5,27.5),(57.5,27.6),(58.5,27.8),(59.5$, 
28.0), (60.5, 28.3), (61.5, 28.5), (62.5, 28.8), (63.5, 28.9), (64.5, 29.1), (65.5, 29.1), (66.6, 29.2), (67.6, 29.2), (68.6, 29.2), (69.6, 29.2), (70.6, 29.2), (71.6, 29.2), (72.6, 27.5), (73.6, 27.5), (74.6, 27.5), (75.6, 27.5), (76.6, 27.5), (77.6, 27.5), (78.7, 27.5), (79.7, 27.5), (80.7, 27.5), (81.7, 27.6), (82.7, 27.8), (83.7, 28.0), (84.7, 28.3), (85.7, 28.5), (86.7, 28.8), (87.7, 28.9), (88.7, 29.1), (89.7, 29.1), (90.8, 29.2), (91.8, 29.2), (92.8, 29.2), (93.8, 29.2), (94.8, 29.2), (95.8, 29.2), (96.8, 27.5), (97.8, 27.5), (98.8, 27.5), (99.8, 27.5), (101, 27.5), (102, 27.5), $(103,27.5),(104,27.5),(105,27.5),(106,27.6),(107,27.8),(108,28.0),(109,28.3),(110,28.5),(111$, 28.8), (112, 28.9), (113, 29.1), (114, 29.1), (115, 29.2), (116, 29.2), (117, 29.2), (118, 29.2), (119, 29.2), $(120,29.2)$

Temp45 $=$ GRAPH $($ TIME $)$

(0.00, 27.5), (1.01, 27.5), (2.02, 27.5), (3.03, 27.5), (4.03, 27.5), (5.04, 27.5), (6.05, 27.5), (7.06, 27.5), (8.07, 27.5), (9.08, 27.6), (10.1, 27.8), (11.1, 27.9), (12.1, 28.1), (13.1, 28.4), (14.1, 28.5), (15.1, 28.7), (16.1, 28.8), $(17.1,28.8),(18.2,28.9),(19.2,28.9),(20.2,28.9),(21.2,28.9),(22.2,28.9),(23.2,28.9),(24.2,27.5),(25.2$, 27.5), (26.2, 27.5), (27.2, 27.5), (28.2, 27.5), (29.2, 27.5), (30.3, 27.5), (31.3, 27.5), (32.3, 27.5), (33.3, 27.6), $(34.3,27.8),(35.3,27.9),(36.3,28.1),(37.3,28.4),(38.3,28.5),(39.3,28.7),(40.3,28.8),(41.3,28.8),(42.4$, 28.9), (43.4, 28.9), (44.4, 28.9), (45.4, 28.9), (46.4, 28.9), (47.4, 28.9), (48.4, 27.5), (49.4, 27.5), (50.4, 27.5), (51.4, 27.5), (52.4, 27.5), (53.4, 27.5), (54.5, 27.5), (55.5, 27.5), (56.5, 27.5), (57.5, 27.6), (58.5, 27.8), (59.5, 27.9), (60.5, 28.1), (61.5, 28.4), (62.5, 28.5), (63.5, 28.7), (64.5, 28.8), (65.5, 28.8), (66.6, 28.9), (67.6, 28.9), (68.6, 28.9), (69.6, 28.9), (70.6, 28.9), (71.6, 28.9), (72.6, 27.5), (73.6, 27.5), (74.6, 27.5), (75.6, 27.5), (76.6, 27.5), (77.6, 27.5), (78.7, 27.5), (79.7, 27.5), (80.7, 27.5), (81.7, 27.6), (82.7, 27.8), (83.7, 27.9), (84.7, 28.1), (85.7, 28.4), (86.7, 28.5), (87.7, 28.7), (88.7, 28.8), (89.7, 28.8), (90.8, 28.9), (91.8, 28.9), (92.8, 28.9), (93.8, 28.9), (94.8, 28.9), (95.8, 28.9), (96.8, 27.5), (97.8, 27.5), (98.8, 27.5), (99.8, 27.5), (101, 27.5), (102, 27.5), $(103,27.5),(104,27.5),(105,27.5),(106,27.6),(107,27.8),(108,27.9),(109,28.1),(110,28.4),(111$, $28.5),(112,28.7),(113,28.8),(114,28.8),(115,28.9),(116,28.9),(117,28.9),(118,28.9),(119,28.9)$, $(120,28.9)$

Temp5 = GRAPH $($ TIME $)$

$(0.00,27.5),(1.01,27.5),(2.02,27.5),(3.03,27.5),(4.03,27.5),(5.04,27.5),(6.05,27.5),(7.06,27.5),(8.07$, 27.5), (9.08, 27.6), (10.1, 27.6), (11.1, 27.9), (12.1, 28.3), (13.1, 28.8), (14.1, 29.2), (15.1, 29.6), (16.1, 29.8), (17.1, 29.6), (18.2, 28.7), (19.2, 27.5), (20.2, 27.5), (21.2, 27.5), (22.2, 27.5), (23.2, 27.5), (24.2, 27.5), (25.2, 27.5), (26.2, 27.5), (27.2, 27.5), (28.2, 27.5), (29.2, 27.5), (30.3, 27.5), (31.3, 27.5), (32.3, 27.5), (33.3, 27.6), $(34.3,27.6),(35.3,27.9),(36.3,28.3),(37.3,28.8),(38.3,29.2),(39.3,29.6),(40.3,29.8),(41.3,29.6),(42.4$, 28.7), (43.4, 27.5), (44.4, 27.5), (45.4, 27.5), (46.4, 27.5), (47.4, 27.5), (48.4, 27.5), (49.4, 27.5), (50.4, 27.5), (51.4, 27.5), (52.4, 27.5), (53.4, 27.5), (54.5, 27.5), (55.5, 27.5), (56.5, 27.5), $(57.5,27.6),(58.5,27.6),(59.5$, 27.9), (60.5, 28.3), (61.5, 28.8), (62.5, 29.2), (63.5, 29.6), (64.5, 29.8), (65.5, 29.6), (66.6, 28.7), (67.6, 27.5), (68.6, 27.5), (69.6, 27.5), (70.6, 27.5), (71.6, 27.5), (72.6, 27.5), (73.6, 27.5), (74.6, 27.5), (75.6, 27.5), (76.6, 27.5), (77.6, 27.5), (78.7, 27.5), (79.7, 27.5), (80.7, 27.5), (81.7, 27.6), (82.7, 27.6), (83.7, 27.9), (84.7, 28.3), (85.7, 28.8), (86.7, 29.2), (87.7, 29.6), (88.7, 29.8), (89.7, 29.6), (90.8, 28.7), (91.8, 27.5), (92.8, 27.5), (93.8, 27.5), (94.8, 27.5), (95.8, 27.5), (96.8, 27.5), (97.8, 27.5), (98.8, 27.5), (99.8, 27.5), (101, 27.5), (102, 27.5), $(103,27.5),(104,27.5),(105,27.5),(106,27.6),(107,27.6),(108,27.9),(109,28.3),(110,28.8),(111$,

29.2), (112, 29.6), (113, 29.8), (114, 29.6), (115, 28.7), (116, 27.5), (117, 27.5), (118, 27.5), (119, 27.5), $(120,27.5)$

Temp55 = GRAPH $($ TIME $)$

(0.00, 27.4), (1.01, 27.4), (2.02, 27.4), (3.03, 27.4), (4.03, 27.4), (5.04, 27.4), (6.05, 27.4), (7.06, 27.4), (8.07, 27.4), (9.08, 27.5), (10.1, 27.7), (11.1, 27.8), (12.1, 28.0), (13.1, 28.2), (14.1, 28.4), (15.1, 28.5), (16.1, 28.6), (17.1, 28.7), (18.2, 28.7), (19.2, 28.7), (20.2, 28.7), (21.2, 28.7), (22.2, 28.7), (23.2, 28.7), (24.2, 27.4), (25.2, 27.4), (26.2, 27.4), (27.2, 27.4), (28.2, 27.4), (29.2, 27.4), (30.3, 27.4), (31.3, 27.4), (32.3, 27.4), (33.3, 27.5), $(34.3,27.7),(35.3,27.8),(36.3,28.0),(37.3,28.2),(38.3,28.4),(39.3,28.5),(40.3,28.6),(41.3,28.7),(42.4$, 28.7), (43.4, 28.7), (44.4, 28.7), (45.4, 28.7), (46.4, 28.7), (47.4, 28.7), (48.4, 27.4), (49.4, 27.4), (50.4, 27.4), (51.4, 27.4), (52.4, 27.4), (53.4, 27.4), (54.5, 27.4), (55.5, 27.4), (56.5, 27.4), (57.5, 27.5), (58.5, 27.7), (59.5, 27.8), (60.5, 28.0), (61.5, 28.2), (62.5, 28.4), (63.5, 28.5), (64.5, 28.6), (65.5, 28.7), (66.6, 28.7), (67.6, 28.7), (68.6, 28.7), (69.6, 28.7), (70.6, 28.7), (71.6, 28.7), (72.6, 27.4), (73.6, 27.4), (74.6, 27.4), (75.6, 27.4), (76.6, 
27.4), (77.6, 27.4), (78.7, 27.4), (79.7, 27.4), (80.7, 27.4), (81.7, 27.5), (82.7, 27.7), (83.7, 27.8), (84.7, 28.0), (85.7, 28.2), (86.7, 28.4), (87.7, 28.5), (88.7, 28.6), (89.7, 28.7), (90.8, 28.7), (91.8, 28.7), (92.8, 28.7), (93.8, 28.7), (94.8, 28.7), (95.8, 28.7), (96.8, 27.4), (97.8, 27.4), (98.8, 27.4), (99.8, 27.4), (101, 27.4), (102, 27.4), $(103,27.4),(104,27.4),(105,27.4),(106,27.5),(107,27.7),(108,27.8),(109,28.0),(110,28.2),(111$, 28.4), (112, 28.5), (113, 28.6), (114, 28.7), (115, 28.7), (116, 28.7), (117, 28.7), (118, 28.7), (119, 28.7), $(120,28.7)$

Temp65 = GRAPH(TIME)

(0.00, 27.4), (1.01, 27.4), (2.02, 27.4), (3.03, 27.4), (4.03, 27.4), (5.04, 27.4), (6.05, 27.4), (7.06, 27.4), (8.07, 27.4), (9.08, 27.5), (10.1, 27.6), (11.1, 27.8), (12.1, 28.0), (13.1, 28.1), (14.1, 28.3), (15.1, 28.4), (16.1, 28.5), $(17.1,28.5),(18.2,28.5),(19.2,28.5),(20.2,28.5),(21.2,28.5),(22.2,28.5),(23.2,28.5),(24.2,27.4),(25.2$, 27.4), (26.2, 27.4), (27.2, 27.4), (28.2, 27.4), (29.2, 27.4), (30.3, 27.4), (31.3, 27.4), (32.3, 27.4), (33.3, 27.5), $(34.3,27.6),(35.3,27.8),(36.3,28.0),(37.3,28.1),(38.3,28.3),(39.3,28.4),(40.3,28.5),(41.3,28.5),(42.4$, 28.5), (43.4, 28.5), (44.4, 28.5), (45.4, 28.5), (46.4, 28.5), (47.4, 28.5), (48.4, 27.4), (49.4, 27.4), (50.4, 27.4), (51.4, 27.4), (52.4, 27.4), (53.4, 27.4), (54.5, 27.4), (55.5, 27.4), (56.5, 27.4), (57.5, 27.5), (58.5, 27.6), (59.5, 27.8), (60.5, 28.0), (61.5, 28.1), (62.5, 28.3), (63.5, 28.4), (64.5, 28.5), (65.5, 28.5), (66.6, 28.5), (67.6, 28.5), (68.6, 28.5), (69.6, 28.5), (70.6, 28.5), (71.6, 28.5), (72.6, 27.4), (73.6, 27.4), (74.6, 27.4), (75.6, 27.4), (76.6, 27.4), (77.6, 27.4), (78.7, 27.4), (79.7, 27.4), (80.7, 27.4), (81.7, 27.5), (82.7, 27.6), (83.7, 27.8), (84.7, 28.0), (85.7, 28.1), (86.7, 28.3), (87.7, 28.4), (88.7, 28.5), (89.7, 28.5), (90.8, 28.5), (91.8, 28.5), (92.8, 28.5), (93.8, 28.5), (94.8, 28.5), (95.8, 28.5), (96.8, 27.4), (97.8, 27.4), (98.8, 27.4), (99.8, 27.4), (101, 27.4), (102, 27.4), $(103,27.4),(104,27.4),(105,27.4),(106,27.5),(107,27.6),(108,27.8),(109,28.0),(110,28.1),(111$, $28.3),(112,28.4),(113,28.5),(114,28.5),(115,28.5),(116,28.5),(117,28.5),(118,28.5),(119,28.5)$, $(120,28.5)$

Temp75 = GRAPH $($ TIME $)$

(0.00, 27.4), (1.01, 27.4), (2.02, 27.4), (3.03, 27.4), (4.03, 27.4), (5.04, 27.4), (6.05, 27.4), (7.06, 27.4), (8.07, 27.4), (9.08, 27.5), (10.1, 27.6), (11.1, 27.7), (12.1, 27.9), (13.1, 28.1), (14.1, 28.2), (15.1, 28.3), (16.1, 28.4), $(17.1,28.4),(18.2,28.4),(19.2,28.4),(20.2,28.4),(21.2,28.4),(22.2,28.4),(23.2,28.4),(24.2,27.4),(25.2$, 27.4), (26.2, 27.4), (27.2, 27.4), (28.2, 27.4), (29.2, 27.4), (30.3, 27.4), (31.3, 27.4), (32.3, 27.4), (33.3, 27.5), $(34.3,27.6),(35.3,27.7),(36.3,27.9),(37.3,28.1),(38.3,28.2),(39.3,28.3),(40.3,28.4),(41.3,28.4),(42.4$, 28.4), (43.4, 28.4), (44.4, 28.4), (45.4, 28.4), (46.4, 28.4), (47.4, 28.4), (48.4, 27.4), (49.4, 27.4), (50.4, 27.4), (51.4, 27.4), (52.4, 27.4), (53.4, 27.4), (54.5, 27.4), (55.5, 27.4), (56.5, 27.4), $(57.5,27.5),(58.5,27.6),(59.5$, 27.7), (60.5, 27.9), (61.5, 28.1), (62.5, 28.2), (63.5, 28.3), (64.5, 28.4), (65.5, 28.4), (66.6, 28.4), (67.6, 28.4), (68.6, 28.4), (69.6, 28.4), (70.6, 28.4), (71.6, 28.4), (72.6, 27.4), (73.6, 27.4), (74.6, 27.4), (75.6, 27.4), (76.6, 27.4), (77.6, 27.4), (78.7, 27.4), (79.7, 27.4), (80.7, 27.4), (81.7, 27.5), (82.7, 27.6), (83.7, 27.7), (84.7, 27.9), (85.7, 28.1), (86.7, 28.2), (87.7, 28.3), (88.7, 28.4), (89.7, 28.4), (90.8, 28.4), (91.8, 28.4), (92.8, 28.4), (93.8, 28.4), (94.8, 28.4), (95.8, 28.4), (96.8, 27.4), (97.8, 27.4), (98.8, 27.4), (99.8, 27.4), (101, 27.4), (102, 27.4), $(103,27.4),(104,27.4),(105,27.4),(106,27.5),(107,27.6),(108,27.7),(109,27.9),(110,28.1),(111$, 28.2), (112, 28.3), (113, 28.4), (114, 28.4), (115, 28.4), (116, 28.4), (117, 28.4), (118, 28.4), (119, 28.4), $(120,28.4)$

Temp85 = GRAPH $($ TIME $)$

(0.00, 27.4), (1.01, 27.4), (2.02, 27.4), (3.03, 27.4), (4.03, 27.4), (5.04, 27.4), (6.05, 27.4), (7.06, 27.4), (8.07, 27.4), (9.08, 27.5), (10.1, 27.6), (11.1, 27.7), (12.1, 27.9), (13.1, 28.0), (14.1, 28.1), (15.1, 28.2), (16.1, 28.3), (17.1, 28.3), (18.2, 28.4), (19.2, 28.4), (20.2, 28.4), (21.2, 28.4), (22.2, 28.4), (23.2, 28.4), (24.2, 27.4), (25.2, 27.4), (26.2, 27.4), (27.2, 27.4), (28.2, 27.4), (29.2, 27.4), (30.3, 27.4), (31.3, 27.4), (32.3, 27.4), (33.3, 27.5), $(34.3,27.6),(35.3,27.7),(36.3,27.9),(37.3,28.0),(38.3,28.1),(39.3,28.2),(40.3,28.3),(41.3,28.3),(42.4$, 28.4), (43.4, 28.4), (44.4, 28.4), (45.4, 28.4), (46.4, 28.4), (47.4, 28.4), (48.4, 27.4), (49.4, 27.4), (50.4, 27.4), (51.4, 27.4), (52.4, 27.4), (53.4, 27.4), (54.5, 27.4), (55.5, 27.4), (56.5, 27.4), (57.5, 27.5), (58.5, 27.6), (59.5, 27.7), (60.5, 27.9), (61.5, 28.0), (62.5, 28.1), (63.5, 28.2), (64.5, 28.3), (65.5, 28.3), (66.6, 28.4), (67.6, 28.4), (68.6, 28.4), (69.6, 28.4), (70.6, 28.4), (71.6, 28.4), (72.6, 27.4), (73.6, 27.4), (74.6, 27.4), (75.6, 27.4), (76.6, 27.4), (77.6, 27.4), (78.7, 27.4), (79.7, 27.4), (80.7, 27.4), (81.7, 27.5), (82.7, 27.6), (83.7, 27.7), (84.7, 27.9), $(85.7,28.0),(86.7,28.1),(87.7,28.2),(88.7,28.3),(89.7,28.3),(90.8,28.4),(91.8,28.4),(92.8,28.4),(93.8$, 
28.4), (94.8, 28.4), (95.8, 28.4), (96.8, 27.4), (97.8, 27.4), (98.8, 27.4), (99.8, 27.4), (101, 27.4), (102, 27.4), $(103,27.4),(104,27.4),(105,27.4),(106,27.5),(107,27.6),(108,27.7),(109,27.9),(110,28.0),(111$, 28.1), (112, 28.2), (113, 28.3), (114, 28.3), (115, 28.4), (116, 28.4), (117, 28.4), (118, 28.4), (119, 28.4), $(120,28.4)$

Temp90 $=$ GRAPH $($ TIME $)$

(0.00, 27.4), (1.01, 27.4), (2.02, 27.4), (3.03, 27.4), (4.03, 27.4), (5.04, 27.4), (6.05, 27.4), (7.06, 27.4), (8.07, 27.4), (9.08, 27.5), (10.1, 27.6), (11.1, 27.7), (12.1, 27.8), (13.1, 28.0), (14.1, 28.1), (15.1, 28.2), (16.1, 28.3), $(17.1,28.3),(18.2,28.3),(19.2,28.3),(20.2,28.3),(21.2,28.3),(22.2,28.3),(23.2,28.3),(24.2,27.4),(25.2$, 27.4), (26.2, 27.4), (27.2, 27.4), (28.2, 27.4), (29.2, 27.4), (30.3, 27.4), (31.3, 27.4), (32.3, 27.4), (33.3, 27.5), $(34.3,27.6),(35.3,27.7),(36.3,27.8),(37.3,28.0),(38.3,28.1),(39.3,28.2),(40.3,28.3),(41.3,28.3),(42.4$, 28.3), (43.4, 28.3), (44.4, 28.3), (45.4, 28.3), (46.4, 28.3), (47.4, 28.3), (48.4, 27.4), (49.4, 27.4), (50.4, 27.4), $(51.4,27.4),(52.4,27.4),(53.4,27.4),(54.5,27.4),(55.5,27.4),(56.5,27.4),(57.5,27.5),(58.5,27.6),(59.5$, 27.7), (60.5, 27.8), (61.5, 28.0), (62.5, 28.1), (63.5, 28.2), (64.5, 28.3), (65.5, 28.3), (66.6, 28.3), (67.6, 28.3), (68.6, 28.3), (69.6, 28.3), (70.6, 28.3), (71.6, 28.3), (72.6, 27.4), (73.6, 27.4), (74.6, 27.4), (75.6, 27.4), (76.6, 27.4), (77.6, 27.4), (78.7, 27.4), (79.7, 27.4), (80.7, 27.4), (81.7, 27.5), (82.7, 27.6), (83.7, 27.7), (84.7, 27.8), $(85.7,28.0),(86.7,28.1),(87.7,28.2),(88.7,28.3),(89.7,28.3),(90.8,28.3),(91.8,28.3),(92.8,28.3),(93.8$, 28.3), (94.8, 28.3), (95.8, 28.3), (96.8, 27.4), (97.8, 27.4), (98.8, 27.4), (99.8, 27.4), (101, 27.4), (102, 27.4), $(103,27.4),(104,27.4),(105,27.4),(106,27.5),(107,27.6),(108,27.7),(109,27.8),(110,28.0),(111$, 28.1), (112, 28.2), (113, 28.3), (114, 28.3), (115, 28.3), (116, 28.3), (117, 28.3), (118, 28.3), (119, 28.3), $(120,28.3)$

Topt15APFA $=(1.2 / 24) *\left(1+4^{*}\left(\left(1.3^{\wedge}(\right.\right.\right.$ Temp15-24) $\left.)-1\right)-(\ln (1.3) / \ln (1.32)) *\left(1.32^{\wedge}(\right.$ Temp15-24) $\left.\left.\left.)-1\right)\right)\right)$

Topt15MSAE $=(.8 / 24) *\left(1+5.77^{*}\left(\left(1.3^{\wedge}(\right.\right.\right.$ Temp15-28.2) -1$)-(\ln (1.3) / \ln (1.37)) *\left(1.37^{\wedge}(\right.$ Temp15-28.2)-1 $\left.\left.)\right)\right)$

Topt25APFA $=(1.2 / 24) *\left(1+4^{*}\left(\left(1.3^{\wedge}(\operatorname{Temp} 25-24)-1\right)-(\ln (1.3) / \ln (1.32))^{*}\left(1.32^{\wedge}(\operatorname{Temp} 25-24)-1\right)\right)\right)$

Topt25MSAE $=(.8 / 24)^{*}\left(1+5.77^{*}\left(\left(1.3^{\wedge}(\operatorname{Temp} 25-28.2)-1\right)-(\ln (1.3) / \ln (1.37)) *\left(1.37^{\wedge}(\operatorname{Temp} 25-28.2)-1\right)\right)\right)$

Topt35APFA $=(1.2 / 24) *\left(1+4^{*}\left(\left(1.3^{\wedge}(\operatorname{Temp} 35-24)-1\right)-(\ln (1.3) / \ln (1.32)) *\left(1.32^{\wedge}(\operatorname{Temp} 35-24)-1\right)\right)\right)$

Topt35MSAE $=(.8 / 24)^{*}\left(1+5.77^{*}\left(\left(1.3^{\wedge}(\operatorname{Temp} 35-28.2)-1\right)-(\ln (1.3) / \ln (1.37)) *\left(1.37^{\wedge}(\operatorname{Temp} 35-28.2)-1\right)\right)\right)$

Topt45APFA $=(1.2 / 24) *\left(1+4^{*}\left(\left(1.3^{\wedge}(\operatorname{Temp} 45-24)-1\right)-(\ln (1.3) / \ln (1.32)) *\left(1.32^{\wedge}(\operatorname{Temp} 45-24)-1\right)\right)\right)$

Topt45MSAE $=(.8 / 24) *\left(1+5.77^{*}\left(\left(1.3^{\wedge}(\operatorname{Temp} 45-28.2)-1\right)-(\ln (1.3) / \ln (1.37)) *\left(1.37^{\wedge}(\operatorname{Temp} 45-28.2)-1\right)\right)\right)$

Topt55APFA $=(1.2 / 24) *\left(1+4^{*}\left(\left(1.3^{\wedge}(\operatorname{Temp} 55-24)-1\right)-(\ln (1.3) / \ln (1.32)) *\left(1.32^{\wedge}(\operatorname{Temp} 55-24)-1\right)\right)\right)$

Topt55MSAE $=(.8 / 24) *\left(1+5.77^{*}\left(\left(1.3^{\wedge}(\operatorname{Temp} 55-28.2)-1\right)-(\ln (1.3) / \ln (1.37)) *\left(1.37^{\wedge}(\operatorname{Temp} 55-28.2)-1\right)\right)\right)$

Topt5APFA $=(1.2 / 24)^{*}\left(1+4^{*}\left(\left(1.3^{\wedge}(\right.\right.\right.$ Temp5-24)-1 $)-(\ln (1.3) / \ln (1.32))^{*}\left(1.32^{\wedge}(\right.$ Temp5-24)-1) $\left.)\right)$

Topt5MSAE $=(.8 / 24) *\left(1+5.77^{*}\left(\left(1.3^{\wedge}(\operatorname{Temp5}-28.2)-1\right)-(\ln (1.3) / \ln (1.37)) *\left(1.37^{\wedge}(\right.\right.\right.$ Temp5-28.2)-1) $\left.)\right)$

Topt65APFA $=(1.2 / 24) *\left(1+4^{*}\left(\left(1.3^{\wedge}(\right.\right.\right.$ Temp65-24) -1$)-(\ln (1.3) / \ln (1.32)) *\left(1.32^{\wedge}(\right.$ Temp65-24)-1) $\left.)\right)$

Topt65MSAE $=(.8 / 24)^{*}\left(1+5.77^{*}\left(\left(1.3^{\wedge}(\operatorname{Temp} 65-28.2)-1\right)-(\ln (1.3) / \ln (1.37))^{*}\left(1.37^{\wedge}(\right.\right.\right.$ Temp65-28.2)-1) $\left.)\right)$

Topt75APFA $=(1.2 / 24) *\left(1+4^{*}\left(\left(1.3^{\wedge}(\right.\right.\right.$ Temp75-24) -1$)-(\ln (1.3) / \ln (1.32))^{*}\left(1.32^{\wedge}(\right.$ Temp75-24) $\left.\left.\left.)-1\right)\right)\right)$

Topt75MSAE $=(.8 / 24) *\left(1+5.77^{*}\left(\left(1.3^{\wedge}(\right.\right.\right.$ Temp75-28.2) -1$)-(\ln (1.3) / \ln (1.37)) *\left(1.37^{\wedge}(\right.$ Temp75-28.2)-1) $\left.)\right)$

Topt85APFA $=(1.2 / 24) *\left(1+4^{*}\left(\left(1.3^{\wedge}(\right.\right.\right.$ Temp85-24)-1) $)(\ln (1.3) / \ln (1.32)) *\left(1.32^{\wedge}(\right.$ Temp85-24)-1) $\left.)\right)$

Topt85MSAE $=(.8 / 24)^{*}\left(1+5.77^{*}\left(\left(1.3^{\wedge}(\operatorname{Temp} 85-28.2)-1\right)-(\ln (1.3) / \ln (1.37))^{*}\left(1.37^{\wedge}(\right.\right.\right.$ Temp85-28.2)-1) $\left.)\right)$

Topt90APFA $=(1.2 / 24) *\left(1+4^{*}\left(\left(1.3^{\wedge}(\right.\right.\right.$ Temp90-24) -1$)-(\ln (1.3) / \ln (1.32)) *\left(1.32^{\wedge}(\right.$ Temp90-24)-1) $\left.)\right)$

Topt90MSAE $=(.8 / 24)^{*}\left(1+5.77^{*}\left(\left(1.3^{\wedge}(\operatorname{Temp} 90-28.2)-1\right)-(\ln (1.3) / \ln (1.37)) *\left(1.37^{\wedge}(\right.\right.\right.$ Temp90-28.2)-1) $\left.)\right)$ 